\title{
Aircraft Loss of Control: Problem Analysis for the Development and Validation of Technology Solutions
}

\author{
Christine M. Belcastro ${ }^{1}$ \\ NASA Langley Research Center \\ Hampton, Virginia, 23681 \\ Dennis A. Crider ${ }^{3}$ \\ National Transportation Safety Board \\ Washington D.C., 20594 \\ John V. Foster ${ }^{5}$ \\ NASA Langley Research Center \\ Hampton, Virginia, 23681
}

\author{
Richard L. Newman ${ }^{2}$ \\ Crew Systems \\ Seattle, Washington, 98165 \\ David H. Klyde ${ }^{4}$ \\ Systems Technology, Inc. \\ Hawthorne, CA, 902504 \\ Loren Groff 6 \\ National Transportation Safety Board \\ Washington D.C., 20594
}

\begin{abstract}
Aircraft loss of control (LOC) is a leading cause of fatal accidents across all transport airplane and operational classes. LOC can result from a wide spectrum of precursors (or hazards), often occurring in combination. Technologies developed for LOC prevention and recovery must therefore be effective under a wide variety of conditions and uncertainties, including multiple hazards, and the validation process must provide a means of assessing system effectiveness and coverage of these hazards. This paper provides a detailed description of a methodology for analyzing LOC as a dynamics and control problem for the purpose of developing effective technology solutions. The paper includes a definition of LOC based on several recent publications, a detailed description of a refined LOC accident analysis process that is illustrated via selected example cases, and a description of planned follow-on activities for identifying future potential LOC risks and the development of LOC test scenarios. Some preliminary considerations for LOC of Unmanned Aircraft Systems (UAS) and for their safe integration into the National Airspace System (NAS) are also discussed.
\end{abstract}

\section{Nomenclature}

AAIB

AAIU

ASN

ATLAS

ATSB

$B E A$

$B F U$

$=$ UK Air Accidents Investigation Branch
$=$ Irish Air Accident Investigation Unit
$=$ Aviation Safety Network
$=$ Aviation Team Looking Ahead at Safety
$=$ Australian Transport Safety Bureau
$=$ French Bureau d'Enquêtes et d'Analyses pour la sécurité de l'aviation civile
$=$ German Bundesstelle für Flugunfalluntersuchungin

\footnotetext{
${ }^{1}$ Senior Researcher, Dynamic Systems and Control Branch, MS 308, E-Mail: christine.m.belcastro@nasa.gov; AIAA Associate Fellow.

${ }^{2}$ Retired, FAA, Post Office Box 25054, E-Mail: dicknewman@earthlink.net; AIAA Associate Fellow.

${ }^{3}$ Chief Technical Advisor, Vehicle Simulation, RE-1, E-Mail: criderd@ntsb.gov; AIAA Senior Member.

${ }^{4}$ Technical Director, E-Mail: dklyde@systemstech.com; AIAA Associate Fellow.

${ }^{5}$ Senior Researcher, Flight Dynamics Branch, MS 308, E-Mail: john.v.foster@nasa.gov; AIAA Associate Fellow.

${ }^{6}$ National Resource Specialist, Safety Data Systems and Analysis, RE-10, E-Mail: groffl@ntsb.gov.
} 


$\begin{array}{ll}\text { CAST } & =\text { Commercial Aviation Safety Team } \\ \text { DoD } & =\text { Department of Defense } \\ \text { ICAO } & =\text { International Civil Aviation Organization } \\ \text { LOC } & =\text { Loss of Control (in-flight) } \\ \text { NAS } & =\text { National Airspace System } \\ \text { NASA } & =\text { National Aeronautics and Space Administration } \\ \text { NextGen } & =\text { Next Generation Airspace Operations Concept } \\ \text { NIA } & =\text { National Institute of Aerospace } \\ \text { NTSB } & =\text { National Transportation Safety Board } \\ \text { SME } & =\text { Subject Matter Expert } \\ \text { TSB } & =\text { Canadian Transportation Safety Board } \\ \text { UAS } & =\text { Unmanned Aerial System }\end{array}$

\section{Introduction}

ircraft loss of control (LOC) is a leading cause of fatal accidents across all transport airplane and operational
chasses. ${ }^{1,2,3}$ The development and validation of technologies for LOC prevention and recovery poses significant
chambes. Aircraft LOC can result from a wide spectrum of precursor events and hazards, often occurring in
recovination ${ }^{4}$, which cannot be fully replicated during evaluation. Technologies developed for LOC prevention and
multiple LOC precursors and hazards, and the validation process must provide some measure of assurance that the
new vehicle safety technologies do no harm - i.e., that they themselves do not introduce new safety risks.

Onboard systems technologies have been developed by NASA as part of a holistic approach for LOC prevention and recovery. ${ }^{5,6}$ A validation framework involving analysis, simulation, and experimental testing has also been developed by NASA for safety-critical integrated systems operating under hazardous conditions that can lead to LOC 7,8 , and a preliminary set of LOC test scenarios ${ }^{9}$ was developed based on a limited set of flight accidents. Preliminary analysis results have been reported ${ }^{10}$ for a comprehensive set of transport aircraft accidents over a recent 15 -year period (1996 - 2010), including a methodology for the identification of worst-case combinations of causal and contributing factors and how they sequence in time. This analysis, when complete, will be used in the development of a set of LOC test scenarios that can be used in the validation of onboard systems technologies for LOC prevention and recovery. Since enhanced engineering simulations are required for batch and piloted evaluations under realistic LOC precursor conditions, these test scenarios also serve as a high-level requirement for defining the simulation enhancements needed for generating realistic LOC test scenarios.

Since publication of the preliminary analysis results for transport aircraft (see Ref. 11), the analysis process has been substantially refined and is being applied to the transport accidents and incidents identified in Ref. 11 as well as for the analysis of unmanned aircraft systems (UAS) mishaps (i.e., accidents and incidents). Refinement of the methodology includes the addition of LOC precursors, the addition of flags for quickly identifying key issues of interest for LOC, the identification of potential research solutions for each accident (if applicable), and the capture of specific comments for each precursor. Each precursor comment is taken from the accident report and specifies why each precursor is included in the sequence. This paper provides a detailed summary of this refined analysis methodology and provides some examples to illustrate it. Section II presents an overview of recent definitions for transport aircraft LOC as well as the refined LOC problem definition used in performing the analysis. Section III provides a detailed description of the refined LOC accident analysis process, which is illustrated via selected example cases. Individual hazards occurrences are also summarized in Section III for the mishaps analyzed to date. Section IV describes the analysis products resulting from this work as well as follow-on research to identify future potential LOC risks and develop hazards-based test scenarios for use in the development and validation of technology solutions for LOC prevention and recovery. Section V presents a discussion of the importance of LOC prevention and recovery for future resilient and autonomous systems as well as some preliminary considerations based on this work for the safe integration of UAS into the National Airspace System (NAS). Section VI provides a summary of the paper and some concluding remarks.

\section{Aircraft Loss-of-Control (LOC) Problem Definition}

LOC can be described as motion that is: outside the normal operating flight envelopes; not predictably altered by routine pilot control inputs; characterized by nonlinear effects, such as kinematic/inertial coupling; disproportionately 
large responses to small state variable changes, or oscillatory/divergent behavior; likely to result in high angular rates and displacements; and characterized by the inability to maintain heading, altitude, and wings-level flight. ${ }^{11}$ LOC also includes situations in which the flight path is outside of acceptable tracking tolerances and cannot be predictably controlled by pilot (or autoflight system) inputs. ${ }^{12}$ LOC is therefore fundamentally a dynamics and control problem. It is important to note that LOC need not be unrecoverable, but if left unaddressed it may become unrecoverable. LOC is also a complex problem in that there are many causal and contributing factors that can lead to LOC (see Refs. 5 \& 11). The primary causes include: entry into a vehicle upset condition; reduction or loss of control power; changes to the vehicle dynamic response in relation to handling/flying qualities; and combinations of these causes. There are numerous factors that have historically led or contributed to LOC. These can be grouped into three major categories: adverse onboard conditions, external hazards and disturbances, and abnormal flight conditions (or vehicle upsets). LOC causal and contributing factors within these categories are summarized in Fig. 1. Adverse onboard conditions include vehicle problems (i.e., impairment, failures, or damage) and inappropriate crew response. External hazards and disturbances consist of inclement weather conditions, atmospheric disturbances, and obstacles that require abrupt maneuvering for avoidance. Vehicle upset conditions include a variety of off-nominal or extreme flight conditions and abnormal trajectories. The complexity of LOC is clearly illustrated in Fig. 1, particularly considering that many LOC accidents involve combinations of the causal and contributing factors that are listed.

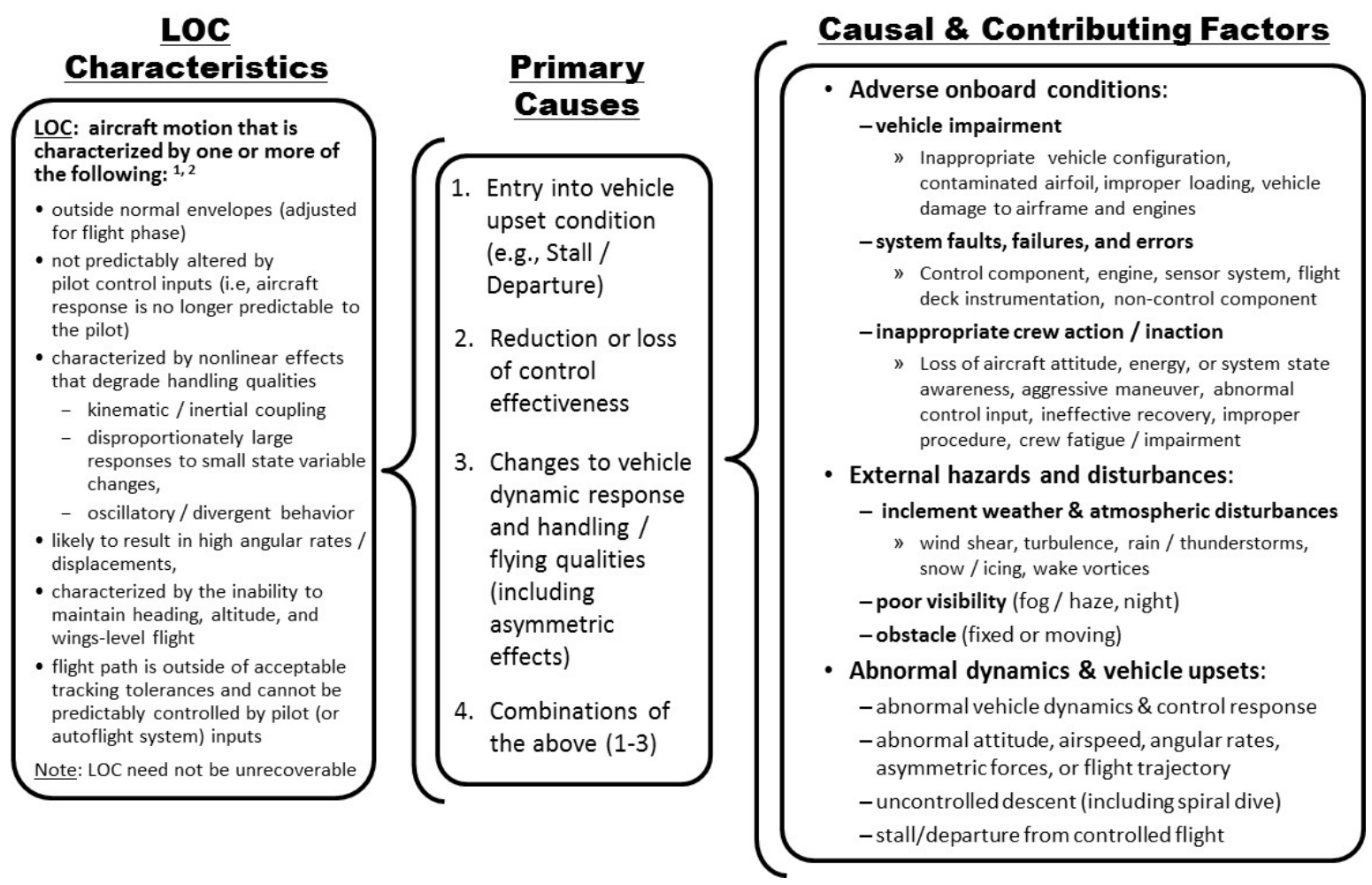

Figure 1. LOC key characteristics, primary causes, and causal \& contributing factors.

Onboard systems of the future must therefore be developed to provide LOC prevention and recovery capabilities under a wide variety of hazards (and their combinations) that can lead to LOC. An integrated system concept for accomplishing this was presented in Ref. 6. The validation of technologies developed for loss of control (LOC) prevention and recovery, such as that of Ref. 6, poses significant challenges. The validation process must provide some measure of assurance that the new vehicle safety technologies are effective and that they do no harm - i.e., that they themselves do not introduce new safety risks. Moreover, a means of assessing hazards coverage must also be included in the validation framework. A validation framework involving analysis, simulation, and experimental testing was previously developed for safety-critical integrated systems operating under hazardous conditions that can lead to LOC (see Refs. 8 \& 9), and a preliminary set of LOC test scenarios was developed (see Ref. 10) based on a limited accident set. 


\section{LOC Accident Analysis Methodology and Example Cases}

This section presents a detailed methodology for the analysis of aircraft accidents and incidents, with the purpose of developing technology solutions for LOC prevention and recovery. The accident / incident set includes inflight LOC (LOC-I) accidents as categorized by the CAST/ICAO Common Taxonomy Team ${ }^{13}$ as well as other LOC accidents (e.g., resulting from control component failures and/or vehicle damage sufficient to alter vehicle dynamics and control characteristics) related to the definition of Section II but not typically included in the LOC-I accident category. Refinement of the analysis methodology includes the addition of LOC precursors, the addition of flags for quickly identifying key issues of interest for LOC, the identification of potential research solutions for each accident (if applicable), and the capture of specific comments for each precursor. Each precursor comment is taken from the accident report or supporting information and specifies why each precursor is included in the sequence. In some cases, consensus comments by the analysis team have been added to enhance clarity. This section provides a detailed summary of this refined analysis methodology and provides some examples to illustrate it.

\section{A. Accident Set Definition}

Air carrier upset accidents were reviewed for the period 1996 through 2010. All reported mishaps to airplanes certified under Transport Category or Commuter Category were considered. The following databases were reviewed:

- Australian Transport Safety Bureau (ATSB) ${ }^{14}$

- UK Air Accidents Investigation Branch (AAIB) ${ }^{15}$

- Canadian Transportation Safety Board (TSB) ${ }^{16}$

- French Bureau d'Enquêtes et d'Analyses pour la sécurité de l'aviation civile (BEA) ${ }^{17}$

- German Bundesstelle für Flugunfalluntersuchungin (BFU) ${ }^{18}$

- Irish Air Accident Investigation Unit (AAIU) ${ }^{19}$

- National Transportation Safety Board (NTSB) ${ }^{20}$

- International Civil Aviation Organization (ICAO) ${ }^{21}$

- Ascend Fleets from Flightglobal ${ }^{22}$

- Aviation Safety Network (ASN) ${ }^{23}$

- Aircraft Accident Report DVD ${ }^{24}$

Database coded event fields and narratives were queried for event categories and/or keywords such as "loss-ofcontrol," "upset," "unusual attitude," "stall," "crash out of control," and "uncontrolled descent." All resulting database records and accident reports were reviewed by the authors to determine applicability to the study. Military airplanes and accidents resulting from criminal or deliberate activities (e. g., Egyptair 990) or pilot incapacitation (e. g., Helios 522) were culled from the list. Test operations were not considered nor were engine-out ferry flights, although positioning flights were included.

The full accident / incident set is provided in Appendix A. Some general statistics associated with the LOC accident / incident set of this study are summarized below in terms of number of events (or mishaps) and fatalities (onboard and ground) relative to phase of flight, aircraft type, operation, and five-year intervals.

Table 1. LOC Events and Fatalities Relative to a.) Five-Year Intervals, b.) Phase of Flight, c.) Aircraft Type, and d.) Operation

\section{a.) LOC Events by 5-Year Intervals}

\begin{tabular}{|l|c|c|c|}
\hline Time Period & Events & Onboard Fatalities & Ground Fatalities \\
\hline $1995-2000$ & 102 & 3007 & 81 \\
\hline $2001-2005$ & 101 & 2143 & 135 \\
\hline $2006-2010$ & 75 & 2104 & 19 \\
\hline Total & 278 & 7254 & 235 \\
\hline
\end{tabular}




\section{b.) LOC Events by Phase of Flight}

\begin{tabular}{|l|c|c|c|}
\hline Flight Phase & Events & Onboard Fatalities & Ground Fatalities \\
\hline Takeoff and Initial Climb & 85 & 1511 & 94 \\
\hline Climb & 44 & 1767 & 33 \\
\hline Cruise & 43 & 2008 & 78 \\
\hline Descent & 17 & 157 & 0 \\
\hline Holding & 2 & 0 & 0 \\
\hline Approach & 47 & 805 & 23 \\
\hline VFR Pattern & 2 & 5 & 0 \\
\hline Circling & 3 & 175 & 0 \\
\hline Landing & 18 & 39 & 0 \\
\hline Go-Around & 10 & 116 & 0 \\
\hline Missed Approach & 7 & 671 & 7 \\
\hline Total & 278 & 7254 & 235 \\
\hline
\end{tabular}

c.) LOC Events by Aircraft Classification

\begin{tabular}{|l|c|c|c|}
\hline Aircraft Classification & Events & Onboard Fatalities & Ground Fatalities \\
\hline Wide-body Turbojets & 38 & 2224 & 17 \\
\hline Narrow-body Turbojets & 83 & 3850 & 170 \\
\hline Business Jets & 57 & 187 & 15 \\
\hline Turboprop Transports & 45 & 620 & 31 \\
\hline Piston Transports & 5 & 34 & 0 \\
\hline Commuter Airplanes & 50 & 339 & 2 \\
\hline Total & 278 & 7254 & 235 \\
\hline
\end{tabular}

\section{d.) LOC Events by Type of Operation}

\begin{tabular}{|l|c|c|c|}
\hline Operation & Events & Onboard Fatalities & Ground Fatalities \\
\hline Scheduled Airlines & 147 & 5900 & 170 \\
\hline Non-Scheduled Airlines & 85 & 1206 & 52 \\
\hline Non-Revenue Operations & 29 & 78 & 6 \\
\hline Executive Transportation & 17 & 70 & 7 \\
\hline Total & 278 & 7254 & 235 \\
\hline
\end{tabular}

\section{B. Accident Analysis Methodology}

The accident analysis methodology was based on the sequential precursor model, which defines an accident as a series of connected events that ultimately lead to an undesired outcome. If a precursor event can be eliminated by an intervention, the accident/incident can be prevented. For this study, the methodology was designed to identify dominant precursors for each accident and the associated temporal sequencing. In contrast to typical root cause analysis, the precursors were selected by identifying all relevant hazards that sequentially led to the mishap (as opposed to the primary / root cause) to better understand LOC more holistically as a multiple-hazards event and thereby enable the development of research and technology interventions that are effective across a wide spectrum of key LOC hazards and their combinations (as opposed to developing separate technologies that target a single hazard). The precursors, shown in Table 2, were defined by the team based on the previous accident analysis of references 56 and were further updated during the analysis process. The wording of each precursor was carefully defined to correlate with terminology typically seen in accident reports and to minimize ambiguities. Some precursors, such as those under "Vehicle Upset," were derived from recent references (e.g., Refs. 4,12) and further, more specific definitions may warrant additional research. An important distinction with this analysis was that the goal was to identify potential technology interventions that merit further research, rather than the root cause or specific near-term interventions. Therefore some accidents were included in the database that did not clearly fit the specific definition 
of a LOC event but contained important precursor information that added substantially to the analysis or should be considered for future analysis.

Table 2. LOC Precursors / Hazards Set Used in the Accident Analysis

\begin{tabular}{|c|c|c|}
\hline Precursor Categories & Subcategories & Precursors / Hazards \\
\hline \multirow[t]{3}{*}{$\begin{array}{l}\text { Adverse Onboard } \\
\text { Conditions }\end{array}$} & $\begin{array}{l}\text { Vehicle } \\
\text { Impairment }\end{array}$ & $\begin{array}{l}\text { Improper Maintenance Action/Inaction/Procedure } \\
\text { Inappropriate Vehicle Configuration } \\
\text { Contaminated Airfoil } \\
\text { Smoke/Fire/Explosion } \\
\text { Improper Loading: Weight/Balance.CG } \\
\text { Airframe Structural Damage } \\
\text { Engine Damage (FOD) }\end{array}$ \\
\hline & $\begin{array}{l}\text { System \& Components } \\
\text { Failure/Malfunction }\end{array}$ & $\begin{array}{l}\text { System Design/Validation Error/Inadequacy } \\
\text { System SW Design/Verification Error/Inadequacy } \\
\text { Control Component Failure/Inadequacy } \\
\text { Engine F/M } \\
\text { Sensor System F/M } \\
\text { Flight Deck Instrumentation Malfunction/Inadequacy } \\
\text { System F/M (Non-Control Component) }\end{array}$ \\
\hline & Crew Action/Inaction & $\begin{array}{l}\text { Loss of Attitude State Awareness/SD } \\
\text { Loss of Energy State Awareness } \\
\text { Lack of Aircraft/System State Awareness } \\
\text { Aggressive Maneuver } \\
\text { Abnormal/Inadvertent Control Input } \\
\text { Improper/Ineffective Recovery } \\
\text { Inadequate Crew Resource Monitoring/Management } \\
\text { Improper/Incorrect/Inappropriate Procedure/Action } \\
\text { Fatigue/Impairment/Incapacitation }\end{array}$ \\
\hline \multirow[t]{3}{*}{$\begin{array}{l}\text { External Hazards \& } \\
\text { Disturbances }\end{array}$} & $\begin{array}{l}\text { Inclement Weather \& } \\
\text { Atmospheric } \\
\text { Disturbances }\end{array}$ & $\begin{array}{l}\text { Thunderstorms/Rain } \\
\text { Wind Shear } \\
\text { Wind/Turbulence } \\
\text { Wake Vortex } \\
\text { Snow/Icing }\end{array}$ \\
\hline & Poor Visibility & $\begin{array}{l}\text { Fog, Haze } \\
\text { Night }\end{array}$ \\
\hline & Obstacle & $\begin{array}{l}\text { Fixed Obstacle } \\
\text { Moving Obstacle }\end{array}$ \\
\hline \multirow[t]{2}{*}{$\begin{array}{l}\text { Abnormal Vehicle } \\
\text { Dynamics } \\
\text { \& Upsets }\end{array}$} & $\begin{array}{l}\text { Abnormal Vehicle } \\
\text { Dynamics }\end{array}$ & $\begin{array}{l}\text { Uncommanded Motions, } \\
\text { Oscillatory Response (Includes PIO) } \\
\text { Abnormal Control for Trim/Flight and/or Control } \\
\text { Asymmetry } \\
\text { Abnormal/Counterintuitive Control Response } \\
\end{array}$ \\
\hline & $\begin{array}{l}\text { Vehicle Upset } \\
\text { Conditions }\end{array}$ & $\begin{array}{l}\text { Abnormal Attitude } \\
\text { Abnormal Airspeed/Energy } \\
\text { Abnormal Angular Rates } \\
\text { Undesired Abrupt Response } \\
\text { Abnormal Flight Trajectory } \\
\text { Vmc / Departure } \\
\text { Stall / Departure }\end{array}$ \\
\hline
\end{tabular}

The analysis was based solely on publicly-available formal accident reports and associated supporting documents when available. For example, knowledge of sub-system design and performance specific to the aircraft was included when appropriate to clarify the precursor or temporal sequencing. Each accident was reviewed and precursors identified in a consensus format and the results were recorded in a spreadsheet document to facilitate data analysis. 
An illustration of the analysis spreadsheet used in the analysis process is provided in Appendix B. The team based the precursor analysis on the published information verbatim and did not inject additional analysis or conclusions. In some cases the accident reports were very limited, which resulted in minimal identified precursors. The temporal sequencing was established by assigning a number to the precursors and in some cases a precursor may have occurred more than once. In most cases, the ending precursor was under the category of "Vehicle Upset Conditions". Because some precursors were somewhat broad in definition, the associated text that was used to justify that precursor was included in the database for completeness and further analysis.

As part of the database, three broad technology categories were flagged for potential relevance to the accident, 1) crew distraction, 2) human-machine interface, and 3) mitigation through research including training. These categories, though not specific precursors, were included due to numerous important and recent studies to address these areas but which were not necessarily addressed in the accident reports. In addition, comments were included to highlight important aspects of the accident that were not necessarily included in a precursor.

Once the precursor sequences are identified, an analysis can be performed to identify worst-case precursor combinations and precursor sequences. "Worst case" in this context is in terms of the number of accidents and fatalities. Worst case precursor combinations are identified using three-dimensional scatter plots with the three dimensions corresponding to the three precursor categories identified in Table 2. The preliminary analysis results documented in Ref. 10 illustrated these scatter plots at the sub-category and precursor levels. An example from Ref. 10 is included in Appendix $\mathrm{C}$ for convenience. Worst-case precursor sequences can be identified using pivot tables in Excel. All sequences associated with an initiating precursor can be drawn with the number of associated accidents and fatalities for each sequence. Examples from Ref. 10 of worst case sequence identification are also included in Appendix C. Individual precursor statistics can also be computed, as illustrated in Ref. 10 and summarized for the mishaps analyzed to date in Subsection III-D.

\section{Accident Analysis Example}

To illustrate the potential use of the database and analysis methodology, an analysis of eight accidents and incidents involving blocked pitot tubes or static port is presented. Table 3 provides a summary of these accidents and incidents.

Table 3. LOC Accidents and Incidents from the Data Set Involving Blocked Pitot Tubes

\begin{tabular}{|c|c|c|c|c|c|c|c|}
\hline $\begin{array}{c}\text { Accident } \\
\text { No. }\end{array}$ & Date & Location & Airline & Flight No. & Aircraft & $\begin{array}{c}\text { Phase of } \\
\text { Flight }\end{array}$ & Fatalities \\
\hline 2 & 2/6/1996 & $\begin{array}{c}\text { Dominican } \\
\text { Republic }\end{array}$ & Birgenair & 301 & B-757-225 & En Route & 189 \\
\hline 14 & 10/2/1996 & Peru & AeroPeru & 603 & B-757 & Climb & 70 \\
\hline 37 & 10/10/1997 & Uruguay & $\begin{array}{c}\text { Austral } \\
\text { Lineas } \\
\text { Aereas }\end{array}$ & 2553 & DC-9 & En Route & 74 \\
\hline 62 & 4/7/1999 & $\begin{array}{l}\text { Ceyhan, } \\
\text { Turkey }\end{array}$ & $\begin{array}{c}\text { THY } \\
\text { Turkish } \\
\text { Airlines }\end{array}$ & 5904 & B-737 & En Route & 6 \\
\hline 142 & $10 / 20 / 2002$ & $\begin{array}{l}\text { Baltimore, } \\
\text { Maryland }\end{array}$ & Icelandair & 662 & B-757 & En Route & 0 \\
\hline 188 & $5 / 12 / 2005$ & Missouri & $\begin{array}{c}\text { Midwest } \\
\text { Airlines } \\
\end{array}$ & & MD-90 & Initial Climb & 0 \\
\hline 254 & 1/28/2009 & Ghana & $\begin{array}{l}\text { Astraeus for } \\
\text { Ghana } \\
\text { Airways }\end{array}$ & & B-757 & Cruise & 0 \\
\hline 260 & $6 / 1 / 2009$ & $\begin{array}{c}\text { Atlantic } \\
\text { Ocean (Near } \\
\text { Sao Paulo } \\
\text { Archipelago) } \\
\end{array}$ & Air France & 447 & A-330 & En Route & 228 \\
\hline
\end{tabular}


A description of the sensor system failure causes, symptoms, and outcomes is summarized below for the above mishaps.

1 Causes of the Sensor System Failure:

a Four sensor system failure events were caused by pitot icing.

Pitot icing can affect all onboard air data systems, the pilot, copilot, and standby systems and all flight control systems that use air data. These include autopilots, flight directors, and some flight control functions.

Three of the failures were caused by inoperative pitot heat (either switched off or failed). One was caused by atmospheric conditions that were worse than pitot design requirements

b Three failure events were caused by a single blocked pitot tube.

A single blocked pitot tube affects a single air data system, usually the pilot's or copilot's systems. In this case, there will be disagreement between the cockpit indications.

Two failures occurred after pitot covers were left off overnight. One failure was caused by an internal blockage.

c One failure event was caused by static ports being taped over by the maintenance crew.

Blocking all static ports affects all onboard air data systems, the pilot, copilot, and standby systems and all flight control systems that use air data. These include autopilots, flight directors, and some flight control functions.

2 Symptoms of the Sensor System Failure:

a Seven failure events resulted in flight crew confusion with misleading or conflicting cues and warnings. It was not clear to the flight crews what was happening. Attempts to isolate the failed systems appeared to be ineffective because the selection logic for airspeed/altitude input to autopilots or flight directors was not clear. The pilots did not understand what the effect of changing altitude had on their indications. Confusing warnings, such as MACH/SPD TRIM and RUDDER RATIO were shown with no previous training documented for the flight crews. Simultaneous overspeed and stall warnings were presented.

b One failure event resulted in the copilot, who was flying, seeing zero airspeed and immediately applying stall recovery which was intended for low altitude stalls and had the effect of causing loss of one slat which precluded recovery.

\section{Differences between accidents and incidents}

a Four accidents showed extreme confusion (as described above) in the flight deck. The crews were still trying to sort out the situation when they crashed, killing all onboard.

b Three incidents showed the same confusion in the flight deck with the same indications. Fortunately for all onboard, the crew finally reverted to basic pitch and power control and safely recovered the airplanes.

Further analysis of these mishaps can be accomplished by identifying the precursor sequences and worst-case combinations associated with each accident and incident. Figure 2 illustrates the accident sequence determined for the Birgenair accident of 1996, which corresponds to Accident No. 2 in Table 3. The blocks in the sequence represent accident precursors (or hazards) that led to this accident. The comments below each box are taken from the accident report to reflect the team rationale for inclusion of each precursor. These comments provide specific information from the accident or incident for each precursor / hazard in the sequence. 


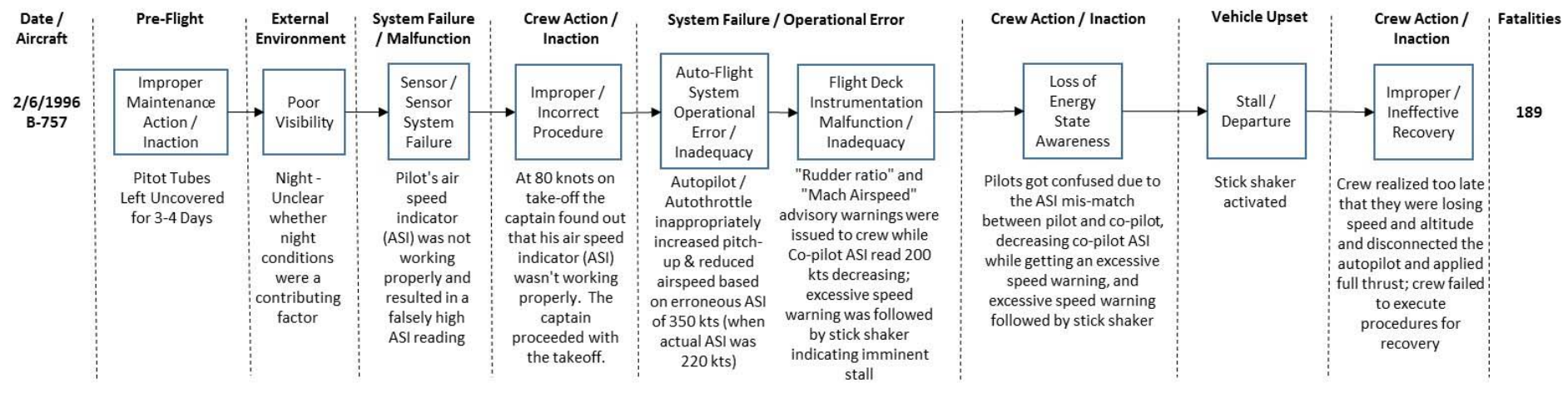

Figure 2. LOC accident sequence for Birgenair 301 (2/6/1996).

The precursor sequences developed for the eight blocked pitot tube or static port mishaps of Table 3 are provided in Appendix D. Some initial observations in analyzing the precursor sequences include the following:

1) What started the event?

a. $\quad 37.5 \%$ (3/8) of the events started with an "Improper Maintenance Action/Inaction.” This means that $37.5 \%$ of these mishaps may have been able to be avoided with proper ground crew actions or adequate preflight by the flight crew - assuming the other hazards and hazards combinations could be mitigated successfully.

b. $50 \%(4 / 8)$ of the remaining mishaps seem to have pitot tube icing as an initiating precursor (under snow, thunderstorm, or other icing conditions).

c. The remaining event (1/8) started with a pitot tube sensor failure, though reasons for the blockage could not be determined.

2) What do the fatality cases all have in common?

a. Three of the five (or 60\%) are characterized by "Improper/Ineffective Recovery.” This precursor could potentially be added to mishap \#62 as well, but information is limited for this case. Adding it would make $4 / 5$ (or $80 \%$ ).

b. One aircraft suffered structural damage that resulted in an inability to control the aircraft. The pilots likely could not make a proper recovery given the damage.

c. All of the fatal events experienced a serious vehicle upset condition, with $80 \%$ (4/5) involving stall / departure and the fifth event involving uncontrolled descent.

d. Three of the five fatal accidents (60\%) involved flight deck instrumentation and/or auto-flight system issues (operational errors, inadequacy, etc.).

e. In 4/5 cases ( $80 \%$ ) there were also a "Loss of Awareness" issue in either aircraft / system state, energy, or attitude.

3) What's different about the nonfatal incident cases?

a. All three of these incidents $(142,188$, and 254$)$ led to vehicle upsets, although only one event involved vehicle stall, and the pilots were able to recover the aircraft.

b. There were still pilot issues as all three had either an "Improper/Incorrect Procedure" or "Abnormal Control Input."

c. Only one of the three (\#254) had a "Lack of Aircraft System State Awareness," but this was limited to the mode switching that was occurring in the background.

In general, the fatal accidents appear to be more complicated (i.e., involving more precursors) than the nonfatal incidents. A comparison of event complexity can be performed by analyzing the worst case precursor combinations using 3-D scatter plots. Figure 3 shows the precursor combinations for the fatal accidents (Figure 3a) and nonfatal incidents (Figure 3b). The axes represent Vehicle Hazards, External Hazards \& Disturbances, and Crew Action / Inaction. These axes were selected to identify the hazards combinations involved in these mishaps, and to enable a more detailed identification of the specific hazards involved. Since all of these mishaps involved a sensor system failure (resulting from a blocked pitot tube or static port), this precursor is assumed and not included in Figure 3. The planes along the External Hazards and Disturbances axis are used to identify the precursor combinations for each mishap. The nodes (or spheres) in Figure 3 identify hazard combinations, where sphere size is proportional to the number of accidents and sphere color relates to the number of fatalities (as indicated by the legend of Figure 3). 


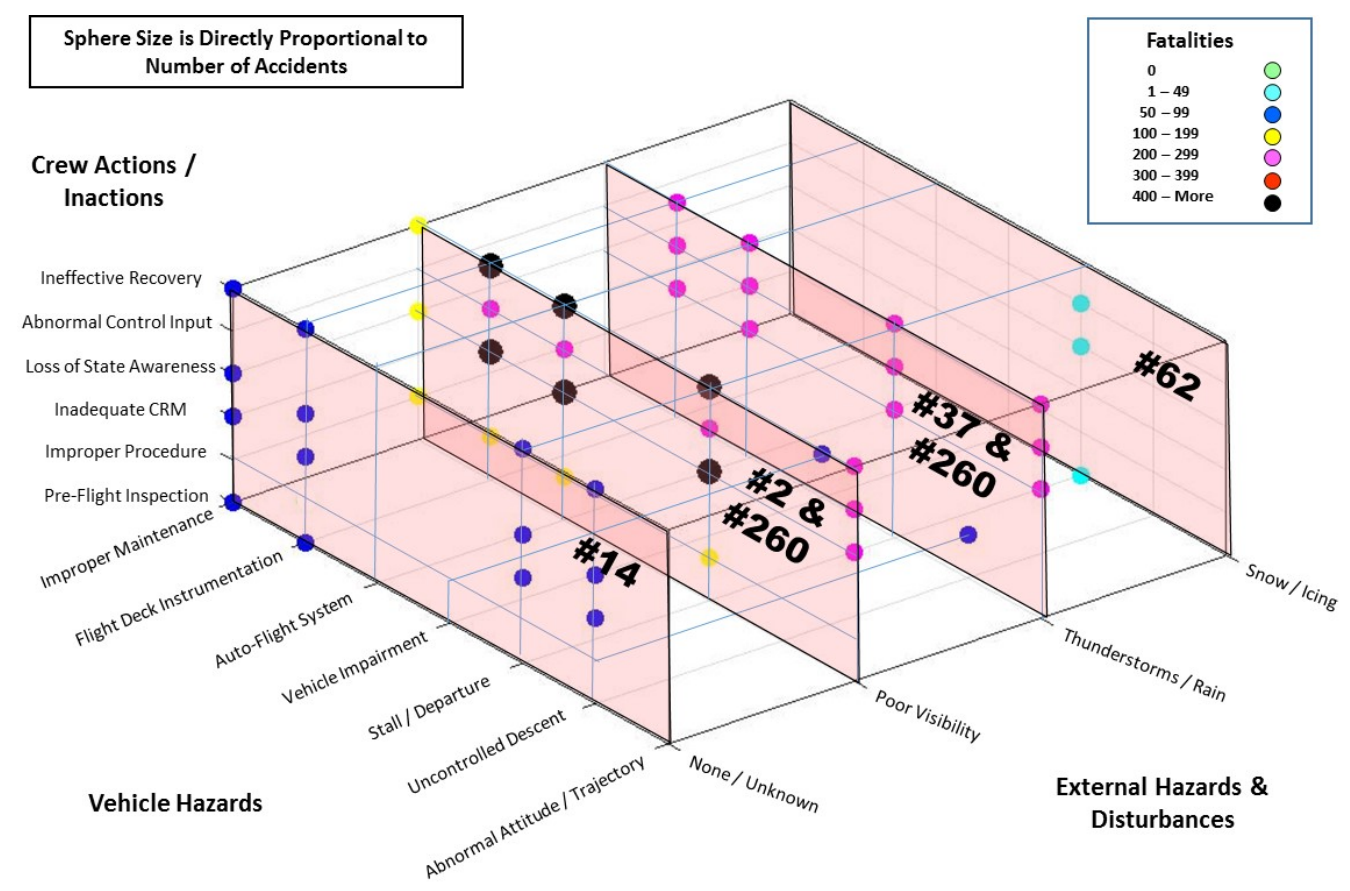

(a.)

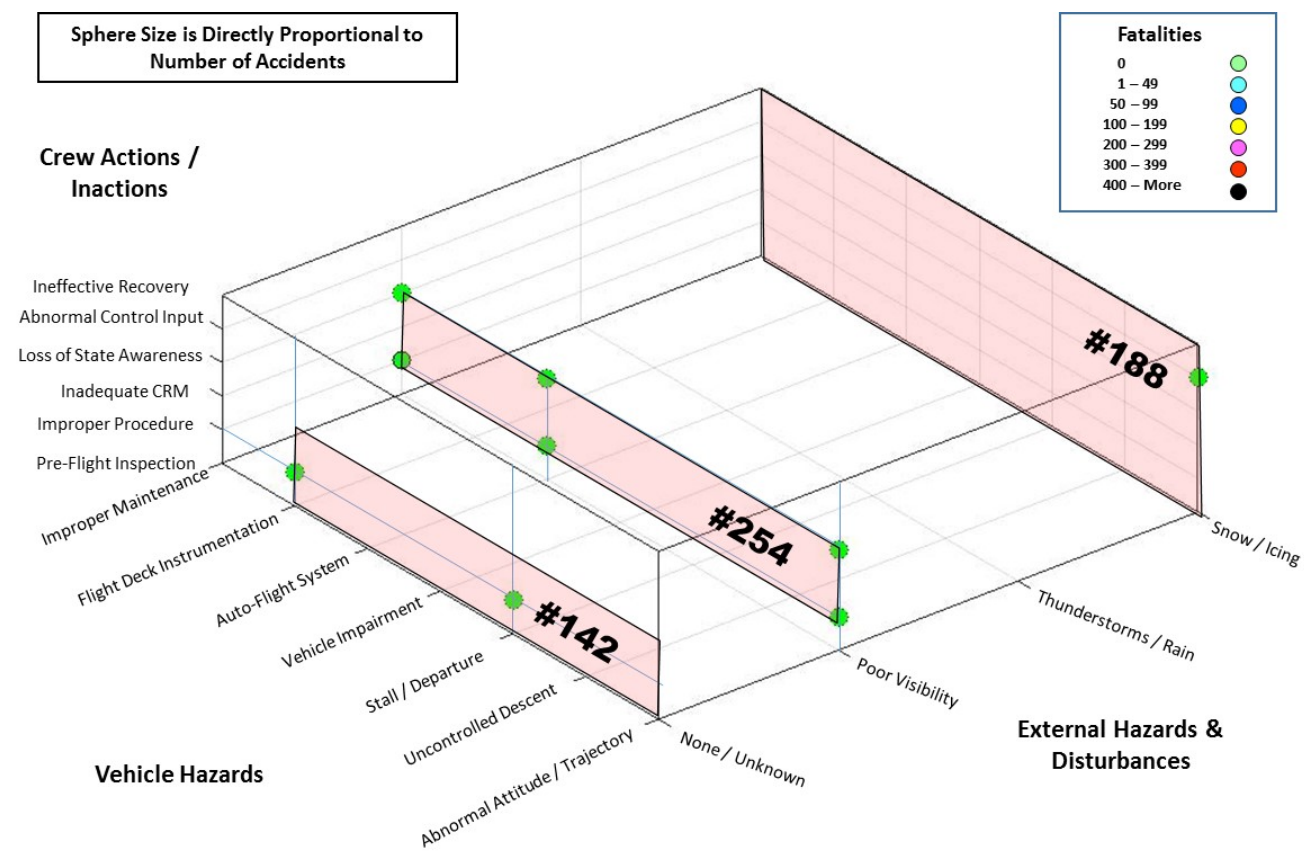

(b.)

Figure 3. Three-Dimensional (3-D) Scatter Plots Showing Precursor Combinations for (a.) Fatal Accidents and (b.) Nonfatal Incidents

Considering the fatal accidents first, it is easy to see from Figure 3a that there are many hazards combinations occurring for \#2, \#37, \#260, and \#14. Mishap \#62 is the least complex in terms of hazards combinations, but this event involves snow/icing conditions, loss of state awareness by the crew, abnormal control inputs, and entry into 
stall. Mishap \#14 involves multiple ineffective crew actions (improper pre-flight inspection, inadequate crew resource management, loss of state awareness, and ineffective recovery), flight deck instrumentation issues, and two serious upset conditions (stall / departure and uncontrolled descent). Accidents \#2, \#37, and \#260 are the most complex, with \#260 being both the most recent fatal accident and the most complex. All three of these events involve both flight deck instrumentation and autoflight system issues (operational errors, inadequacies, etc.), multiple crew hazards (including loss of state awareness, abnormal control inputs, and ineffective recovery), and stall / departure. Mishap \#2 occurred under poor visibility conditions, \#37 occurred under thunderstorms / rain conditions, and \#260 involved both of these external hazards. Mishap \#37 also involved vehicle impairment that resulted from an inappropriate configuration that led to structural damage and abnormal vehicle dynamics and control.

By comparison, the nonfatal incidents of Figure $3 \mathrm{~b}$ are much less complex involving fewer hazards combinations. Incident \#188 is the simplest event involving a single combination of snow / icing, abnormal control input, and abnormal attitude / trajectory. Incident \#142 is slightly more complicated. Although there is no involvement by External Hazards \& Disturbances, it does involve flight deck instrumentation and stall / departure, but only involves improper procedure by the crew. The final incident, \#254, occurred under poor visibility conditions, involved the auto-flight system, two crew hazards (improper procedure and loss of state awareness), and abnormal attitude. The only stall event was not complicated further by inclement weather or poor visibility, nor by multiple instances of ineffective crew involvement. The other two incidents never entered into more severe vehicle upset conditions (such as stall / departure or controlled descent).

It is noted that very few incident investigations get the level of attention given to fatal accidents, but it would be difficult to quantify this difference (e.g., length of the report, length of the investigation, number of parties to the investigation, etc.) and thereby determine any potential impact this may have on complexity findings. It is also noted that the flight crews of the incidents were able to "break the chain" of events and thereby avert an accident. However, this could be either a cause or effect of less complexity. That is, less complex events may be easier for crews to identify and correct before they become an accident, or breaking the chain earlier in the sequence of events could prevent progression to a more highly complex event. Regardless, it is worth noting that the complexity of some circumstances make it less likely that crews will be able to correctly identify and correct the situation before it progresses too far.

The comments and flags included in the analysis process can also provide some insight into key issues and potential methods for mitigating through research. Tables of this data are contained in Appendix D. In three of the five fatal accidents, the crew was distracted or overwhelmed by conditions related to the pitot system failure (with one of these accidents exacerbated by the presence of cabin crew in the cockpit). Four of the five fatal accidents involved potential human-machine interface issues, with the accident report for the fifth accident lacking enough information to make this determination. In some cases the auto-flight system flew the aircraft into stall (due to the erroneous airspeed indications), and flight deck instrumentation provided little information for improved situation awareness and no guidance on appropriate actions to take. Moreover, in some instances multiple conflicting warnings and alerts were sounding simultaneously - which further confused the crew. In contrast, none of the non-fatal incidents involved crew distraction. Although the onboard systems provided similar opportunities for confusion or to further exacerbate the situation, the comparatively less complex hazards profile enabled the pilots to successfully recover to a safe flight condition.

Comparing the fatal and nonfatal mishaps of this study, it can be concluded that there is a level of hazards complexity at which pilots (or any human) become confused and are unable to respond effectively. Moreover, current systems are essentially designed for nominal conditions and either disengage or respond inappropriately (adding additional confusion to the situation). Some potential mitigation strategies to prevent these kinds of mishaps in the future are provided in the tables of Appendix D for each mishap, and summarized here as follows:

1. Improved pilot training relative to diagnosing and mitigating onboard system failures (including sensor system failures and use of alternate instrumentation);

2. Improved crew training under unexpected and abnormal conditions (including multiple hazards events) and in the implications of existing protections associated with system operational modes;

3. Sensor integrity management system capable of detecting, identifying and mitigating sensor system failures (including blocked pitot tube or static ports and common mode sensor failures);

4. Improved algorithms and displays that provide improved situational awareness to the systems and crew under multiple hazards conditions; 
5. Resilient flight control system capable of ensuring flight safety under multiple hazards (including system failures, external disturbances, and inappropriate control inputs by the crew and/or autoflight systems);

6. Resilient upset recovery system capable of providing guidance for and/or automatic recovery from upset conditions (including stall) under multiple hazards conditions.

\section{Individual Hazards Occurrences}

To date, the team has analyzed 122 of the 278 mishaps in the set using the analysis approach described herein. Individual occurrences of the precursors / hazards, arranged by the categories identified in Table 2, in the accident data analyzed to date are shown in Figures 4, 5 and 6 for Adverse Onboard Conditions, External Hazards \& Disturbances, and Abnormal Vehicle Dynamics \& Upsets, respectively.

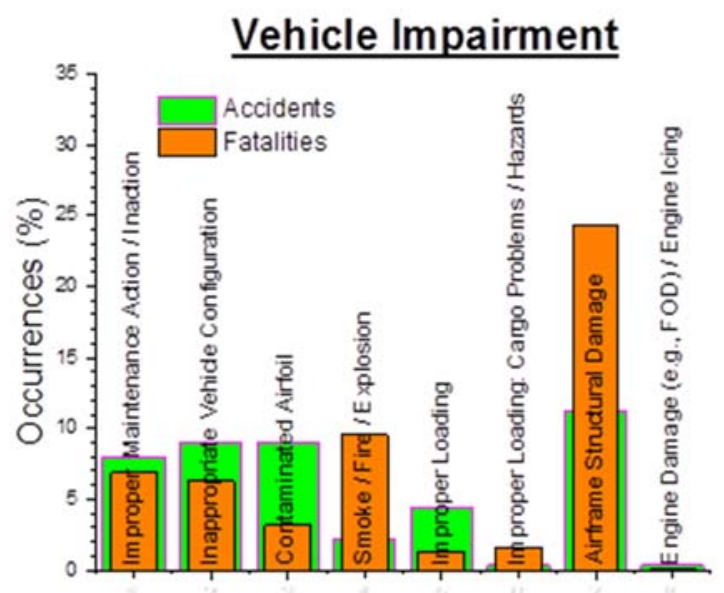

(a.)

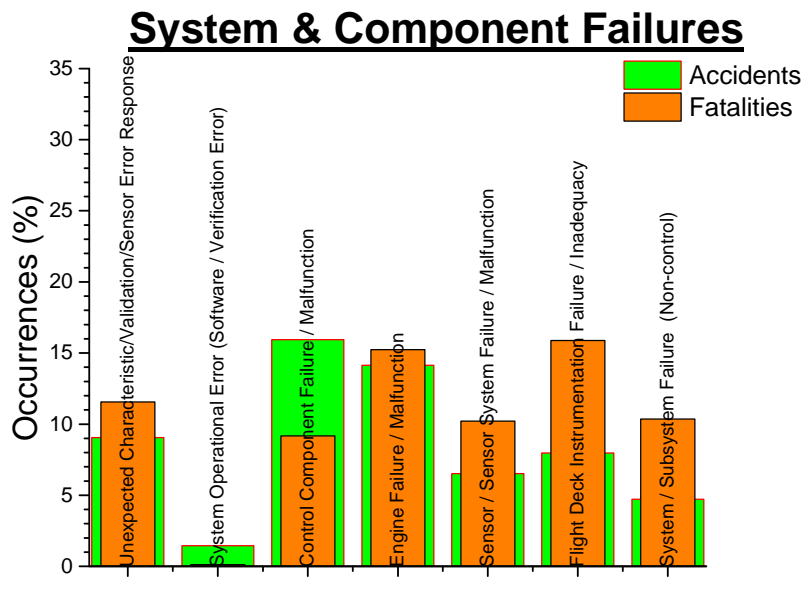

(b.)

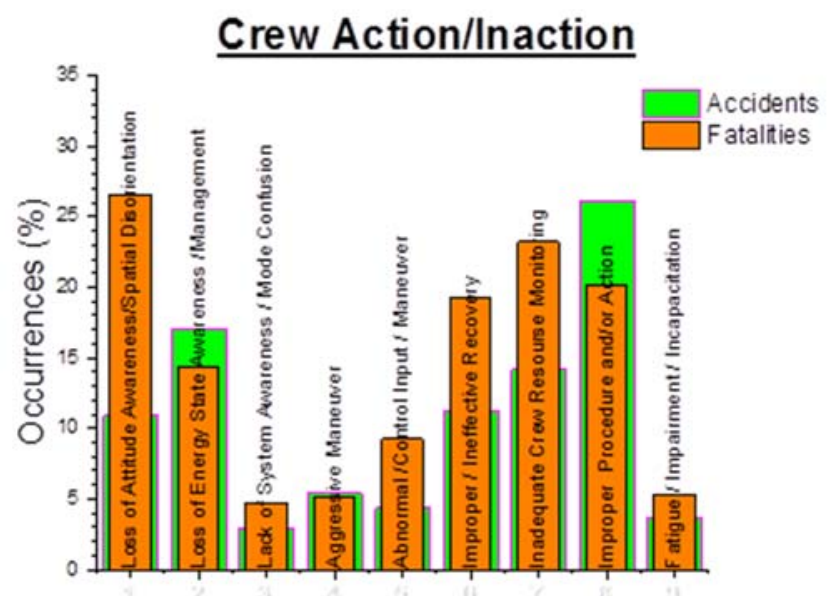

(c.)

Figure 4. Percent Occurrence of Hazards from Adverse Onboard Conditions Resulting from (a.) Vehicle Impairment, (b.) System \& Component Failures, and (c.) Crew Actions / Inactions.

Relative to hazards from Adverse Onboard Conditions (see Figure 4), airframe structural damage has occurred in approximately $25 \%$ of the mishaps analyzed to date, and system and component failures have occurred in a large percentage of mishaps and are fairly evenly distributed at $15 \%$ each involving control component failures, engine failures, and flight deck instrumentation malfunctions, with system operational errors, sensor system failures, and 
system failures (non-control components) occurring in approximately $10-12 \%$ of the accidents and incidents. Crew actions / inactions are dominated by loss of attitude and energy state awareness at approximately $27 \%$ and $17 \%$, respectively, improper procedure at approximately $27 \%$, inadequate crew resource monitoring or management at approximately $23 \%$, and improper or ineffective recovery at about $19 \%$.

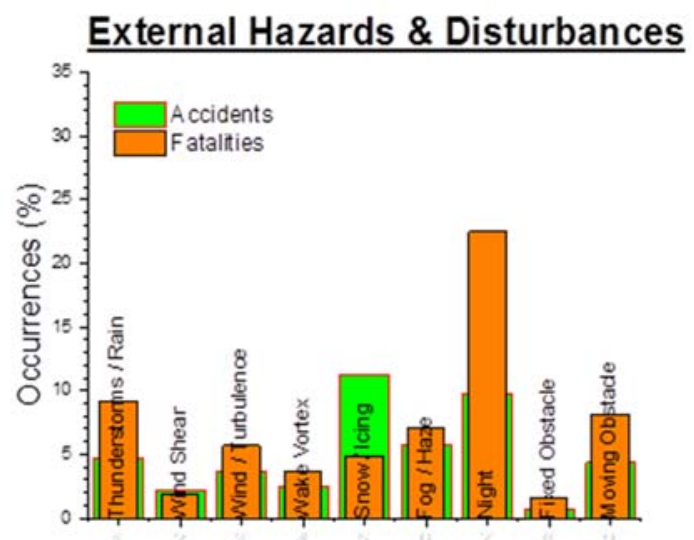

Figure 5. Percent Occurrence of Hazards from External Hazards \& Disturbances.

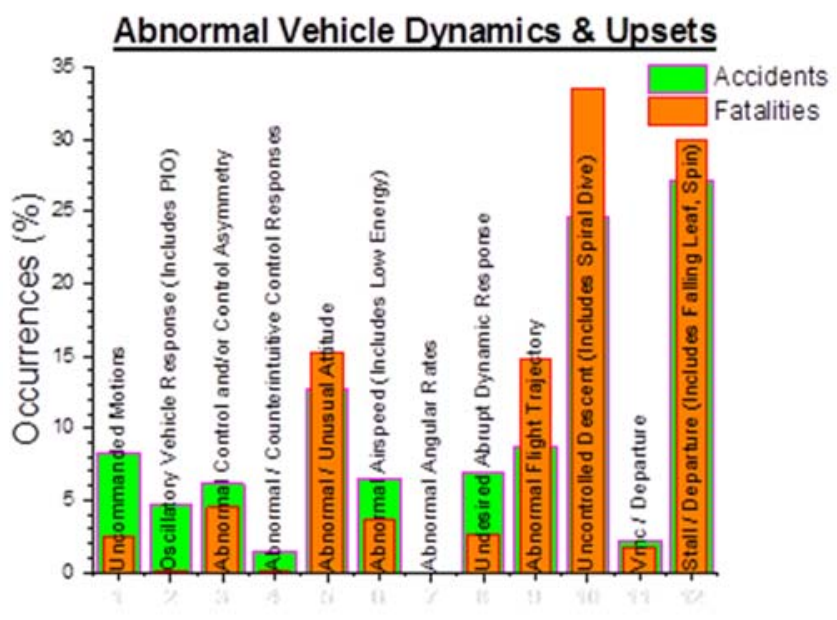

Figure 6. Percent Occurrence of Hazards from Abnormal Vehicle Dynamics \& Upsets.

External Hazards and Disturbances (see Figure 5) are dominated by night visibility issues at approximately 22\%, with snow or icing occurring in a little more than $10 \%$ of the mishaps evaluated to date. Other key external hazards include thunderstorms / rain at 9\%, moving obstacles at $8 \%$, and visibility issues related to fog or haze at $7 \%$.

Hazards associated with Abnormal Vehicle Dynamics and Upsets (see Figure 6) are dominated by uncontrolled descent (which occurred in approximately 34\% of the mishaps analyzed thus far) and stall / departure (which occurred in approximately 30\%). Other key hazards related to vehicle upset conditions include abnormal / unusual attitude and abnormal flight trajectory (each occurring in approximately $15 \%$ of the mishaps analyzed to date). Hazards related to abnormal vehicle dynamics occurred less frequently, with uncommanded motion occurring in approximately $8.5 \%$ of the mishaps analyzed thus far, followed by abnormal control and/or control asymmetry (6\%), oscillatory vehicle response (4\%), and abnormal or counterintuitive control response (2\%).

Overall (i.e., looking at the entire set of plots in Figures 4-6), it appears that a relatively high percentage of the accidents analyzed to date have involved the human element, Crew Action / Inaction. There is also a significant 
contribution of poor visibility under night conditions within the External Hazards \& Disturbances category, and of events involving uncontrolled descent and stall / departure under the Vehicle Upsets sub-category. This may indicate the need for improved systems that better account for human involvement and provide improved man/machine interfaces.

\section{Accident Analysis Products and Follow-On Research}

Analysis products will be made available from the process of Section III, and follow-on research is planned for the identification of future potential safety risks related to LOC and the development of LOC test scenarios based on the current and future hazards sets and their analysis. The analysis products and follow-on research are described in the following subsections.

\section{A. Aircraft Accident Analysis Products}

A goal of this effort is to facilitate further research on LOC as well as the development of technology solutions for LOC prevention and recovery. The authors therefore plan to make the data and analysis files available online so that the LOC analysis of this study can be openly investigated and additional LOC studies can be performed by other groups. Data files include the aircraft accident dataset described in Section III-A, accident summaries used in the analysis, and the full accident reports that have been obtained. Analysis products from the work described in Section III-B include the analysis spreadsheet used to identify precursor sequences for the accidents in the data set, the spreadsheets used to organize the data for generating worst-case precursor combinations and sequences, and the references sited as being applicable to potentially addressing each accident or incident. We also hope to develop an intelligent interface with links that enable querying the analysis results of this study. For example, clicking on a worstcase precursor combination sphere shown in Fig. B-1 would enable seeing lower level combinations (such as those shown in Fig. B-2) as well as a listing of which accidents and incidents from the set are represented in that combination.

\section{B. Future Potential Risks}

In developing technology solutions for LOC prevention and recovery, it is not only important to understand current causal and contributing factors (or precursors) but also future potential risks. The identification of future potential LOC risks is more difficult than current risks because there is no data that can be analyzed. Future potential LOC risks will be identified by the authors by considering current trends and future directions. A preliminary set of future potential LOC risks was identified in Ref. 10, and is repeated here for convenience in Table 4.

Table 4. Potential future LOC risks listed by trend from Ref. 10.

\begin{tabular}{|c|c|c|}
\hline No. & Current Trend / Future Direction & Potential LOC Risk Factors \\
\hline 1 & Increased Automation without Improved Crew Interfaces & Increase in Inappropriate Crew Response \\
\hline 2 & $\begin{array}{l}\text { Future Vehicle Configurations without Identification of Upset } \\
\text { Characteristics }\end{array}$ & Increased Incidents of Vehicle Upsets \\
\hline 3 & $\begin{array}{l}\text { Increased System Complexity without Comprehensive } \\
\text { Evaluation Process }\end{array}$ & $\begin{array}{l}\text { Increase in System Faults / Failures / Errors / } \\
\text { Insufficiencies }\end{array}$ \\
\hline 4 & High-Density Operations in Terminal Area & Increase in Wake Vortex Encounters \\
\hline 5 & High-Density Operations in Terminal Area & Increase in Pilot Workload \\
\hline 6 & Increase in Flight Deck Automation & Decrease in Manual Piloting Skills \\
\hline 7 & All-Weather Operations & Increase in Snow/Icing Encounters \\
\hline 8 & All-Weather Operations in Terminal Area & Increase in Wind Shear / Turbulence Encounters \\
\hline 9 & High-Density Mixed-Vehicle Operations & $\begin{array}{l}\text { Increased Incidence of Near-Miss and Mid-Air } \\
\text { Collision Events }\end{array}$ \\
\hline 10 & $\begin{array}{l}\text { New Vehicle Materials with Lack of Long-Term Data on Aging } \\
\text { and Damage Tolerance }\end{array}$ & Increase in Damage-Initiated LOC Events \\
\hline
\end{tabular}


Some of the trends / directions identified in Table 4 result from the NextGen Operations concept ${ }^{25,26}$ being developed for the next generation of the air transportation system. Specifically, future directions 4, 7, 8, and 9 relate to NextGen Operations. Although NextGen operations will ultimately improve safety, any change has the potential to introduce unintended risks. The intention here is to identify these future potential risks in an effort to proactively address these in technology solutions that are effective mitigations of both current and future LOC risks.

Another current trend / future direction is the introduction of Unmanned Aircraft Systems (UAS) in the National Airspace System (NAS). In this case, LOC risks can relate to the UAS as well as manned vehicles as a result of unexpected near-miss events involving UAS. Relative to Table 4, future direction 9 includes risks associated with UAS operation near airports and we are already experiencing an increase in this risk ${ }^{27,} 28,29$. Other risks related to UAS LOC pertain to ground infrastructure and loss of life in developed areas. These will directly relate to intended use cases for UAS by industry, government agencies, and academia, and the effectiveness (and far-sightedness) of regulations for UAS in the NAS developed by the FAA. This is an expanding market with many use cases already identified and many more to come. Some current potential use cases for UAS include search and rescue support, border patrol, infrastructure inspection, and package delivery. These and future potential use cases will need to be studied to identify future potential risks related to safety and security (including LOC).

Increasing levels of autonomy in civil aviation ${ }^{30}$ is another current trend / future direction that could potentially impact future LOC risk. This risk relates to future direction 3 in Table 4.

\section{LOC Test Scenarios}

Once the accident / incident analysis of section III and the future potential risks identified as discussed in Section IV-B are completed, a comprehensive set of hazards-based LOC test scenarios will be developed based on the current and future analysis results. It is anticipated that the test scenarios will include multiple precursor hazards, including adverse vehicle conditions, inappropriate crew response, external hazards and disturbances, and vehicle upset conditions. The test scenarios will include recommended evaluation methods, and flight conditions. The test scenarios will be developed with traceability to the current and future hazards sets for use in resilience testing. This traceability enables the evaluation of hazards coverage and technology effectiveness in providing that coverage. Figure 7 illustrates this concept.

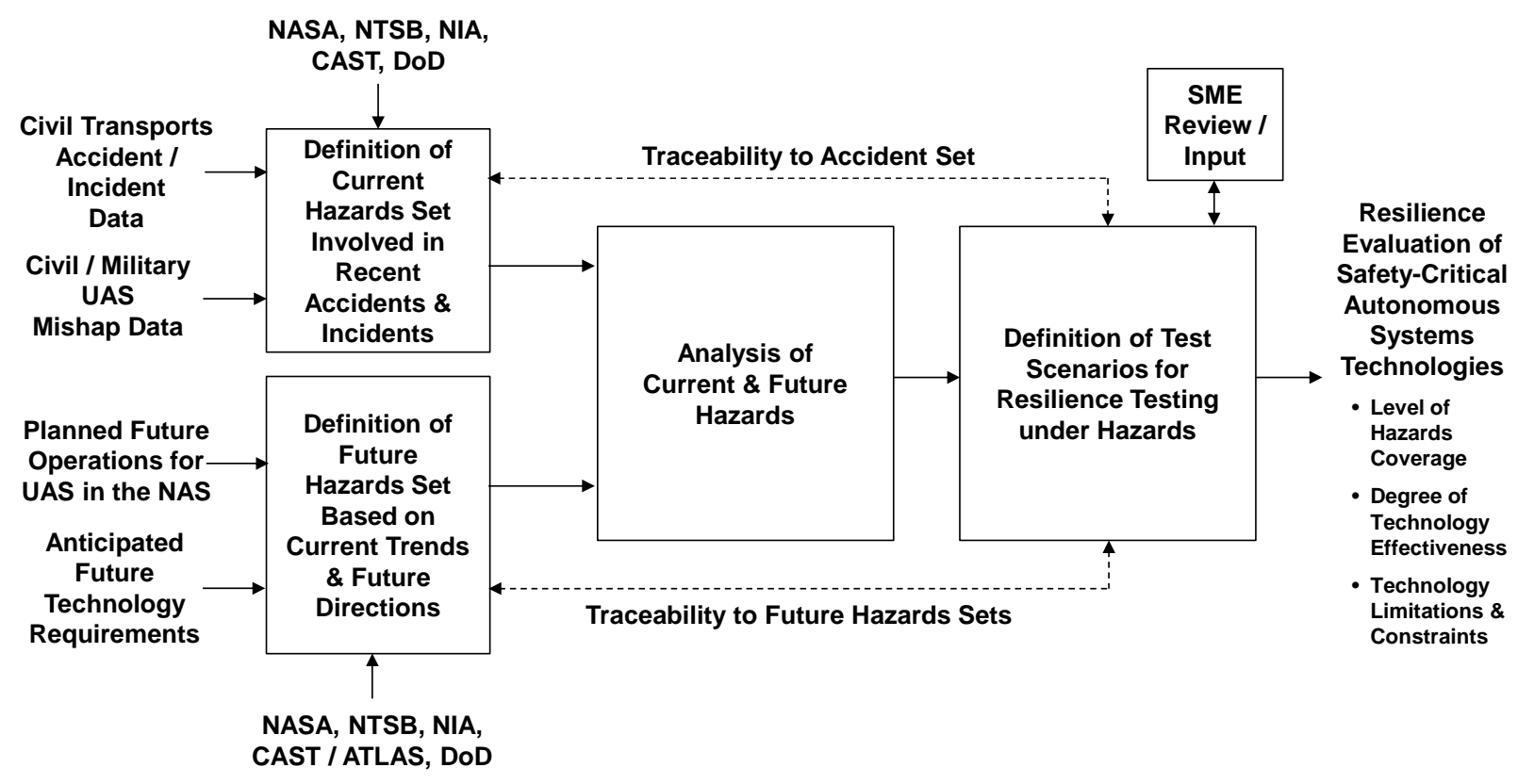

Figure 7. Resilience Evaluation Concept for Determination of Effective LOC Hazards Coverage.

A preliminary set of hazards-based test scenarios was developed in Ref. 10 to support the validation of safetycritical systems developed for LOC prevention and recovery. The authors intend that the hazards-based test scenarios 
to be developed as part of this study can be utilized as a universal set of test scenarios for resilience testing of technologies for future safety-critical autonomous and semi-autonomous vehicle systems.

\section{LOC and Resilience Implications for Future Aircraft Systems}

LOC prevention and recovery is a key requirement for future resilient and autonomous aircraft systems as well as for the safe integration of UAS into the National Airspace System (NAS). Research and technology development needs are discussed in the following subsections.

\section{A. LOC Prevention and Recovery for Future Resilient Autonomous Aircraft Systems}

LOC prevention and recovery is a critical capability for future safety-critical autonomous and semi-autonomous aircraft systems. In particular, current and future LOC hazards and the hazards-based test scenarios described in Section IV provide a rich set of conditions for evaluating resilience under uncertain, unexpected, and hazardous conditions. Figure 8 illustrates the importance of resilience for key aviation goals within the NASA Aeronautics Research Mission Directorate (ARMD) that will enable transformative capabilities in the future aviation system. More detailed technology development and validation requirements for resilient autonomous and semi-autonomous systems are provided in Appendix E.

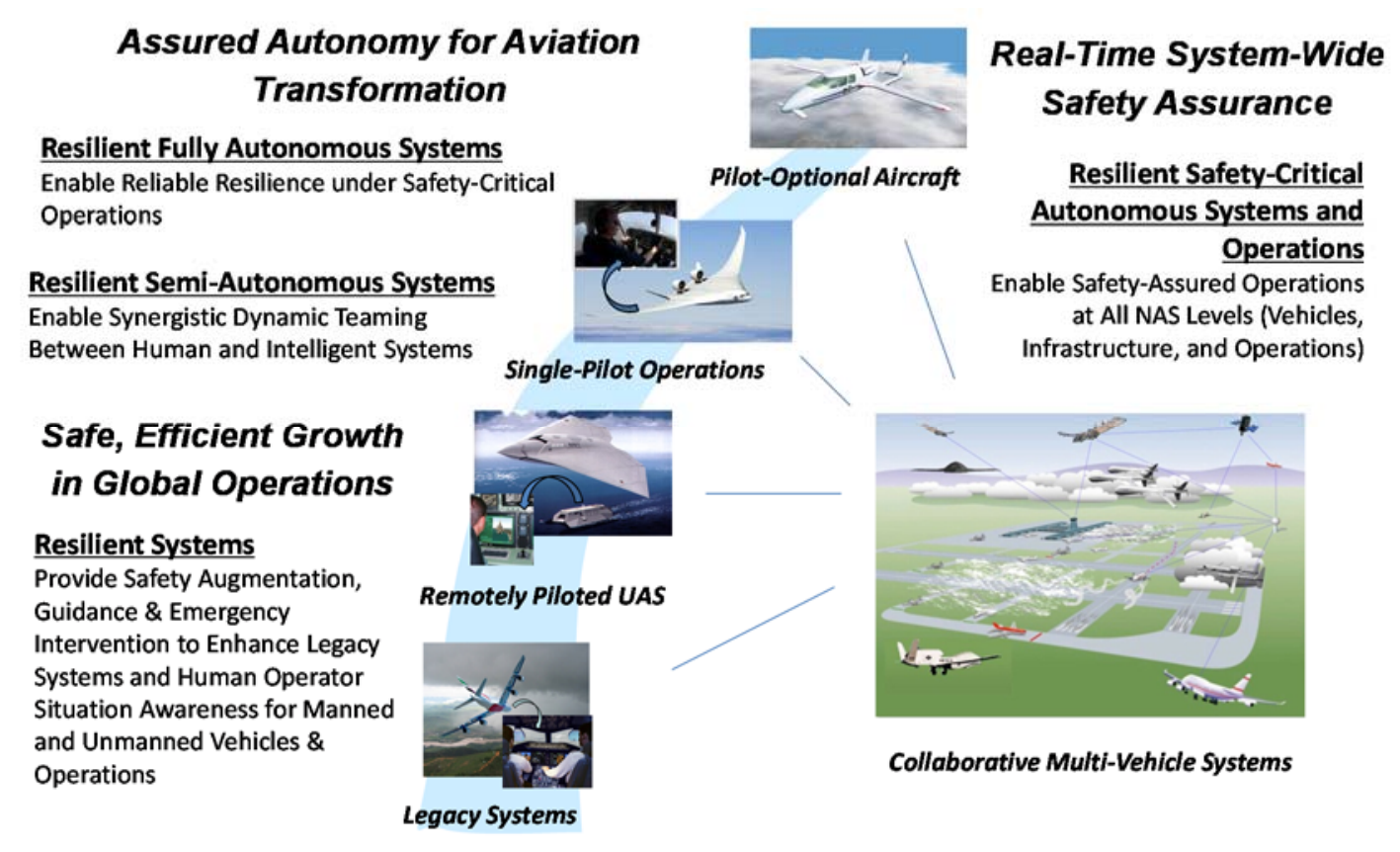

Figure 8. Importance of Resilience for Future Safety-Critical Autonomous Aircraft Systems.

\section{B. LOC Implications for Safe UAS Integration into the National Airspace System (NAS)}

Research is currently underway in analyzing UAS accidents and incidents utilizing the LOC analysis methodology of Section III to UAS. As discussed in Section IV, future potential safety risks associated with UAS operation in the NAS and hazards-based test scenarios for evaluating system resilience will also be developed with a focus on UAS relative to LOC as well as to a broader set of hazards. Figure 9 depicts the current strategy for safety/risk analysis research. 


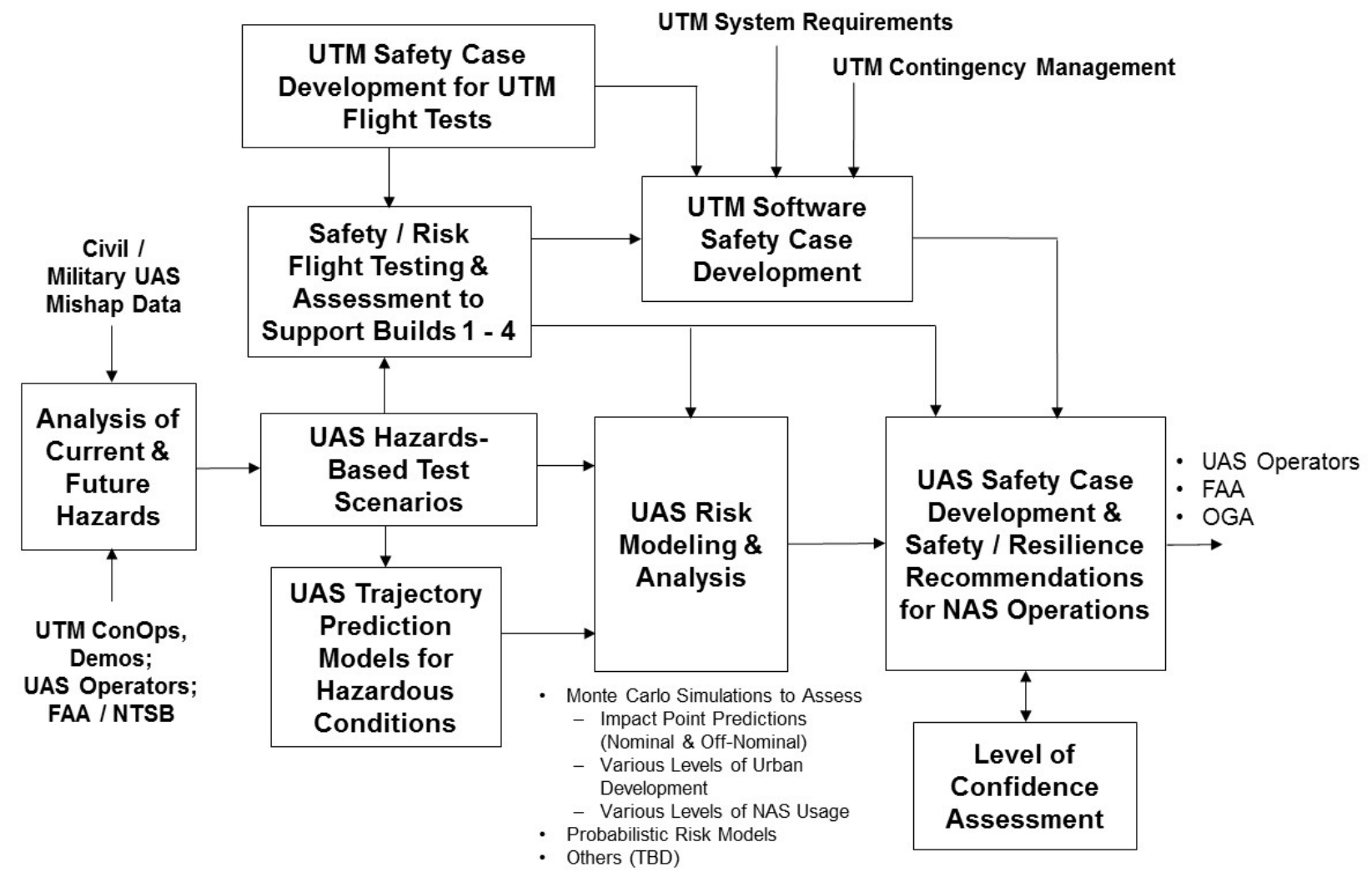

Figure 9. UAS Safety / Risk Analysis for NAS Operations.

An analysis of current hazards will be based on an analysis of civil and military UAS mishaps similar to the approach described in Section III. Future hazards will be identified based on concepts of operation for UAS Traffic Management (UTM) Systems, UTM flight demonstrations, use cases identified by UAS operators, and relevant information obtained from the FAA and NTSB. Hazards-based test scenarios will be developed with traceability to the current and future hazards as described in Section IV. Risk modeling and analyses will utilize trajectory prediction models developed for off-nominal conditions (including LOC hazards). Monte Carlo simulation techniques will be utilized to characterize impact point predictions under nominal and off-nominal conditions, various levels of urban development, and various levels of NAS usage. Probabilistic risk models are also being considered for evaluating the effectiveness of contingency management strategies at the UTM system as well as the vehicle level. Flight testing will be performed to introduce safety risks and evaluate the effectiveness of contingency responses. Safety cases will be developed at various levels of UTM system development, including in support of flight demonstrations, for assessing UTM software, and more broadly for UAS operation in the NAS. A level of confidence assessment will provide a measure of the level of confidence associated with the UAS safety case to be developed.

\section{Conclusion}

This paper presented an analysis approach to evaluate LOC accidents and incidents for the purpose of developing technology solutions that enable LOC prevention and recovery under a wide spectrum of relevant hazards. The analysis approach identifies precursor / hazards sequences, worst case hazards combinations, and key attributes (e.g., crew distraction and human-machine interface issues) associated with each LOC accident or incident. This analysis process was illustrated for eight accidents and incidents (from a defined set of accidents and incidents over a recent 15-year period) involving blocked pitot tube or static ports. Five of these mishaps were fatal accidents, and the remaining three mishaps were non-fatal incidents. The analysis developed precursor sequences and hazards 
combinations to compare and contrast the fatal with the non-fatal mishaps. An evaluation of the precursor sequences included a number of observations, including the initiating event (3/8 started from an "Improper Maintenance Action / Inaction," 4/8 were initiated from pitot tube icing, and 1/8 was undetermined) and common features of the fatal and non-fatal mishaps. The fatal accidents had the following key features: 1.) 3/5 were characterized by "Improper / Ineffective Recovery;” 2.) 5/5 experienced a serious vehicle upset condition, with 4/5 involving a "Stall / Departure," and 1/5 entering into an "Uncontrolled Descent;" 3.) 3/5 involved flight deck instrumentation and/or auto-flight system issues (e.g., operational errors or inadequacies); and 4.) 4/5 cases also involved "Loss of Awareness" by the crew associated with the aircraft / system, energy, or attitude state. The non-fatal incidents involved vehicle upsets, but only one entered into a stall. Only one non-fatal incident involved "Loss of Awareness." There were still pilot issues for the non-fatal incidents, but these involved fewer occurrences and varieties of crew error.

In general, the fatal accidents appear to be more complicated (i.e., involving more precursors and precursor combinations) than the nonfatal incidents. A comparison of event complexity was performed by analyzing the worst case precursor combinations using 3-D scatter plots. The fatal accidents involved numerous multiple hazards combinations, and the non-fatal incidents were clearly less complex. Comments and flags identifying key attributes of each mishaps were also evaluated. In three of the five fatal accidents, the crew was distracted or overwhelmed by conditions related to the pitot system failure (with one of these accidents exacerbated by the presence of cabin crew in the cockpit). Four of the five fatal accidents involved potential human-machine interface issues, with the accident report for the fifth accident not having enough information to make this determination. In some cases the auto-flight system flew the aircraft into stall (due to the erroneous airspeed indications), and flight deck instrumentation provided little information for improved situation awareness and no guidance on appropriate actions to take. Moreover, in some instances multiple conflicting warnings and alerts were sounding simultaneously - which further confused the crew. By comparison, none of the non-fatal incidents involved crew distraction. Although the onboard systems provided similar opportunities for confusion or to further exacerbate the situation, the comparatively less complex hazards profile enabled the pilots to successfully recover to a safe flight condition.

Comparing the fatal and nonfatal mishaps of this study, it can be concluded that there is a level of hazards complexity at which pilots (or any human) become confused and are unable to respond effectively. Moreover, current systems are essentially designed for nominal conditions and either disengage or respond inappropriately (adding additional confusion and complexity to the situation). Some potential mitigation strategies to prevent these kinds of mishaps in the future include: 1.) Improved pilot training relative to diagnosing and mitigating onboard system failures (including sensor system failures and use of alternate instrumentation); 2.) Improved crew training under unexpected and abnormal conditions (including multiple hazards events) and in the implications of existing protections associated with system operational modes; 3.) Sensor integrity management system capable of detecting, identifying and mitigating sensor system failures (including blocked pitot tube or static ports and common mode sensor failures); 4.) Improved algorithms and displays that provide improved situational awareness to the systems and crew under multiple hazards conditions; 5.) Resilient flight control system capable of ensuring flight safety under multiple hazards (including system failures, external disturbances, and inappropriate control inputs by the crew and/or autoflight systems); and 6.) Resilient upset recovery system capable of providing guidance for and/or automatic recovery from upset conditions (including stall) under multiple hazards conditions.

Percent occurrences of individual hazards were also summarized for the 122 mishaps analyzed to date from the set of 278 mishaps. Hazards related to Vehicle Upsets associated with uncontrolled descent and stall / departure have occurred in $34 \%$ and $30 \%$ of the mishaps analyzed thus far. Hazards related to Adverse Onboard Conditions include Vehicle Impairment (with airframe structural damage dominating at 25\%), System \& Component Failures (fairly evenly distributed at 10-15\% across six of the seven hazards contained therein), and Crew Action / Inaction (with loss of attitude state awareness, improper procedure, inadequate crew resource monitoring / management, ineffective recovery, and loss of energy state awareness all occurring most often ranging from $17 \%$ to $27 \%$ ).

Further work will include the identification of future potential LOC hazards and the development of hazards-based test scenarios for the resilience evaluation of future semi-autonomous and autonomous systems developed for LOC prevention and recovery. This work is highly relevant to UAS and their safe operation in the NAS. An approach for assessing UAS safety and risk was also discussed. 
Appendix A: Accident / Incident Set

\begin{tabular}{|c|c|c|c|c|c|c|c|c|c|c|c|c|}
\hline No & Date & Aircraft & Registr'n & Ident & Loc'n & Light & Wea & Fat & Dam & Phase & Occurrence & Result \\
\hline 1 & 1/7/1996 & DC-9 & $\mathrm{N}--922 \mathrm{~V}$ & VJA 558 & KBNA & $\mathrm{D}$ & V & 0 & $\mathrm{~s}$ & Landing & Uncommanded Spoiler Extension & Hard Landing \\
\hline 2 & 2/6/1996 & B-757 & TC-GEN & ALW 301 & MDPP & $\mathrm{N}$ & $u$ & 189 & $\mathrm{D}$ & Climb & Instrument Failure & Uncontrolled Descent to Ground/Water \\
\hline 3 & 2/12/1996 & GAF-24 & $\mathrm{N}-224 \mathrm{E}$ & $\mathrm{N}-224 \mathrm{E}$ & MTPP & D & $\mathrm{V}$ & 10 & $\mathrm{D}$ & Initial climb & Undetermined & Uncontrolled Descent to Ground/Water \\
\hline 4 & 2/19/1996 & CE-550 & D-CASH & PWF ASH & & U & U & 10 & $\mathrm{D}$ & Approach & Icing Stall & Uncontrolled Descent to Ground/Water \\
\hline 5 & 2/22/1996 & MD-11 & B-152 & CAL 4 & RCTP & U & U & 0 & $u$ & Initial climb & Pilot Induced Oscillation (PIO) & Upset \\
\hline 6 & 5/11/1996 & DC-9 & $\mathrm{N}-904 \mathrm{VJ}$ & VJA 592 & KMIA & $\mathrm{D}$ & $\mathrm{V}$ & 110 & $\mathrm{D}$ & Climb & Structural Failure - Fire/Explosion & Uncontrolled Descent to Ground/Water \\
\hline 7 & 6/5/1996 & MD-80 & $\mathrm{N}-224 \mathrm{AA}$ & AAL 873 & KABQ & $\mathrm{D}$ & $\mathrm{V}$ & 0 & M & Landing & Atmospheric Disturbance & Hard Landing \\
\hline 8 & 6/9/1996 & B-737 & $\mathrm{N}-221 \mathrm{US}$ & EW09 51 & KRIC & $\mathrm{N}$ & V & 0 & $\mathrm{~N}$ & Approach & Uncommanded Bank & Upset \\
\hline 9 & 6/14/1996 & A-320 & N-347NW & NWA 395 & KBOS & $\mathrm{D}$ & V & 0 & $\mathrm{~N}$ & Climb & Flight Control System & Uncommanded Pitch \\
\hline 10 & $6 / 21 / 1996$ & A-340 & D-AIBE & DLH 436 & KDFW & U & u & 0 & $u$ & Climb & Unexpected Control Gains & Cabin Injuries \\
\hline 11 & 7/13/1996 & MD-11 & N-1768D & AAL 68D & & $\mathrm{D}$ & V & 0 & $\mathrm{~N}$ & Descent & Attempt To Override Autopilot & Cabin Injuries \\
\hline 12 & $7 / 17 / 1996$ & B-747 & N-93119 & TWA 800 & KJFK & $\mathrm{T}$ & $\mathrm{V}$ & 230 & $\mathrm{D}$ & Climb & Structural Failure - Fire/Explosion & Uncontrolled Descent to Ground/Water \\
\hline 13 & $7 / 20 / 1996$ & DC-6 & $\mathrm{N}-313 \mathrm{RS}$ & NAC 33 & PARS & $\mathrm{D}$ & V & 4 & $\mathrm{D}$ & Cruise & Structural Failure - Fire/Explosion & Uncontrolled Descent to Ground/Water \\
\hline 14 & 10/2/1996 & B-757 & N-52AW & PLI 603 & & $\mathrm{~N}$ & । & 70 & $\mathrm{D}$ & Climb & Spatial Disorientation & Collision W/Terrain \\
\hline 151 & 10/22/1996 & B-707 & $\mathrm{N}-751 \mathrm{MA}$ & MIRA 1M & SEMT & u & $u$ & 4 & $\mathrm{D}$ & Climb & Stall & Collision W/Obstacle \\
\hline 161 & 10/31/1996 & FO-100 & PT-MRK & TAM 402 & SBSP & $\mathrm{D}$ & V & 96 & $\mathrm{D}$ & Initial climb & Asymmetric Thrust/Drag & Collision W/Obstacle \\
\hline 17 & 11/7/1996 & B-727 & $5 \mathrm{~N}-\mathrm{BBG}$ & ADK 86 & & $u$ & $\mathrm{U}$ & 144 & $\mathrm{D}$ & Approach & Aggressive Maneuver & Uncontrolled Descent to Ground/Water \\
\hline 181 & $11 / 12 / 1996$ & B-747 & HZ-AlH & SVA 763 & & U & u & 312 & D & Climb & Structural Failure - Midair & Uncontrolled Descent to Ground/Water \\
\hline 191 & 11/12/1996 & II-76 & UN-76435 & KZA 1907 & & $u$ & U & 37 & $\mathrm{D}$ & Descent & Structural Failure - Midair & Uncontrolled Descent to Ground/Water \\
\hline 20 & 12/9/1996 & DC-3 & $\mathrm{N}-75142$ & D7T 142 & KBOI & $\mathrm{N}$ & $\mathrm{V}$ & 2 & $\mathrm{D}$ & Initial climb & Stall & Collision W/Terrain \\
\hline 211 & 12/10/1996 & An-74 & RA-74037 & VSA 037 & UERR & $\mathrm{N}$ & U & 0 & $\mathrm{D}$ & Initial climb & Thrust Reverse-Unwanted & Collision W/Terrain \\
\hline 221 & $12 / 21 / 1996$ & An-32 & HK-4008X & SDV 08X & SKRG & $\mathrm{N}$ & u & 4 & $\mathrm{D}$ & Approach & Undetermined & Collision W/Terrain \\
\hline 23 & $1 / 9 / 1997$ & $\mathrm{E}-120$ & $\mathrm{~N}-265 \mathrm{CA}$ & COM 327 & KDTW & $\mathrm{D}$ & 1 & 29 & $\mathrm{D}$ & Descent & Icing Stall & Uncontrolled Descent to Ground/Water \\
\hline 24 & 1/25/1997 & $\|-76$ & RA-76834 & VSO 834 & UHMA & $u$ & U & 0 & $\mathrm{D}$ & Initial climb & Attempted TO W/Incorrect Config & Collision W/Terrain \\
\hline 25 & 2/1/1997 & HS-748 & 6V-AEO & DS AEO & GOTT & $u$ & $\mathrm{U}$ & 23 & $\mathrm{D}$ & Initial climb & Undetermined & Collision W/Terrain \\
\hline 26 & 3/2/1997 & $\mathrm{BE}-200$ & N-117WM & N-117WM & KSLC & $\mathrm{T}$ & I & 1 & $\mathrm{~s}$ & Final approach - prec & Stall & Uncontrolled Descent to Ground/Water \\
\hline 27 & 3/14/1997 & $\mathrm{F}-27$ & D2-TFP & DTA TFP & FCBB & $u$ & U & 3 & $\mathrm{D}$ & Initial climb & Undetermined & Collision W/Terrain \\
\hline 28 & 4/14/1997 & An-24 & RA-46516 & RA-46516 & & $\mathrm{D}$ & $u$ & 50 & $\mathrm{D}$ & Cruise & Structural Failure - Fatigue & Uncontrolled Descent to Ground/Water \\
\hline 29 & 4/19/1997 & BAE-ATP & PK-MTX & MNA 106 & WIOD & $\mathrm{N}$ & U & 15 & $\mathrm{D}$ & Approach & Undetermined & Uncontrolled Descent to Ground/Water \\
\hline 30 & $5 / 8 / 1997$ & B-737 & B-2925 & CSN 3456 & ZGSZ & $\mathrm{N}$ & I & 35 & $\mathrm{D}$ & Landing & Atmospheric Disturbance & Hard Landing \\
\hline 31 & $5 / 12 / 1997$ & A-300 & N-90070 & AAL 903 & KPBI & $\mathrm{D}$ & I & 0 & M & Level off from desce & Stall & Upset \\
\hline 32 & $5 / 20 / 1997$ & AC-1121 & $\mathrm{N}-1121 \mathrm{~F}$ & $\mathrm{~N}-1121 \mathrm{~F}$ & & $\mathrm{D}$ & I & 4 & $\mathrm{D}$ & Cruise & Atmospheric Disturbance & Uncontrolled Descent to Ground/Water \\
\hline 33 & 6/8/1997 & MD-11 & JA-8580 & JAL 706 & RJNA & $\mathrm{D}$ & U & 0 & M & Descent & Pilot Induced Oscillation (PIO) & Upset \\
\hline 34 & $7 / 3 / 1997$ & $\mathrm{~F}-27$ & VT-SSA & LBE SSA & VABB & $\mathrm{N}$ & I & 2 & $\mathrm{D}$ & Initial climb & Undetermined & Uncontrolled Descent to Ground/Water \\
\hline 35 & $7 / 12 / 1997$ & DC-9 & $\mathrm{N}-9138$ & NWA 944 & KMEM & $\mathrm{D}$ & V & 0 & M & Landing & Flight Controls & Upset \\
\hline 36 & 8/7/1997 & DC-8 & $\mathrm{N}-27 \mathrm{UA}$ & FBF 101 & KMIA & $\mathrm{D}$ & $\mathrm{V}$ & 4 & $\mathrm{D}$ & Initial climb & Load - C/G Out Of Range & Uncontrolled Descent to Ground/Water \\
\hline 371 & 10/10/1997 & DC-9 & LV-WEG & AUT 2553 & & $\mathrm{~N}$ & I & 75 & $\mathrm{D}$ & Descent & Structural Failure - Exceeded Limit & Uncontrolled Descent to Ground/Water \\
\hline 381 & $12 / 13 / 1997$ & SA-226 & CP-1635 & SAVE 635 & SLVT & U & u & 10 & $\mathrm{D}$ & Initial climb & Undetermined & Collision W/Terrain \\
\hline 391 & $12 / 16 / 1997$ & CL-600 & C-FSKI & ACA 646 & CYFC & $\mathrm{N}$ & I & 0 & $\mathrm{D}$ & Go-around & Stall & Collision W/Terrain \\
\hline 40 & 2/16/1998 & A-300 & B-1814 & CAL 676 & RCTP & $\mathrm{N}$ & I & 196 & $\mathrm{D}$ & Missed approach & Stall & Uncontrolled Descent to Ground/Water \\
\hline
\end{tabular}




\begin{tabular}{|c|c|c|c|c|c|c|c|c|c|c|c|c|}
\hline No & Date & Aircraft & Registr'n & Ident & Loc'n & Light & Wea & Fat & Dam & Phase & Occurrence & Result \\
\hline 41 & $3 / 18 / 1998$ & SF-340 & B-12255 & FOS 255 & RCPO & $\mathrm{N}$ & I & 13 & $\mathrm{D}$ & Climb & Attempted TO W/Incorrect Config & Uncontrolled Descent to Ground/Water \\
\hline 42 & $5 / 21 / 1998$ & DC-10 & $\mathrm{N}-68043$ & COA 75 & KLAX & $\mathrm{D}$ & $\mathrm{V}$ & 0 & M & Climb & Autopilot & Uncommanded Pitch \\
\hline 43 & 6/18/1998 & SA-226 & C-GQAL & PRO 420 & CYUL & D & $u$ & 11 & $\mathrm{D}$ & Climb & Structural Failure - Fire/Explosion & Uncontrolled Descent to Ground/Water \\
\hline 44 & $7 / 23 / 1998$ & An-12 & RA-11886 & RA-11886 & ULLP & $\mathrm{D}$ & $u$ & 0 & $\mathrm{D}$ & Initial climb & Loss-of-Control (Vmc) & Collision W/Terrain \\
\hline 45 & $7 / 28 / 1998$ & SA-227 & EC-FXD & SWT 704 & LEBL & N & $\mathrm{V}$ & 2 & $\mathrm{D}$ & Approach & Loss-of-Control (Vmc) & Uncontrolled Descent to Ground/Water \\
\hline 46 & $7 / 30 / 1998$ & Do-228 & VT-EJW & LLR EJW & VOCC & D & $\mathrm{V}$ & 6 & $\mathrm{D}$ & Initial climb & Flight Control Actuator & Uncontrolled Descent to Ground/Water \\
\hline 47 & $7 / 30 / 1998$ & BE-1900 & F-GSJM & PRB 706 & & D & $\mathrm{V}$ & 14 & $\mathrm{D}$ & Approach & Structural Failure - Midair & Uncontrolled Descent to Ground/Water \\
\hline 48 & 8/24/1998 & DC-3 & ZS-NKK & SPZ NKK & FAWB & D & $\mathrm{V}$ & 1 & $\mathrm{D}$ & Initial climb & Attempted TO W/Mis-set Trim & Uncontrolled Descent to Ground/Water \\
\hline 49 & 9/2/1998 & MD-11 & HB-IWF & SWR 111 & $\mathrm{CYHZ}$ & $\mathrm{N}$ & $u$ & 229 & $\mathrm{D}$ & Cruise & Loss Of All Attitude Displays & Collision W/Terrain \\
\hline 50 & 10/17/1998 & BE-99 & N-299GL & TIMA 501 & KMSO & N & $\mathrm{V}$ & 0 & S & Go-around & Failure To Maintain Airspeed & Collision W/Terrain \\
\hline 51 & 10/18/1998 & A-320 & El-TLI & TRZ TLI & EIDW & $u$ & $u$ & 0 & M & Approach & Jammed Flight Controls & Upset \\
\hline 52 & 10/21/1998 & $\mathrm{E}-120$ & PT-WKH & PT-WKH & SBFZ & $\mathrm{D}$ & $u$ & 3 & $\mathrm{D}$ & Approach & Improper Control Operation & Uncontrolled Descent to Ground/Water \\
\hline 53 & 11/11/1998 & SF-340 & VH-LPI & KDA LPI & YMML & D & 1 & 0 & $\mathrm{~N}$ & holding (IFR) & Icing Stall & Upset \\
\hline 54 & 12/2/1998 & CE-501 & N-501EZ & N-501EZ & & D & $\mathrm{V}$ & 1 & $\mathrm{D}$ & Cruise & Undetermined & Uncontrolled Descent to Ground/Water \\
\hline 55 & $12 / 4 / 1998$ & An-12 & LZ-SFG & LXR SFG & LPLA & $\mathrm{N}$ & $u$ & 7 & $\mathrm{D}$ & Initial climb & Asymmetric Thrust/Drag & Uncontrolled Descent to Ground/Water \\
\hline 56 & 12/11/1998 & A-310 & HS-TIA & TIA 261 & VSSB & $\mathrm{N}$ & I & 101 & $\mathrm{D}$ & Missed approach & Somatogravic Illusion & Uncontrolled Descent to Ground/Water \\
\hline 57 & 1/12/1999 & $\mathrm{F}-27$ & G-CHNL & EXS HNL & EGJB & $u$ & $u$ & 2 & $\mathrm{D}$ & Approach & Stall & Uncontrolled Descent to Ground/Water \\
\hline 58 & 1/28/1999 & LR-35 & $\mathrm{N}-130 \mathrm{~F}$ & USC 251 & KMD & $\mathrm{N}$ & $\mathrm{V}$ & 0 & $\mathrm{~s}$ & Landing & Unstabilized Approach & Hard Landing \\
\hline 59 & 2/2/1999 & An-12 & EY-ASS & FDN ASS & FNLU & $\mathrm{N}$ & $u$ & 11 & $\mathrm{D}$ & Initial climb & Undetermined & Collision W/Obstacle \\
\hline 60 & 2/24/1999 & Tu-154 & B-2622 & CSW 450 & ZSWZ & $U$ & $u$ & 61 & $\mathrm{D}$ & Approach & Flight Control Disconnected & Uncontrolled Descent to Ground/Water \\
\hline 61 & 4/5/1999 & DHC-6 & N-838MA & DCC 8MA & KLNA & $\mathrm{D}$ & $\mathrm{V}$ & 0 & S & Approach & Loss-of-Control (Vmc) & Collision W/Terrain \\
\hline 62 & 4/7/1999 & B-737 & TC-JEP & THY 5904 & LTAF & $\mathrm{N}$ & I & 6 & $\mathrm{D}$ & Climb & Instrument Failure & Uncontrolled Descent to Ground/Water \\
\hline 63 & $4 / 15 / 1999$ & MD-11 & HL-7373 & KAL 6316 & ZSSS & D & $u$ & 3 & $\mathrm{D}$ & Climb & Spatial Disorientation & Uncontrolled Descent to Ground/Water \\
\hline 64 & 8/31/1999 & B-737 & LV-WRZ & LPR 3142 & SABE & $\mathrm{N}$ & $u$ & 63 & $\mathrm{D}$ & Initial climb & Attempted TO W/Incorrect Config & Uncontrolled Descent to Ground/Water \\
\hline 65 & 9/2/1999 & B-737 & N-371UA & UAL 2036 & & D & V & 0 & M & Cruise & Wake Turbulence & Cabin Injuries \\
\hline 66 & 9/14/1999 & DA-900 & SX-ECH & OAL 3838 & LROP & $u$ & $u$ & 7 & S & Descent & Attempt To Override Autopilot & Upset \\
\hline 67 & 9/24/1999 & A-320 & C-FKCO & ACA 630 & CYSJ & $\mathrm{N}$ & V & 0 & M & Landing & Flight Controls Mode Change & Landed Short \\
\hline 68 & 10/9/1999 & DA-900 & $N-523 A C$ & $N-523 A C$ & KGRR & $U$ & $u$ & 0 & $U$ & Descent & Attempt To Override Autopilot & Aircraft Pitch/Roll Oscillations \\
\hline 69 & 10/18/1999 & SF-340 & SE-LES & GAO 750 & ENSN & $\mathrm{N}$ & 1 & 0 & M & Climb & Stall & Upset \\
\hline 70 & 10/25/1999 & LR-35 & $\mathrm{N}-47 \mathrm{BA}$ & SJ8 7BA & & $u$ & $u$ & 6 & $\mathrm{D}$ & Climb & Incapacitation: Hypoxia & Spiral Dive Into Ground \\
\hline 71 & 11/9/1999 & DC-9 & XA-TKN & TEJ 725 & MMPN & N & $u$ & 18 & $\mathrm{D}$ & Climb & Spatial Disorientation & Collision W/Terrain \\
\hline 72 & 12/5/1999 & II-114 & UK-91004 & СТВ 004 & UUDD & $u$ & $u$ & 5 & $\mathrm{D}$ & Initial climb & Jammed Flight Controls & Collision W/Obstacle \\
\hline 73 & 12/12/1999 & IAI-1124 & N-50PL & N-50PL & & D & $\mathrm{V}$ & 3 & $\mathrm{D}$ & Descent & Flight Control Disconnected & Uncontrolled Descent to Ground/Water \\
\hline 74 & 12/22/1999 & B-747 & HL-7451 & KAL 8509 & EGSS & $\mathrm{N}$ & $u$ & 4 & $\mathrm{D}$ & Climb & Spatial Disorientation & Uncontrolled Descent to Ground/Water \\
\hline 75 & $1 / 5 / 2000$ & E-110 & $5 N-A X L$ & EAN AXL & DNAA & $u$ & $u$ & 1 & $\mathrm{D}$ & Approach & Stall & Collision W/Terrain \\
\hline 76 & $1 / 10 / 2000$ & SF-340 & HB-AKK & CRX 498 & LSZH & $\mathrm{N}$ & 1 & 10 & $\mathrm{D}$ & Initial climb & Spatial Disorientation & Spiral Dive Into Ground \\
\hline 77 & $1 / 30 / 2000$ & A-310 & 5Y-BEN & KQA 431 & DIAP & $\mathrm{N}$ & $\mathrm{V}$ & 169 & $\mathrm{D}$ & Initial climb & Stall & Collision W/Terrain \\
\hline 78 & $1 / 31 / 2000$ & MD-80 & N-963AS & ASA 261 & & D & $\mathrm{V}$ & 88 & $\mathrm{D}$ & Cruise & Jammed Flight Controls & Uncontrolled Descent to Ground/Water \\
\hline 79 & $2 / 16 / 2000$ & DC-8 & N-8079U & EWW 17 & KMHR & $\mathrm{N}$ & $\mathrm{V}$ & 3 & $\mathrm{D}$ & Initial climb & Flight Control Disconnected & Uncontrolled Descent to Ground/Water \\
\hline 80 & $2 / 27 / 2000$ & B-747 & G-BDXL & BAW 179 & & N & I & 0 & $\mathrm{~N}$ & Descent & Uncommanded Pitch & Upset \\
\hline 81 & $3 / 9 / 2000$ & Yak-40 & RA-88170 & VGV 170 & UUEE & D & $u$ & 9 & $\mathrm{D}$ & Initial climb & Attempted TO W/Contaminated & Uncontrolled Descent to Ground/Water \\
\hline
\end{tabular}

20

American Institute of Aeronautics and Astronautics 


\begin{tabular}{|c|c|c|c|c|c|c|c|c|c|c|c|c|}
\hline No & Date & Aircraft & Registr'n & Ident & Loc'n & Light & Wea & Fat & Dam & Phase & Occurrence & Result \\
\hline 82 & $3 / 17 / 2000$ & DC-3 & C-FNTF & PTSN NT & CYJC & $U$ & $\mathrm{U}$ & 2 & $\mathrm{D}$ & Go-around & Load - C/G Out Of Range & Uncontrolled Descent to Ground/Water \\
\hline 83 & 3/30/2000 & B-767 & $\mathrm{N}-182 \mathrm{DN}$ & DAL 106 & KJFK & $\mathrm{N}$ & I & 0 & $\mathrm{~N}$ & Climb & Spatial Disorientation & Upset \\
\hline 84 & $5 / 2 / 2000$ & LR-35 & G-MURI & NEX 4B & LFLL & $u$ & $u$ & 2 & $\mathrm{D}$ & Landing & Engine Failure & Uncontrolled Descent to Ground/Water \\
\hline 85 & $5 / 21 / 2000$ & JS-3101 & $\mathrm{N}-16 \mathrm{EJ}$ & ORA 6EJ & KAVP & $\mathrm{D}$ & I & 19 & $\mathrm{D}$ & Approach & Directional Control Not Maintained & Uncontrolled Descent to Ground/Water \\
\hline 86 & $6 / 22 / 2000$ & $\mathrm{Y}-7$ & B-3479 & CWU 343 & $\mathrm{ZHHH}$ & D & 1 & 42 & $\mathrm{D}$ & Approach & Wind Shear & Collision W/Obstacle \\
\hline 87 & $6 / 23 / 2000$ & LR-55 & $\mathrm{N}-220 \mathrm{JC}$ & UJT OJC & KBCT & $\mathrm{D}$ & $\mathrm{V}$ & 3 & $\mathrm{D}$ & Climb & Structural Failure - Midair & Uncontrolled Descent to Ground/Water \\
\hline 88 & $6 / 27 / 2000$ & A-300 & $\mathrm{N}-14065$ & AAL 065 & EGLL & D & $\mathrm{V}$ & 0 & $\mathrm{~N}$ & Climb & Wake Turbulence & Landed Without Further Incident \\
\hline 89 & $7 / 17 / 2000$ & B-737 & VT-EGD & LLR 7412 & VEPT & D & M & 55 & $\mathrm{D}$ & Approach & Stall & Uncontrolled Descent to Ground/Water \\
\hline 90 & $7 / 19 / 2000$ & G-159 & C-GNAK & AWV 980 & & $\mathrm{~N}$ & I & 2 & $\mathrm{D}$ & Cruise & Loss-of-Control (Vmc) & Uncontrolled Descent to Ground/Water \\
\hline 91 & $7 / 20 / 2000$ & DC-3 & N-54AA & $N-54 A A$ & MYNN & D & $\mathrm{V}$ & 2 & $\mathrm{D}$ & Initial climb & Undetermined & Collision W/Terrain \\
\hline 92 & $7 / 25 / 2000$ & AS-100 & F-BTSC & AFR 4590 & LFPG & $\mathrm{D}$ & $\mathrm{V}$ & 109 & $\mathrm{D}$ & Initial climb & Structural Failure - Fire/Explosion & Uncontrolled Descent to Ground/Water \\
\hline 93 & $8 / 23 / 2000$ & A-320 & A4-OEK & GFA 72 & OBBI & $\mathrm{N}$ & $\mathrm{v}$ & 143 & $\mathrm{D}$ & Missed approach & Somatogravic Illusion & Collision W/Terrain \\
\hline 94 & $8 / 31 / 2000$ & An-26 & D2-FDI & NCL FDI & FNSA & $U$ & $u$ & 44 & $\mathrm{D}$ & Cruise & Undetermined & Uncontrolled Descent to Ground/Water \\
\hline 95 & $10 / 2 / 2000$ & A-340 & TC-JDN & THY JDN & & $u$ & $u$ & 0 & $\mathrm{~N}$ & Cruise & Flight Controls Mode Change & Altitude Deviation \\
\hline 961 & $10 / 26 / 2000$ & CL-600 & $\mathrm{N}-958 \mathrm{CA}$ & COM 8CA & & D & $\mathrm{V}$ & 0 & $\mathrm{~N}$ & Cruise & Wake Turbulence & Upset \\
\hline 97 & $11 / 1 / 2000$ & DHC-6 & C-GGAW & YWZ 151 & $\mathrm{CYHC}$ & $\mathrm{D}$ & $u$ & 0 & $\mathrm{D}$ & Initial climb & Loss-of-Control (Vmc) & Collision W/Terrain \\
\hline 98 & $11 / 9 / 2000$ & SA-226 & $\mathrm{N}-731 \mathrm{AC}$ & ETA4 100 & KFWA & $\mathrm{N}$ & 1 & 1 & $\mathrm{D}$ & Initial climb & Instrument Failure & Uncontrolled Descent to Ground/Water \\
\hline 991 & $11 / 15 / 2000$ & An-24 & D2-FCG & API FCG & FNLU & $\mathrm{D}$ & $u$ & 57 & $\mathrm{D}$ & Initial climb & Loss-of-Control (Vmc) & Collision W/Terrain \\
\hline 1001 & $11 / 25 / 2000$ & MD-11 & $\mathrm{N}-582 \mathrm{FE}$ & FDE 3015 & KEWR & $\mathrm{D}$ & $\mathrm{V}$ & 0 & $\mathrm{~N}$ & Climb & Flight Controls & Pilot Induced Oscillation (PIO) \\
\hline 101 & $12 / 2 / 2000$ & LR-35 & C-GDJH & C-GDJH & CYVR & $u$ & $u$ & 0 & $\mathrm{~N}$ & Climb & Jammed Flight Controls & Uncommanded Bank \\
\hline 102 & $12 / 27 / 2000$ & E-135 & $\mathrm{N}-721 \mathrm{HS}$ & EGF 230 & KORD & $\mathrm{N}$ & $\mathrm{V}$ & 0 & $\mathrm{~N}$ & Initial climb & Jammed Flight Controls & Upset \\
\hline 103 & $1 / 25 / 2001$ & DC-3 & $Y V-224 C$ & RUC 225 & SVCB & D & $u$ & 24 & $\mathrm{D}$ & Approach & Unknown & Uncontrolled Descent to Ground/Water \\
\hline 104 & $1 / 27 / 2001$ & BE-200 & N-81PF & JEK 1PF & & $\mathrm{T}$ & 1 & 10 & $\mathrm{D}$ & Cruise & Instrument Failure & Uncontrolled Descent to Ground/Water \\
\hline 105 & $2 / 7 / 2001$ & A-320 & EC-HKJ & IBE 1456 & LEBB & N & $\mathrm{V}$ & 0 & $\mathrm{D}$ & Landing & Unexpected Control Gains & Hard Landing \\
\hline 106 & $2 / 8 / 2001$ & LR-35 & I-MOCO & I-MOCO & EDDN & $\mathrm{D}$ & $\mathrm{V}$ & 3 & $\mathrm{D}$ & Approach & Stall & Uncontrolled Descent to Ground/Water \\
\hline 107 & 3/17/2001 & A-320 & N-357NW & NWA 985 & KDTW & $\mathrm{N}$ & 1 & 0 & S & Initial climb & Pilot Induced Oscillation (PIO) & Collision W/Terrain \\
\hline 108 & 3/19/2001 & $\mathrm{E}-120$ & $\mathrm{~N}-266 \mathrm{CA}$ & COM 505 & KPBA & D & I & 0 & S & Descent & Icing Stall & Upset \\
\hline 109 & 3/20/2001 & A-320 & D-AIPW & DLH IPW & EDFF & $\mathrm{U}$ & $u$ & 0 & $\mathrm{~N}$ & Initial climb & Reversed Controls & Uncommanded Bank \\
\hline 110 & $3 / 24 / 2001$ & DHC-6 & F-OGES & ISB 1501 & TFFJ & D & $\mathrm{V}$ & 19 & $\mathrm{D}$ & Final approach - non & Loss-of-Control (Vmc) & Uncontrolled Descent to Ground/Water \\
\hline 111 & $4 / 2 / 2001$ & CE-501 & $\mathrm{N}-405 \mathrm{PC}$ & $\mathrm{N}-405 \mathrm{PC}$ & KGRB & D & I & 1 & $\mathrm{D}$ & Climb & Spatial Disorientation & Collision W/Obstacle \\
\hline 112 & $5 / 25 / 2001$ & A-340 & F-GLZC & AFR 3682 & SOCA & D & $\mathrm{V}$ & 0 & M & Landing & Atmospheric Disturbance & Landed Short \\
\hline 113 & $7 / 4 / 2001$ & Tu-154 & RA-85845 & VLK 352 & & $\mathrm{~N}$ & I & 145 & $\mathrm{D}$ & Approach & Autopilot-Induced Stall & Uncontrolled Descent to Ground/Water \\
\hline 114 & $8 / 9 / 2001$ & BE-200 & N-899RW & N-899RW & KOKZ & D & 1 & 0 & $\mathrm{D}$ & Approach & Stall & Collision W/Terrain \\
\hline 115 & $8 / 24 / 2001$ & LR-25 & N-153TW & AJI 3TW & $\mathrm{KITH}$ & $\mathrm{N}$ & 1 & 2 & $\mathrm{D}$ & Initial climb & Somatogravic Illusion & Collision W/Terrain \\
\hline 116 & 9/12/2001 & Let-410 & XA-ACM & XA-ACM & MMCT & D & $\mathrm{v}$ & 19 & $\mathrm{D}$ & Initial climb & Failure To Maintain Control & Uncontrolled Descent to Ground/Water \\
\hline 117 & 9/14/2001 & BE-1900 & C-GSKC & SKK 621 & CYYT & $\mathrm{N}$ & 1 & 0 & $\mathrm{D}$ & Initial climb & Uncommanded Pitch & Forced Landing \\
\hline 118 & 9/18/2001 & Let-410 & TG-CFE & TG-CFE & MGGT & $u$ & $u$ & 8 & $\mathrm{D}$ & Initial climb & Stall & Uncontrolled Descent to Ground/Water \\
\hline 119 & $10 / 4 / 2001$ & Tu-154 & RA-85693 & SBI 1812 & & D & $u$ & 78 & $\mathrm{D}$ & Cruise & Hostile Action & Uncontrolled Descent to Ground/Water \\
\hline 120 & 10/10/2001 & SA-226 & EC-GDV & FTL 101 & & $\mathrm{D}$ & I & 10 & $\mathrm{D}$ & Cruise & Loss Of All Attitude Displays & Uncontrolled Descent to Ground/Water \\
\hline 121 & 10/16/2001 & E-145 & $\mathrm{N}-825 \mathrm{MJ}$ & ASH 5733 & KROA & $\mathrm{N}$ & V & 0 & S & Landing & Stall & Hard Landing \\
\hline 122 & 11/12/2001 & A-300 & N-14053 & AAL 587 & KJFK & $\mathrm{D}$ & $\mathrm{V}$ & 260 & $\mathrm{D}$ & Climb & Wake Turbulence & In-flight Breakup \\
\hline
\end{tabular}

21

American Institute of Aeronautics and Astronautics 


\begin{tabular}{|c|c|c|c|c|c|c|c|c|c|c|c|c|}
\hline No & Date & Aircraft & Registr'n & Ident & Loc'n & Light & Wea & Fat & Dam & Phase & Occurrence & Result \\
\hline 123 & $11 / 19 / 2001$ & II-18 & RA-75840 & LDF 840 & & $\mathrm{U}$ & $U$ & 27 & $\mathrm{D}$ & Cruise & Flight Control System & Uncontrolled Descent to Ground/Water \\
\hline 124 & $11 / 22 / 2001$ & LR-25 & $N-5 U J$ & UJT 5UJ & KPIT & D & $\mathrm{V}$ & 2 & D & Initial climb & Overcontrol & Collision W/Terrain \\
\hline 125 & $12 / 10 / 2001$ & LR-24 & N-997TD & X5CA 36 & & $\mathrm{~N}$ & $\mathrm{~V}$ & 2 & $\mathrm{D}$ & Descent & Undetermined & Uncontrolled Descent to Ground/Water \\
\hline 126 & $12 / 14 / 2001$ & DC-8 & $\mathrm{N}-825 \mathrm{BX}$ & RTI 8101 & PANC & $\mathrm{N}$ & $\mathrm{V}$ & 0 & $\mathrm{~N}$ & Initial climb & Flight Control Hardover & Uncommanded Bank \\
\hline 127 & $12 / 20 / 2001$ & CE-560 & HB-VLV & EGU 220 & LSZH & $\mathrm{N}$ & I & 2 & D & Initial climb & Somatogravic Illusion & Uncontrolled Descent to Ground/Water \\
\hline 128 & $1 / 4 / 2002$ & CL-600 & N-90AG & N-90AG & EGBB & $\mathrm{D}$ & $\mathrm{V}$ & 5 & D & Initial climb & Attempted TO W/Contaminated & Uncontrolled Descent to Ground/Water \\
\hline 129 & $1 / 22 / 2002$ & B-757 & TF-FIO & ICE 315 & ENGM & D & I & 0 & $\mathrm{~N}$ & Go-around & Somatogravic Illusion & Upset \\
\hline 130 & $4 / 12 / 2002$ & SA-227 & EC-GKR & TDC GKR & LEPA & $\mathrm{N}$ & $u$ & 2 & D & Approach & Aggressive Maneuver & Collision W/Terrain \\
\hline 131 & $5 / 4 / 2002$ & BAC-111 & $5 N-E S F$ & EXW 422 & KNKN & $D$ & $u$ & 71 & $\mathrm{D}$ & Cruise & Stall & Uncontrolled Descent to Ground/Water \\
\hline 132 & $5 / 25 / 2002$ & B-747 & B-18255 & CAL 611 & & $\mathrm{D}$ & 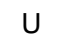 & 225 & $\mathrm{D}$ & Cruise & Structural Failure - Fatigue & Uncontrolled Descent to Ground/Water \\
\hline 133 & $6 / 3 / 2002$ & MD-11 & N-588FE & FEX 5181 & & $\mathrm{~N}$ & I & 0 & $\mathrm{~S}$ & Descent & Overcontrol & Structural Failure \\
\hline 134 & $6 / 4 / 2002$ & MD-80 & N-823NK & NKS 970 & & D & $\mathrm{V}$ & 0 & $\mathrm{~N}$ & Cruise & Autopilot-Induced Stall & Upset \\
\hline 135 & $6 / 14 / 2002$ & A-330 & C-GHLM & ACA 875 & EDDF & $\mathrm{U}$ & 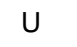 & 0 & N & Approach & Flight Control Logic & Uncommanded Pitch \\
\hline 136 & 6/28/2002 & SF-340 & VH-OLM & HZL 185 & YBTH & $\mathrm{N}$ & $u$ & 0 & $\mathrm{~N}$ & Approach & Icing Stall & Upset \\
\hline 137 & $7 / 1 / 2002$ & Tu-154 & RA-85816 & BTC 2937 & & $\mathrm{~N}$ & $u$ & 69 & D & Cruise & Structural Failure - Midair & Uncontrolled Descent to Ground/Water \\
\hline 138 & $7 / 1 / 2002$ & B-757 & A9-CDHL & DHL 611 & & $\mathrm{~N}$ & $u$ & 2 & $\mathrm{D}$ & Cruise & Structural Failure - Midair & Uncontrolled Descent to Ground/Water \\
\hline 139 & $7 / 28 / 2002$ & II-86 & RA-86060 & PLK 060 & UUEE & D & $u$ & 14 & $\mathrm{D}$ & Initial climb & Runaway Pitch Trim & Uncontrolled Descent to Ground/Water \\
\hline 140 & $8 / 14 / 2002$ & ATR-42 & PT-MTS & TTL 5561 & & $\mathrm{~N}$ & $u$ & 2 & $\mathrm{D}$ & Cruise & Runaway Pitch Trim & Uncontrolled Descent to Ground/Water \\
\hline 141 & 10/9/2002 & B-747 & N-661US & NWA 85 & PANC & $\mathrm{N}$ & $\mathrm{V}$ & 0 & M & Cruise & Flight Control Hardover & Uncommanded Bank \\
\hline 142 & $10 / 20 / 2002$ & B-757 & TF-FII & ICE 662 & KBWI & $\mathrm{N}$ & $\mathrm{U}$ & 0 & $\mathrm{~N}$ & Climb & Spatial Disorientation & Upset \\
\hline 143 & $11 / 8 / 2002$ & $|A|-1124$ & N-61RS & BQVA 1R & KSKX & $\mathrm{D}$ & $\mathrm{V}$ & 2 & D & Approach & Atmospheric Disturbance & Uncontrolled Descent to Ground/Water \\
\hline 144 & $12 / 3 / 2002$ & A-300 & Unknown & Unknown & EDDM & D & $u$ & 0 & $\mathrm{~N}$ & Climb & Controls (Trim) & Design Airspeed Exceeded (Vne/Vmo) \\
\hline 145 & $12 / 7 / 2002$ & A-320 & C-GIUF & ACA 1130 & CYYZ & $\mathrm{U}$ & $u$ & 0 & $\mathrm{~N}$ & Final approach - prec & Pilot Induced Oscillation (PIO) & Go Around \\
\hline 146 & $12 / 7 / 2002$ & A-320 & C-GJVX & ACA 457 & CYYZ & $\mathrm{U}$ & 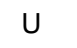 & 0 & $\mathrm{~N}$ & Final approach - prec & Pilot Induced Oscillation (PIO) & Hard Landing \\
\hline 147 & $12 / 21 / 2002$ & ATR-72 & B-22708 & TNA 791 & & $\mathrm{~N}$ & 1 & 2 & $\mathrm{D}$ & Descent & Icing Stall & Uncontrolled Descent to Ground/Water \\
\hline 148 & $12 / 27 / 2002$ & Let-410 & 9X-RRB & 9X-RRB & FMCV & D & 1 & 1 & D & Missed approach & Spatial Disorientation & Uncontrolled Descent to Ground/Water \\
\hline 149 & $1 / 8 / 2003$ & BE-1900 & N2-33YV & AMW 548 & KCLT & $\mathrm{D}$ & $\mathrm{V}$ & 21 & D & Initial climb & Flight Control Integrity Lost & Uncontrolled Descent to Ground/Water \\
\hline 150 & $2 / 10 / 2003$ & An-28 & ES-NOY & ENI 827 & EETN & $\mathrm{N}$ & I & 2 & D & Initial climb & Attempted TO W/Contaminated & Collision W/Obstacle \\
\hline 151 & $3 / 6 / 2003$ & B-737 & 7T-VEZ & DAH 6289 & DAAT & $\mathrm{D}$ & $\mathrm{U}$ & 102 & $\mathrm{D}$ & Initial climb & Stall & Uncontrolled Descent to Ground/Water \\
\hline 152 & $4 / 23 / 2003$ & BE-99 & C-FDYF & ABS DYF & CYPA & $\mathrm{D}$ & $u$ & 0 & $\mathrm{D}$ & Approach & Flight Control Actuator & Uncontrolled Descent to Ground/Water \\
\hline 153 & $5 / 1 / 2003$ & LR-45 & I-ERJC & I-ERJC & ASN & $U$ & $u$ & 2 & $\mathrm{D}$ & Initial climb & Structural Failure - Birdstrike & Uncontrolled Descent to Ground/Water \\
\hline 154 & $6 / 16 / 2003$ & A-320 & C-GTDK & SSV TDK & EGGD & $\mathrm{U}$ & $u$ & 0 & $\mathrm{~S}$ & Landing & Unexpected Control Gains & Hard Landing \\
\hline 155 & $7 / 8 / 2003$ & B-737 & ST-AFK & SUD 139 & HSSP & $\mathrm{N}$ & $u$ & 116 & D & Missed approach & Failure To Maintain Control & Uncontrolled Descent to Ground/Water \\
\hline 156 & $8 / 4 / 2003$ & LR-35 & $\mathrm{N}-135 \mathrm{PT}$ & RM6A 5P & KGON & $\mathrm{D}$ & $\mathrm{V}$ & 2 & D & Approach & Inadvertent Control Input & Collision W/Obstacle \\
\hline 157 & $8 / 24 / 2003$ & Let-410 & HH-PRV & HH-PRV & $\mathrm{MTCH}$ & $\mathrm{N}$ & 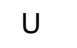 & 21 & D & Circling approach & Failure To Maintain Control & Uncontrolled Descent to Ground/Water \\
\hline 158 & $8 / 26 / 2003$ & BE-1900 & $\mathrm{N}-240 \mathrm{CJ}$ & CJC 9446 & KHYA & D & $\mathrm{V}$ & 2 & D & Initial climb & Reversed Controls & Uncontrolled Descent to Ground/Water \\
\hline 159 & 10/3/2003 & CV-580 & ZK-KFU & AFN 642 & & $\mathrm{~N}$ & I & 2 & D & Descent & Icing Stall & In-flight Breakup \\
\hline 160 & $10 / 26 / 2003$ & $\mathrm{FH}-227$ & LV-MGV & CTZ 760 & & $\mathrm{~N}$ & 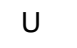 & 5 & D & Cruise & Loss-of-Control (Vmc) & Uncontrolled Descent to Ground/Water \\
\hline 161 & $11 / 22 / 2003$ & A-300 & OO-DLL & BCS DLL & ORBS & $\mathrm{D}$ & $\mathrm{V}$ & 0 & S & Climb & Hostile Action & Runway Departure \\
\hline 162 & $12 / 23 / 2003$ & LR-24 & $\mathrm{N}-600 \mathrm{XJ}$ & $\mathrm{N}-600 \mathrm{XJ}$ & & D & $\mathrm{V}$ & 2 & D & Climb & Undetermined & Uncontrolled Descent to Ground/Water \\
\hline 163 & $1 / 3 / 2004$ & B-737 & SU-ZCF & FLS 604 & HESH & $\mathrm{N}$ & $\mathrm{V}$ & 148 & $\mathrm{D}$ & Climb & Spatial Disorientation & Spiral Dive Into Ground \\
\hline
\end{tabular}


164 2/10/2004 FO-50

$1653 / 4 / 2004$ II-76

166 3/19/2004 LR-35

167 5/5/2004 SA-227

168 5/6/2004 Let-410

$1695 / 17 / 2004$ DHC-6

$170 \quad 5 / 18 / 2004 \quad$ II-76

171 6/18/2004 SF-340

$172 \quad 7 / 2 / 2004 \quad$ IAI-1124

173 7/21/2004 DC-9

174 8/11/2004 B-737

175 10/5/2004 An-12

176 10/14/2004 B-747

177 10/14/2004 CL-600

178 11/21/2004 CL-600

179 11/28/2004 CL-600

180 11/30/2004 HFB-320

181 12/10/2004 BE-200

182 1/13/2005 E-110

183 2/16/2005 CE-560

184 2/24/2005 IAI-1124

185 3/15/2005 An-26

186 3/26/2005 Let-410

$187 \quad 5 / 2 / 2005$ SA-227

188 5/12/2005 MD-90

189 5/21/2005 CL-600

190 5/27/2005 DHC-8

191 8/1/2005 B-777

192 8/14/2005 B-737

193 8/16/2005 MD-80

194 9/5/2005 B-737

195 9/5/2005 B-737

196 9/30/2005 B-737

197 10/3/2005 E-170

198 10/22/2005 B-737

199 11/5/2005 A-320

200 11/8/2005 E-110

201 12/19/2005 G-73

202 12/23/2005 An-140

203 12/28/2005 LR-35

204 1/2/2006 SF-340
E-PLCA IRK 7170 OMSI $\quad$ D $\quad U \quad 43 \quad$ D $\quad$ Final approach - non Undetermined

0 S Go-around

HK-4275X HK-4275X SKLC D $\quad V \quad 5 \quad$ D VFR pattern-final

6 D Initial climb

9X-REF

8Q-TMC TMW TM VRMM D U

4KAZ27 AHC Z27 ZWW D U

VH-KEQ REXKEQ YMML D I

N-280AT N-280AT MPTO D U

XA-BCS SER 706 MMMX U U

3X-GCM GIB GCM GFLL U U

ST-SAF

9G-MKJ

$\mathrm{N}-8396 \mathrm{~A}$

SRW SAF

MKA 1602 CYHZ N U

CES 5210 ZBOW D

N-873G YQCA 73 KMTJ D

N-604GA GAE 4GA KSUS N

N-648KA YSDA 8K TS94 D V

N-49BA RLR 2352 KEEN N

N-500AT N-500AT KPUB D

XC-COL XC-COL D U

OB-1778P AMP 78P SPIM D U

HK-4146 WCW 99 SKPV D U

ZK-POA AWK 23 N

$\mathrm{N}$-10ME MEP 490 KIRK N

$\mathrm{N}-699 \mathrm{CW}$ DGFA 9C KAGS $\mathrm{N}$

C-GZKH C-GZKH CYYT D

9M-MRG MAS 124 YPPH U

5B-DBY HCY 522 LGAV

HK-4374X WCW 70

PR-BRY BRB 907

PK-RIM MDL91 WIMM

D-ABEA DLH BEA EDDF

N-650RW UHL 7621 KIAD

5N-BFN BVU 210

OO-TCX TCW TC EDDF

N-78010 BOTA 35 KMHT

N-2969 CHK $101 \quad$ KMPB

4K-AZ48 AHY 217

N-781RS S2KA 1R KTRK

N-390AE SIM 3008
0 D Initial climb

7 D Initial climb

0 U Descent

6 D Initial climb

0 D Initial climb

4 D Cruise

7 D Initial climb

2 D Cruise

53 D Initial climb

3 D Initial climb

2 D Initial climb

0 D Initial climb

1 D Missed approach

9 D Initial climb

2 D Cruise

$0 \mathrm{~N}$ Cruise

$0 \quad \mathrm{~N}$ Climb

$0 \quad \mathrm{~N}$ Climb

0 N Climb

121 D Climb

160 D Cruise

$0 \mathrm{U}$ Cruise

100 D Initial climb

0 N Approach

117 D Climb

0 N Approach

0 D Initial climb

20 D Initial climb

23 D Cruise

2 D Approach

$0 \quad \mathrm{~N}$ Climb

23
0 D Initial climb

0 S Initial climb

$0 \quad \mathrm{~N}$ Approach
Stall

Uncontrolled Descent to Ground/Wate

Hard Landing

Uncontrolled Descent to Ground/Water

Uncontrolled Descent to Ground/Water

Attempted TO W/Incorrect Config Collision W/Obstacle

Undetermined

Stall

Undetermined

Collision W/Terrain

Upset

Uncontrolled Descent to Ground/Water Collision W/Terrain

Attempted TO W/Incorrect Config Collision W/Terrain

Failure To Maintain Control

Stall

Autopilot-Induced Stall

Attempted TO W/Contaminated

Attempted TO W/Contaminated

Controls (Trim)

Icing Stall
Undetermined

Uncontrolled Descent to Ground/Water Collision W/Terrain

Collision W/Terrain

Uncontrolled Descent to Ground/Water

Uncontrolled Descent to Ground/Water

Collision W/Terrain

Collision W/Obstacle

Uncontrolled Descent to Ground/Water

Uncontrolled Descent to Ground/Water Collision W/Terrain

A Collision W/Terrain

Loss-of-Control (Vmc)

Load - C/G Out Of Range

Instrument Failure

Aggressive Maneuver

Icing Stall

Uncommanded Pitch

Incapacitation: Hypoxia

Autopilot-Induced Stall

Uncommanded Bank

Uncontrolled Descent to Ground/Water Uncontrolled Descent to Ground/Water Aircraft Pitch/Roll Oscillations

Cabin Injuries

Upset

Upset

Uncontrolled Descent to Ground/Water Uncontrolled Descent to Ground/Water Upset

Attempted TO W/Incorrect Config Collision W/Obstacle

Wake Turbulence

Aggressive Maneuver

Undetermined

Wake Turbulence

Loss-of-Control (Vmc)

Structural Failure - Fatigue

Loss Of All Attitude Displays

Stall

Icing Stall
Landed Without Further Incident

Cabin Injuries

Collision W/Terrain

Collision W/Obstacle

Uncontrolled Descent to Ground/Water Uncontrolled Descent to Ground/Water Uncontrolled Descent to Ground/Water Upset
Landed Without Further Incident

American Institute of Aeronautics and Astronautics 


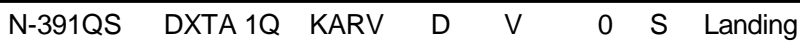

N-629EK GAE 9EK

$\mathrm{N}-900 \mathrm{LG}$

N-900LG KASE

EK-32009 RNV 967 URSS

9N-AEQ

NYT AEQ VNJL

AP-BAL

PIA 688 OPMT

$7 \mathrm{~T}-\mathrm{VHG}$

DAH 2208

RA-85185 PLK 612

PR-GTD GLO 1907

N-600X

N-600XL

$\mathrm{N}-924 \mathrm{FR}$

FFT 539

$5 \mathrm{~N}-\mathrm{BFK}$

$\mathrm{N}-322 \mathrm{FX}$

XA-TNP

PK-KKW

N-40AN

$\mathrm{N}-77215$

F-GMPG

$\mathrm{N}-168 \mathrm{CK}$

N-511AT

HZ-AEN

5Y-KYA

TN-AHE

N-550BP

RA-93912

F-OIQI

G-THOF

N-31MC

PT-OVC

$\mathrm{N}-925 T \mathrm{~T}$

$\mathrm{N}-470 Z \mathrm{~W}$

C-GBHZ

EW-101PJ BRU 1834 UDYZ

$\mathrm{N}-113 \mathrm{SH} \quad \mathrm{N}-113 \mathrm{SH} \quad \mathrm{KPWA}$

VH-OZA VH-OZA YSSY

N-195GA TIM 5008 KBIL

RA12957

N-554FE

GAI 2063 USCC

WIG 6601 KHYA

ST-WTB BBE 700 HSSS

CC-CFM CC-CFM SCPF

D V 1 D Cruise

0 S Approach

113 D Missed approach

9 D Go-around

45 D Initial climb

3 D Cruise

170 D Cruise

154 D Cruise

0 S Cruise

$0 \quad \mathrm{~N}$ Landing

96 D Initial climb

0 N Approach

2 D Landing

102 D Cruise

0 S Cruise

2 D Initial climb

O S Initial climb

0 D Initial climb

0 S Landing

$0 \cup$ Descent

114 D Initial climb

3 D Initial climb

6 D Climb

7 D Initial climb

20 D Initial climb

0 N Final approad

0 S Landing

2 D Initial climb

2 D Initial climb

O S Landing

0 M Climb

0 D Initial climb

5 D Climb

1 D Climb

1 D Initial climb

9 D Climb

0 S holding (IFR)

1 D Initial climb

4 D Initial climb

9 D Initial climb
Stall

Undetermined

Wake Turbulence

Spatial Disorientation

Aggressive Maneuver

Stall

Undetermined

Turbulence

Structural Failure - Midair

Structural Failure - Midair

Inadvertent Control Input

Wind Shear

Aggressive Maneuver

Undetermined

Spatial Disorientation

Intentional Acrobatics

Stall

Attempted TO W/Contaminated

Undetermined

Contaminated Airfoil

Undetermined

Spatial Disorientation

Undetermined

Spatial Disorientation

Loss-of-Control (Vmc)

Flight Control Integrity Lost

Stall

Aircraft Pitch/Roll Oscillations

Undetermined

Attempted TO W/Contaminated Stall

Wake Turbulence

Attempted TO W/Contaminated

Structural Failure - Birdstrike

Spatial Disorientation

Undetermined

Flight Control Integrity Lost

Stall

Attempted TO W/Gust Locks Eng Uncontrolled Descent to Ground/Water Attempted TO W/Incorrect Config

Stall
Collision W/Obstacle

Uncontrolled Descent to Ground/Water Hard Landing

Uncontrolled Descent to Ground/Water

Collision W/Terrain

Collision W/Terrain

Uncontrolled Descent to Ground/Water

Uncontrolled Descent to Ground/Water

Uncontrolled Descent to Ground/Water

Forced Landing

Uncommanded Pitch

Uncontrolled Descent to Ground/Water

Cabin Injuries

Collision W/Obstacle

Spiral Dive Into Ground

Exceeded Design Loads

Uncontrolled Descent to Ground/Water

Collision W/Obstacle

Uncontrolled Descent to Ground/Water

Collision W/Terrain

Uncommanded Pitch

Spiral Dive Into Ground

Collision W/Obstacle

Spiral Dive Into Ground

Uncontrolled Descent to Ground/W ater

Uncontrolled Descent to Ground/Water

Uncommanded Pitch

Collision W/Terrain

Uncontrolled Descent to Ground/Water

Collision W/Obstacle

Hard Landing

Upset

Collision W/Terrain

Collision W/Terrain

Spiral Dive Into Ground

Uncontrolled Descent to Ground/Water Uncontrolled Descent to Ground/Water Exceeded Design Loads

Collision W/Terrain

Uncontrolled Descent to Ground/Water 


\begin{tabular}{|c|c|c|c|c|c|c|c|c|c|c|c|c|}
\hline No & Date & Aircraft & Registr'n & Ident & Loc'n & Light & Wea & Fat & Dam & Phase & Occurrence & Result \\
\hline 246 & $7 / 16 / 2008$ & DHC-6 & C-GBEB & NWI BEB & & D & $\mathrm{V}$ & 0 & S & VFR pattern-base tur & Stall & Collision W/Obstacle \\
\hline 247 & $8 / 20 / 2008$ & MD-80 & EC-HFP & JKK 5022 & LEMD & 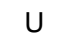 & $U$ & 154 & $\mathrm{D}$ & Initial climb & Attempted TO W/Incorrect Config & Collision W/Terrain \\
\hline 248 & 9/14/2008 & B-737 & VP-BKO & AFL BKO & USPP & N & 1 & 88 & $\mathrm{D}$ & Approach & Spatial Disorientation & Spiral Dive Into Ground \\
\hline 249 & $10 / 7 / 2008$ & A-330 & VH-QPA & QFA 72 & YPLM & $U$ & $U$ & 0 & M & Cruise & Flight Control Logic & Upset \\
\hline 250 & $11 / 1 / 2008$ & CASA-212 & N-437RA & ATS 7RA & & $\mathrm{T}$ & $\mathrm{V}$ & 0 & S & Go-around & Asymmetric Thrust/Drag & Collision W/Terrain \\
\hline 251 & $11 / 4 / 2008$ & LR-45 & XC-VMC & $\mathrm{XC}-\mathrm{VMC}$ & MMMX & $u$ & $U$ & 9 & $\mathrm{U}$ & Approach & Wake Turbulence & Uncontrolled Descent to Ground/Water \\
\hline 252 & $12 / 7 / 2008$ & LR-23 & XC-LGD & XC-LGD & & $u$ & $U$ & 2 & D & Go-around & Undetermined & Uncontrolled Descent to Ground/Water \\
\hline 253 & $1 / 27 / 2009$ & ATR-42 & $\mathrm{N}-902 \mathrm{FX}$ & CFS 8284 & KLLB & N & I & 0 & s & Final approach - prec & Stall & Uncontrolled Descent to Ground/Water \\
\hline 254 & $1 / 28 / 2009$ & B-757 & G-STRZ & AEU TRZ & DGAA & $\mathrm{N}$ & I & 0 & $\mathrm{~N}$ & Cruise & Instrument Failure & Landed Without Further Incident \\
\hline 255 & 2/7/2009 & CE-650 & I-FEEV & AOE 301 & & $u$ & $u$ & 2 & D & Climb & Undetermined & Spiral Dive Into Ground \\
\hline 256 & 2/7/2009 & $\mathrm{E}-110$ & PT-SEA & PT-SEA & SWK & D & $U$ & 24 & D & Climb & Undetermined & Collision W/Terrain \\
\hline 257 & 2/12/2009 & DHC-8 & N-200WQ & CJC 3407 & KBUF & N & $\mathrm{V}$ & 49 & D & Approach & Stall & Uncontrolled Descent to Ground/Water \\
\hline 258 & $2 / 25 / 2009$ & B-737 & TC-JGE & THY 1951 & EHAM & D & $u$ & 9 & D & Approach & Stall & Collision W/Terrain \\
\hline 259 & $5 / 11 / 2009$ & B-747 & G-BYGA & BAW YG & FAJS & $\mathrm{N}$ & $\mathrm{V}$ & 0 & $\mathrm{~N}$ & Initial climb & Uncommanded Configuration Cha & Stall Buffet \\
\hline 260 & $6 / 1 / 2009$ & A-330 & F-GZCP & AFR 447 & TASIL & $\mathrm{N}$ & 1 & 228 & D & Cruise & Spatial Disorientation & Uncontrolled Descent to Ground/Water \\
\hline 261 & 6/30/2009 & A-310 & 7O-ADJ & IYE 626 & $\mathrm{FMCH}$ & $\mathrm{N}$ & $\mathrm{V}$ & 152 & D & Circling approach & Failure To Maintain Airspeed & Collision W/Terrain \\
\hline 262 & $7 / 15 / 2009$ & Tu-154 & EP-CPG & CMP 790 & & $u$ & $U$ & 168 & D & Cruise & Undetermined & Collision W/Terrain \\
\hline 263 & 10/21/2009 & B-707 & ST-AKW & SUD 2241 & OMSJ & $U$ & $U$ & 6 & D & Initial climb & Failure To Maintain Control & Uncontrolled Descent to Ground/Water \\
\hline 264 & $11 / 1 / 2009$ & $\|-76$ & RF-76801 & RF-76801 & UERR & $u$ & $u$ & 11 & D & Initial climb & Undetermined & Collision W/Terrain \\
\hline 265 & $11 / 28 / 2009$ & MD-11 & Z-BAV & SMJ 324 & ZSPD & $U$ & $U$ & 3 & D & Initial climb & Undetermined & Uncontrolled Descent to Ground/Water \\
\hline 266 & $1 / 5 / 2010$ & LR-35 & N-720RA & RAX 988 & KPWK & D & $\mathrm{V}$ & 2 & D & Circling approach & Undetermined & Uncontrolled Descent to Ground/Water \\
\hline 267 & $1 / 6 / 2010$ & BE-99 & N-206AV & JIKA 6AV & KEAR & w & 1 & 0 & S & Landing & Icing Stall & Hard Landing \\
\hline 268 & $1 / 21 / 2010$ & BE-1900 & $N-112 A X$ & AER 22 & PASD & $\mathrm{N}$ & $\mathrm{V}$ & 2 & D & Initial climb & Undetermined & Uncontrolled Descent to Ground/Water \\
\hline 269 & $1 / 25 / 2010$ & B-737 & ET-ANB & ETH 409 & OLBA & $\mathrm{N}$ & 1 & 90 & D & Climb & Spatial Disorientation & Spiral Dive Into Ground \\
\hline 270 & $2 / 13 / 2010$ & B-737 & $\mathrm{N}-221 \mathrm{WN}$ & SWA 253 & KBUR & $\mathrm{D}$ & $\mathrm{V}$ & 0 & $\mathrm{~N}$ & Approach & Aggressive Maneuver & Cabin Injuries \\
\hline 271 & $2 / 14 / 2010$ & CE-550 & $\mathrm{OK}-\mathrm{ACH}$ & TIE 039C & & N & $\mathrm{V}$ & 2 & D & Cruise & Intentional Acrobatics & Uncontrolled Descent to Ground/Water \\
\hline 272 & $5 / 12 / 2010$ & A-330 & $5 \mathrm{~A}-\mathrm{ONG}$ & AAW 771 & HLLT & $\mathrm{D}$ & 1 & 103 & D & Go-around & Somatogravic Illusion & Collision W/Terrain \\
\hline 273 & $8 / 25 / 2010$ & Let-410 & 9Q-CCN & 9Q-CCN & ZFBO & $u$ & $u$ & 20 & D & Approach & Load - C/G Out Of Range & Collision W/Terrain \\
\hline 274 & 9/3/2010 & B-747 & N-571UP & UPS 006 & OMDB & N & $U$ & 2 & D & Climb & Structural Failure - Fire/Explosion & Uncontrolled Descent to Ground/Water \\
\hline 275 & 10/11/2010 & A-380 & F-HPJA & AFR 006 & KJFK & D & $u$ & 0 & $\mathrm{~N}$ & Go-around & Flap/Slat Extension Speed Exceed & Altitude Deviation \\
\hline 276 & $11 / 4 / 2010$ & ATR-72 & CUT1549 & CRN 883 & & $u$ & I & 68 & D & Cruise & Contaminated Airfoil & Uncontrolled Descent to Ground/Water \\
\hline 277 & $11 / 5 / 2010$ & BE-1900 & AP-BJD & JSJ BJD & OPKC & $u$ & $u$ & 21 & D & Initial climb & Loss-of-Control (Vmc) & Collision W/Terrain \\
\hline 278 & $11 / 28 / 2010$ & $\|-76$ & 4L-GNI & 4L-GNI & OPKC & $u$ & $U$ & 8 & D & Initial climb & Loss-of-Control (Vmc) & Collision W/Obstacle \\
\hline
\end{tabular}


Appendix B: LOC Accident Analysis Spreadsheet Illustration

Example LOC Analysis Spreadsheet Entry: Birgenair 301 (2/6/1996)

The spreadsheet entries below illustrate the precursor analysis, comments, and potential for mitigation through research for Birgenair 301

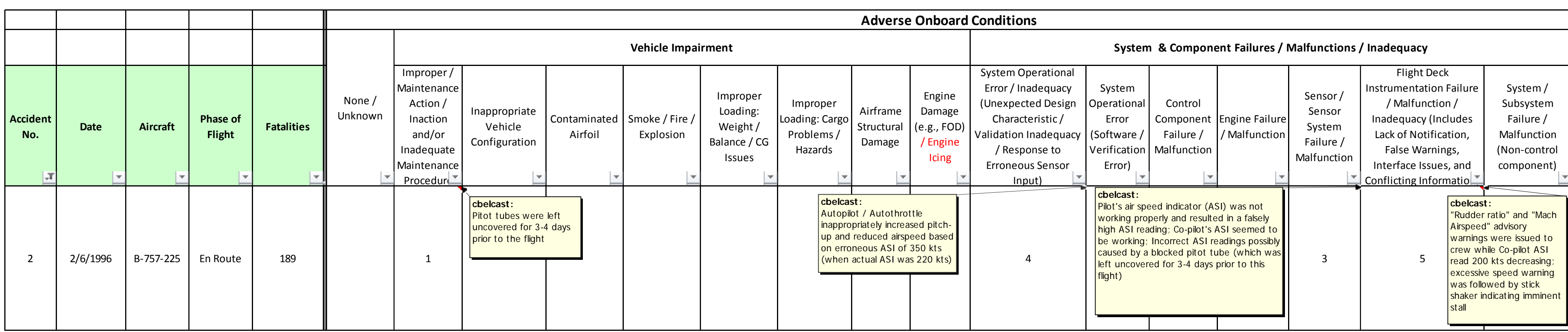

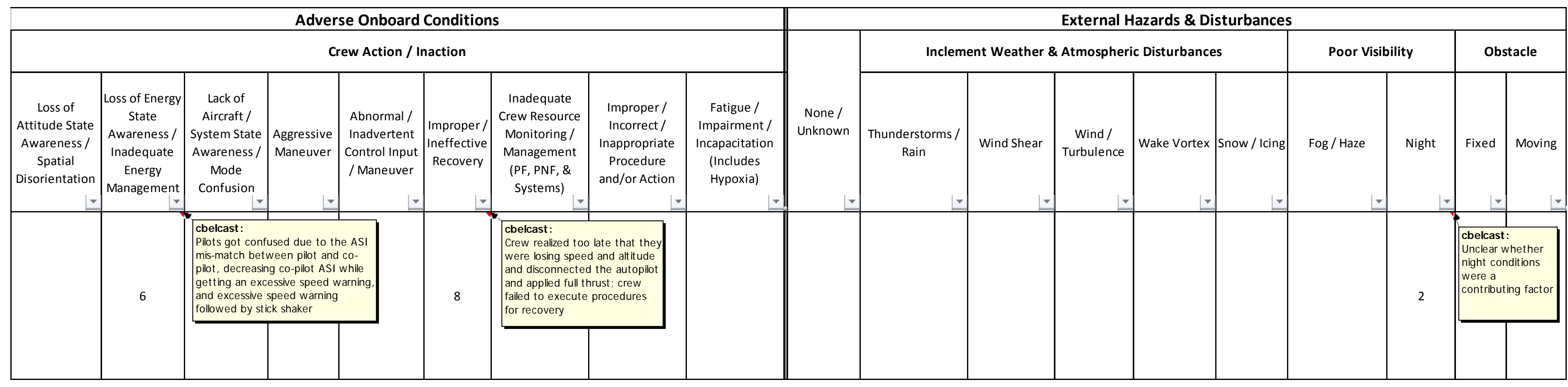




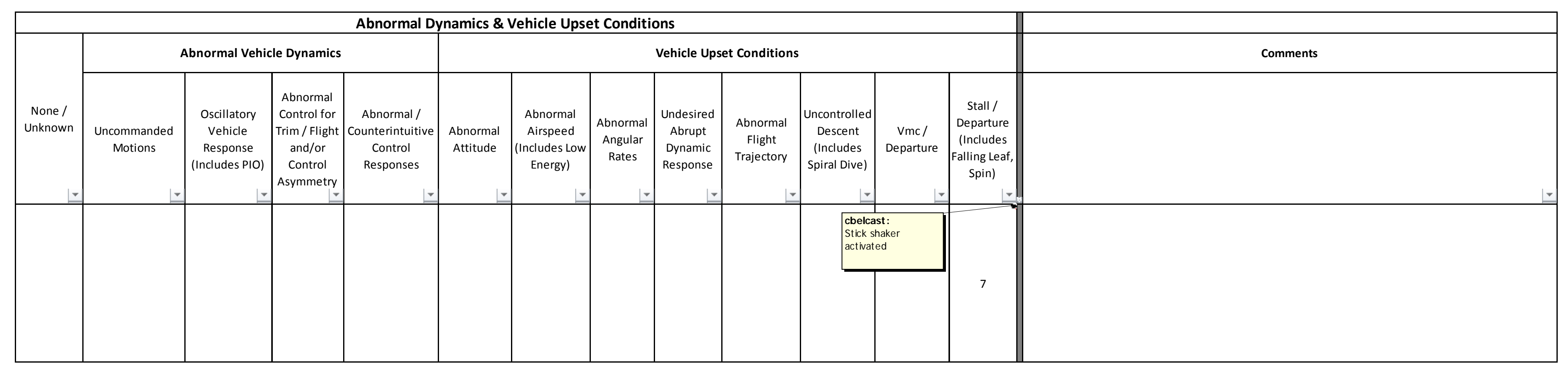

\begin{tabular}{|c|c|c|c|c|c|c|}
\hline \multicolumn{2}{|c|}{ Crew Distraction / Preoccupation / Mis-aligned Focus Flag } & \multicolumn{2}{|c|}{$\begin{array}{l}\text { Potential Human-Machine Interface Issue Flag (Includes Displays, Controls, Flight } \\
\text { Management, Envelope Protection, \& Warning Systems that Influence Flight Control) }\end{array}$} & \multicolumn{3}{|c|}{ Potential to Mitigate through Research (Technologies, Training, Procedures, etc.) } \\
\hline $\begin{array}{c}\text { Yes / No / Not } \\
\text { Enough } \\
\text { Information (NEI) }\end{array}$ & Comment & $\begin{array}{c}\text { Yes / No / Not } \\
\text { Enough } \\
\text { Information } \\
\text { (NEI) }\end{array}$ & Comment & $\begin{array}{c}\text { Yes / No / Not } \\
\text { Enough } \\
\text { Information } \\
\text { (NEI) }\end{array}$ & Mitigation Description & References \\
\hline No & & Yes & $\begin{array}{l}\text { Faulty ASI to Autopilot/Autothrottle caused aircraft to pitch up and lower } \\
\text { airspeed, which led to stall; Conflicting warnings in flight deck (overspeed } \\
\text { and stick shaker) }\end{array}$ & Yes & $\begin{array}{l}\text { 1. Improved pilot training } \\
\text { 2. NASA NRA with UIUC includes sensor failure detection and } \\
\text { isolation (FDI) } \\
\text { 3. NASA SBIRs on Sensor Integrity Management with Scientific } \\
\text { Systems and Barron Associates (Awarded 2014) } \\
\text { 4. NASA SBIR with Barron Associates on Upset Recovery Guidance } \\
\text { System } \\
\text { 5. Resilient flight control }\end{array}$ & $\begin{array}{l}\text { 1. } \\
\text { 2. Felemban, Che, Cao, Hovakimyan, and Gregory, "Estimation of } \\
\text { Airspeed Using Continuous Polynomial Adaptive Estimator," } 2014 \\
\text { SciTech Conference, National Harbor MD. } \\
\text { 3. None vet } \\
\text { 4. Gandhi, Neha, Richards, Nathan D., and Bateman, Alec J., } \\
\text { "Simulator Evaluation of an In-Cockpit Cueing Systems for Upset } \\
\text { Recovery," } 2014 \text { SciTech Conference, National Harbor, MD. } \\
\text { 5. }\end{array}$ \\
\hline
\end{tabular}




\section{Appendix C: Worst Case Precursor Analysis Examples}

Worst case precursor combinations are illustrated in Figures C.1 and C.2 at the sub-category and precursor levels, respectively. Note that sphere size is directly proportional to number of accidents, and sphere color relates to number of fatalities.

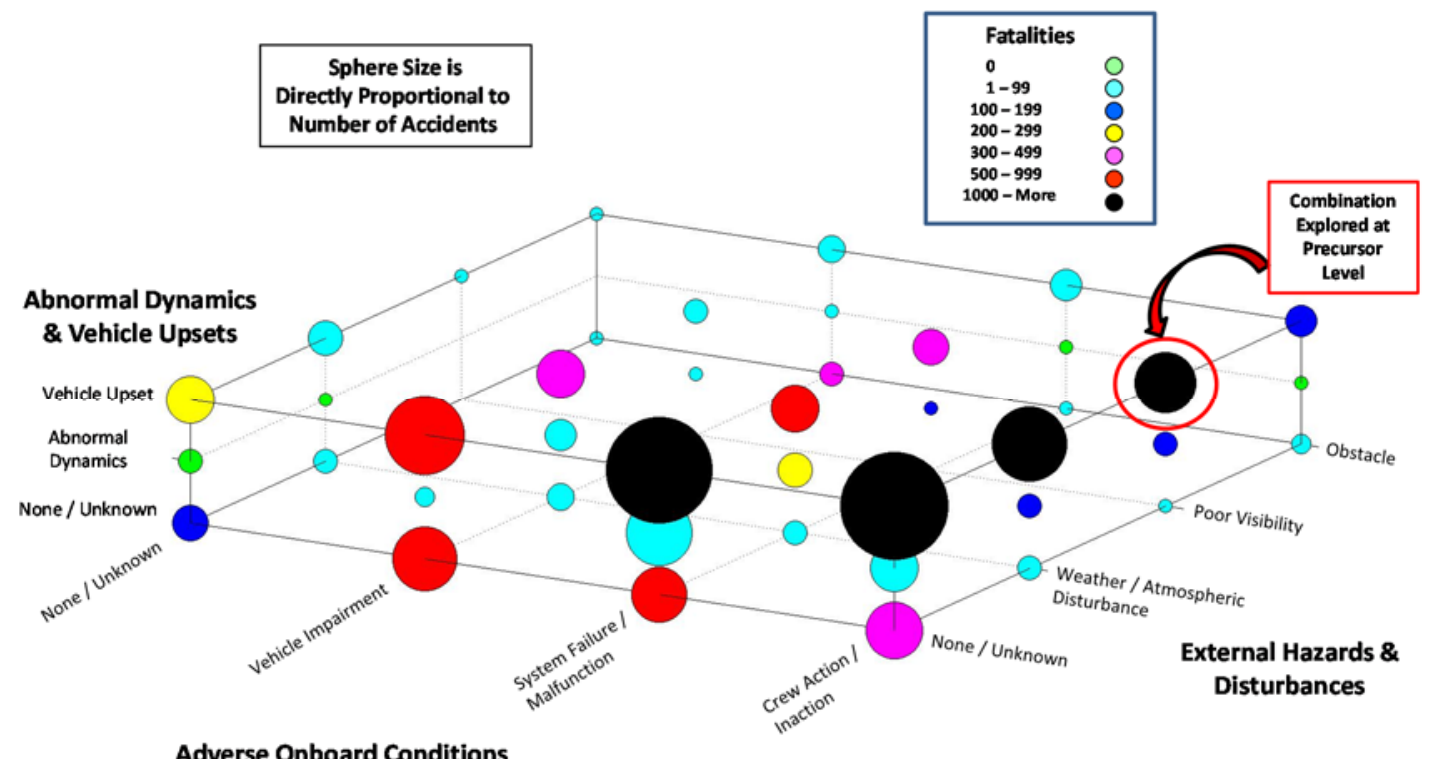

Figure C.1. Example of Worst Case Precursor Combinations Analysis at the Sub-Category Level, with one Combination Indicated for Analysis at Precursor Level (see Figure A.2).

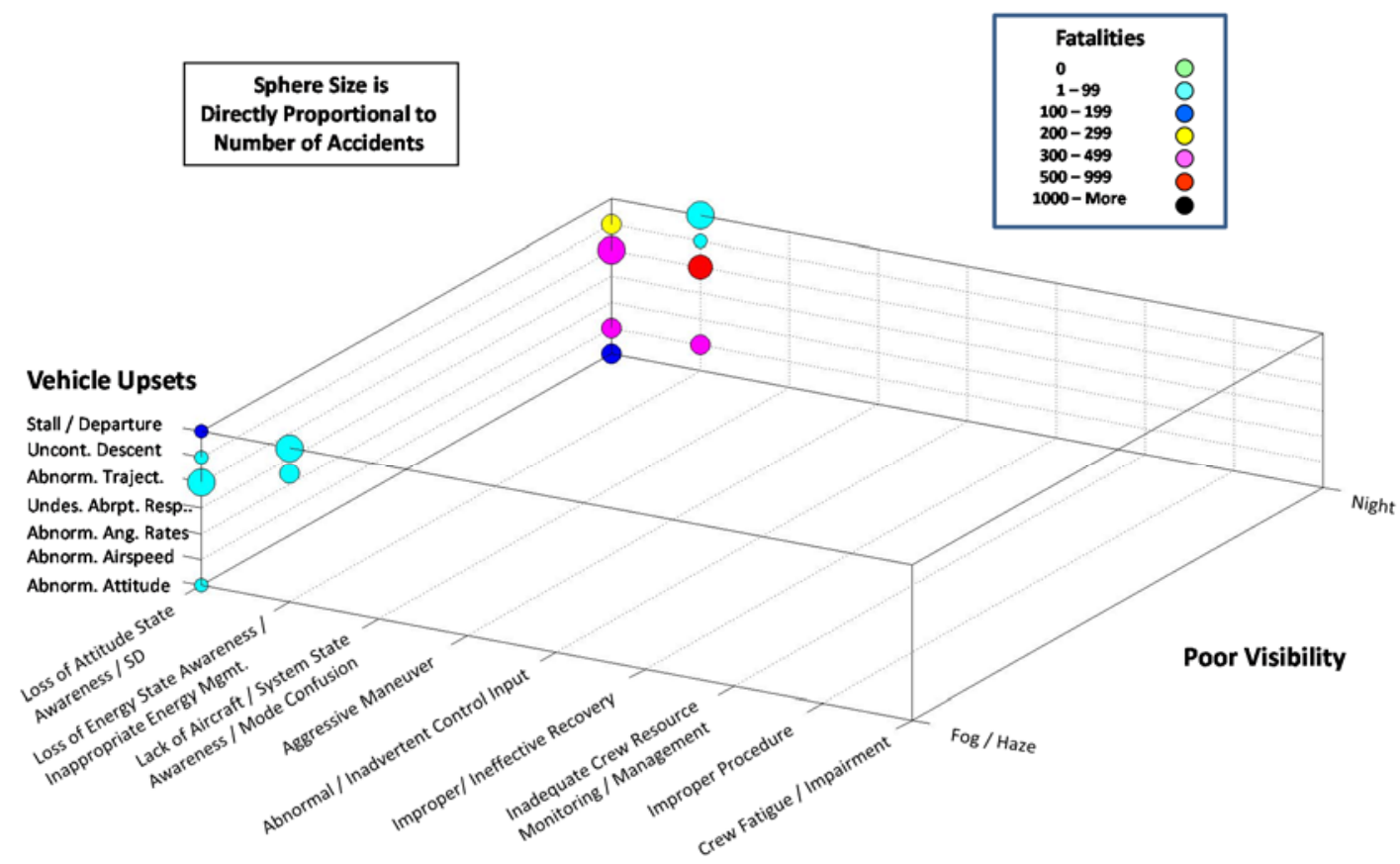

Inappropriate Crew Action / Inaction

Figure C.2. Precursor Combinations within Sub-Category Combination of Figure A.1. 
Worst case precursor sequences are illustrated in Figure C.3 for events initiated by system and component failures, and in Figure C.4 for events initiated by inappropriate crew action (or inaction).

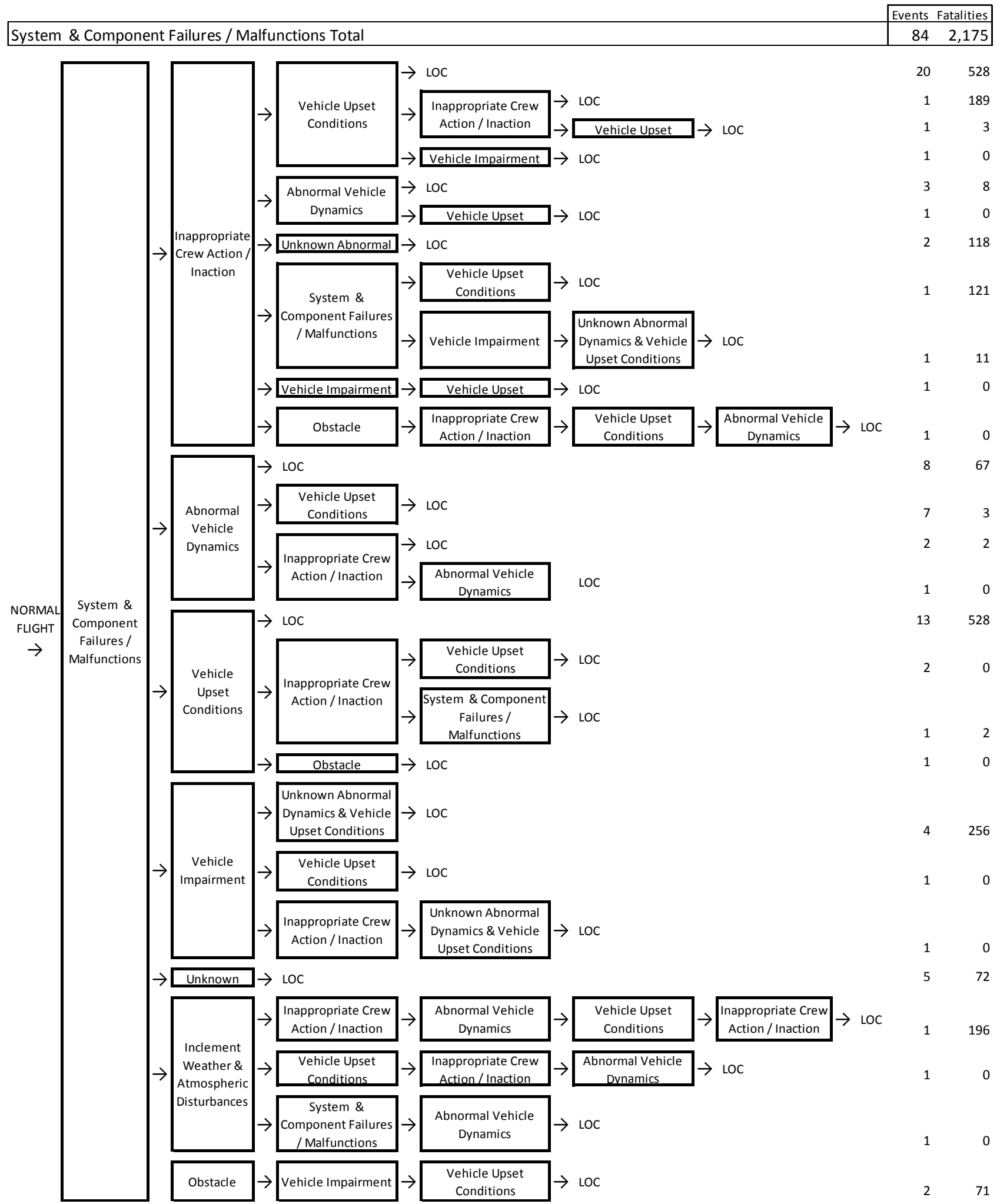

Figure C.3. LOC Sequences Initiated by System \& Component Failures / Malfunctions. 


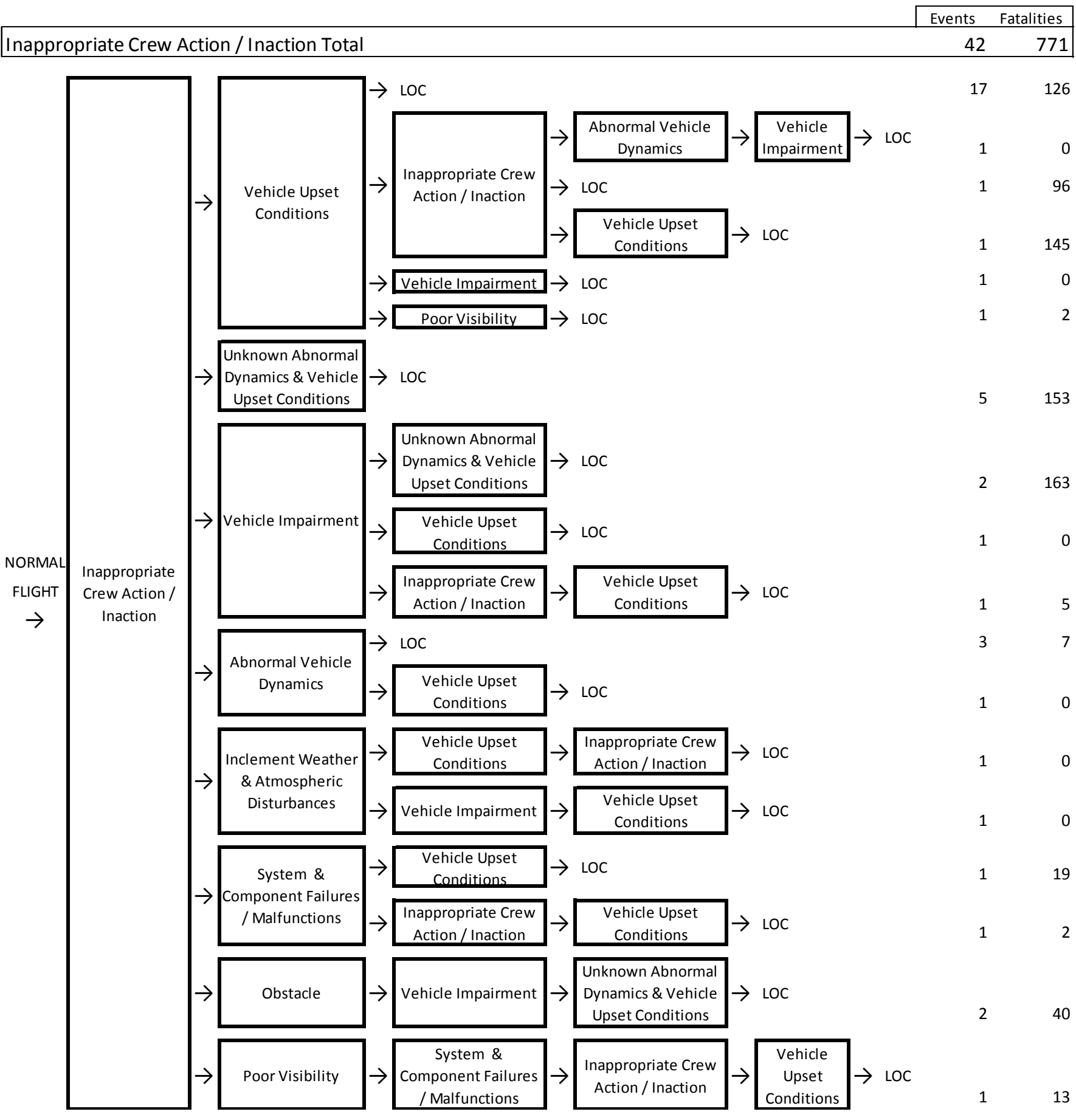

Figure C.4. LOC Sequences Initiated by Inappropriate Crew Action / Inaction.

Note that the example results illustrated in Figures C.1 - C.4 are taken from Ref. 10. 


\section{Appendix D. Precursor Sequences for Mishaps Involving Blocked Pitot Tubes or Static Ports}

The precursor sequences for the blocked pitot tube or static ports mishaps presented in Section III-C are provided below in Figures D.1 - D.8. The comments and flags associated with these mishaps are presented in Tables D.2 - D.3. The information in Table 3 from Section III-C is repeated here as Table D.1 with the fatal accidents nonfatal incidents grouped together.

Table D.1. LOC Accidents and Incidents from the Data Set Involving Blocked Pitot Tubes or Static Ports, Grouped by Fatal and Nonfatal Events

\begin{tabular}{|c|c|c|c|c|c|c|c|}
\hline $\begin{array}{c}\text { Accident } \\
\text { No. }\end{array}$ & Date & Location & Airline & Flight No. & Aircraft & $\begin{array}{c}\text { Phase of } \\
\text { Flight }\end{array}$ & Fatalities \\
\hline 2 & 2/6/1996 & $\begin{array}{c}\text { Dominican } \\
\text { Republic }\end{array}$ & Birgenair & 301 & B-757-225 & En Route & 189 \\
\hline 14 & 10/2/1996 & Peru & AeroPeru & 603 & B-757 & Climb & 70 \\
\hline 37 & 10/10/1997 & Uruguay & $\begin{array}{c}\text { Austral } \\
\text { Lineas } \\
\text { Aereas } \\
\end{array}$ & 2553 & DC-9 & En Route & 74 \\
\hline 62 & 4/7/1999 & $\begin{array}{l}\text { Ceyhan, } \\
\text { Turkey }\end{array}$ & $\begin{array}{c}\text { THY } \\
\text { Turkish } \\
\text { Airlines } \\
\end{array}$ & 5904 & B-737 & En Route & 6 \\
\hline 260 & 6/1/2009 & $\begin{array}{c}\text { Atlantic } \\
\text { Ocean (Near } \\
\text { Sao Paulo } \\
\text { Archipelago) }\end{array}$ & Air France & 447 & A-330 & En Route & 228 \\
\hline 142 & 10/20/2002 & $\begin{array}{l}\text { Baltimore, } \\
\text { Maryland }\end{array}$ & Icelandair & 662 & B-757 & En Route & 0 \\
\hline 188 & $5 / 12 / 2005$ & Missouri & $\begin{array}{c}\text { Midwest } \\
\text { Airlines }\end{array}$ & & MD-90 & Initial Climb & 0 \\
\hline 254 & 1/28/2009 & Ghana & $\begin{array}{c}\text { Astraeus for } \\
\text { Ghana } \\
\text { Airways }\end{array}$ & & B-757 & Cruise & 0 \\
\hline
\end{tabular}




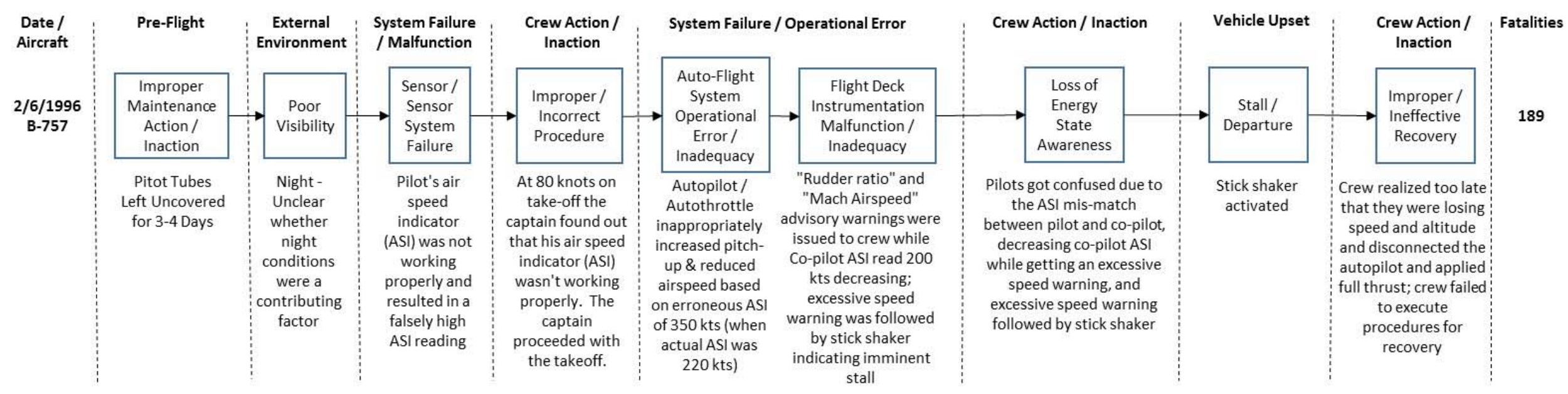

Figure D.1. Precursor Sequence for Fatal Accident No.2 of Table D.1 


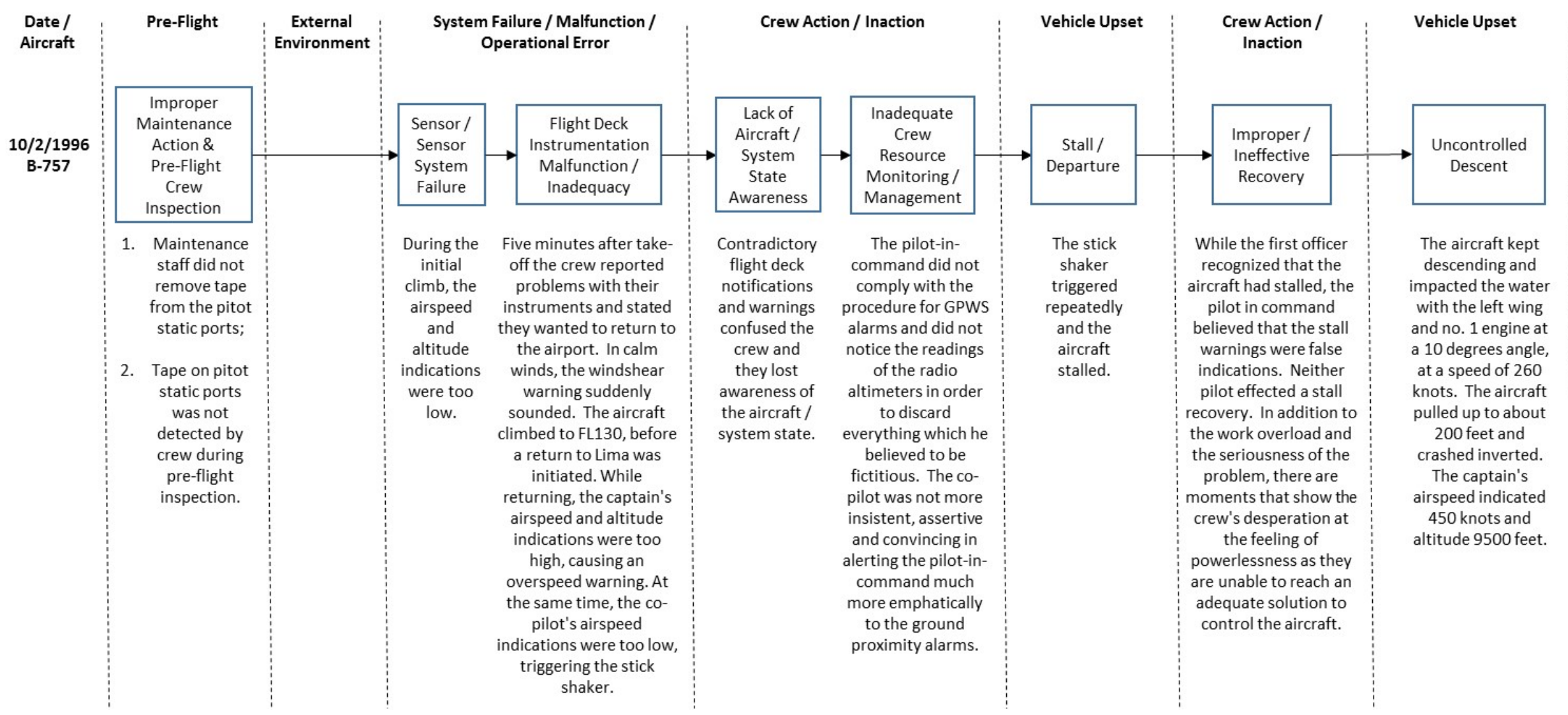

Figure D.2. Precursor Sequence for Fatal Accident No. 14 of Table D.1 


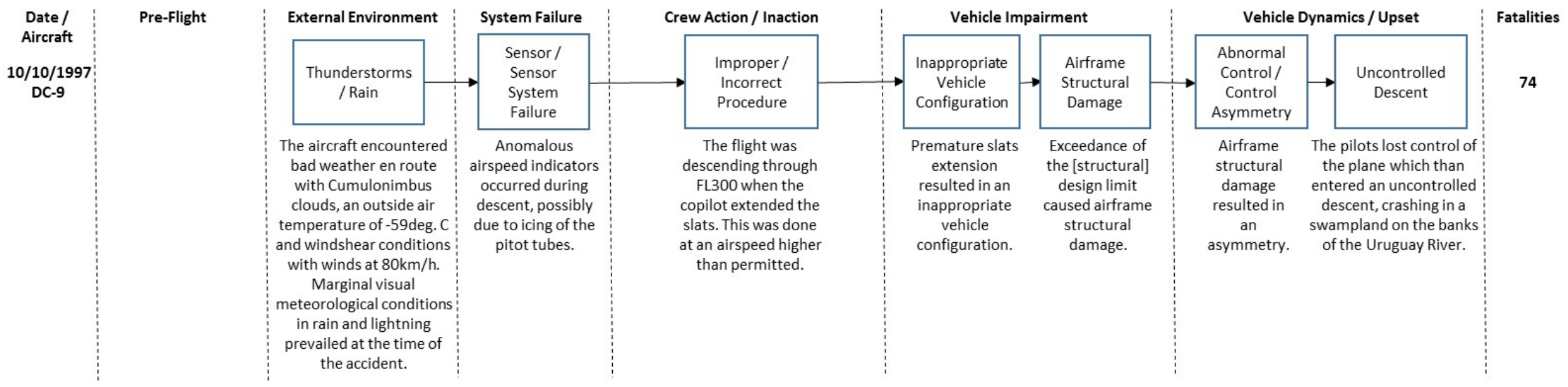

Figure D.3. Precursor Sequence for Accident No. 37 of Table D.1

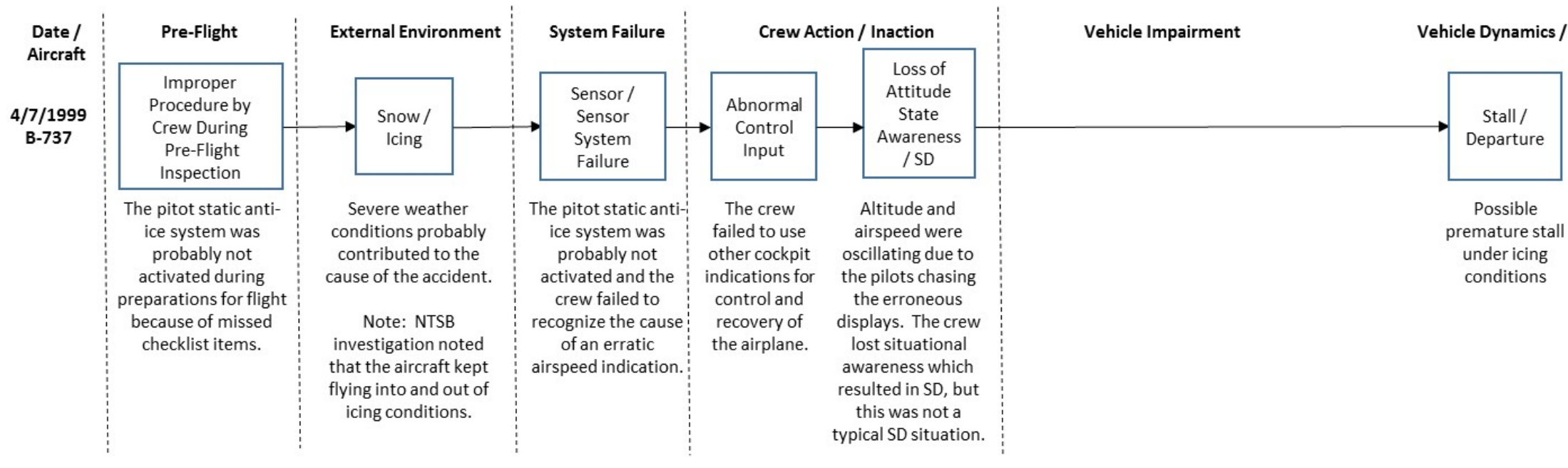

Figure D.4. Precursor Sequence for Accident No. 62 of Table D.1 


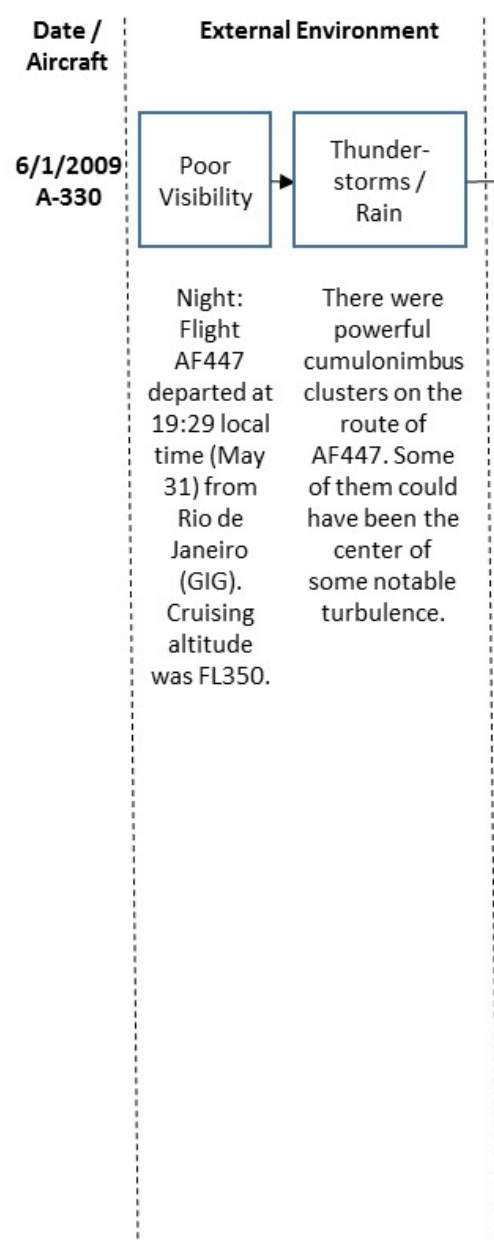

\begin{tabular}{|c|c|c|c|c|}
\hline \multicolumn{2}{|c|}{$\begin{array}{l}\text { System Failure / Malfunction / } \\
\text { Inadequacy }\end{array}$} & \multirow{2}{*}{$\begin{array}{l}\text { Crew Action / } \\
\text { Inaction } \\
\begin{array}{c}\text { Abnormal } \\
\text { Control } \\
\text { Input }\end{array}\end{array}$} & \multirow{2}{*}{$\begin{array}{l}\text { Vehicle Upset } \\
\begin{array}{|c|}\text { Abnormal } \\
\text { Flight } \\
\text { Trajectory }\end{array}\end{array}$} & $\begin{array}{l}\text { System Malfunction } \\
\text { / Inadequacy }\end{array}$ \\
\hline $\begin{array}{l}\text { Sensor / } \\
\text { Sensor } \\
\text { System } \\
\text { Failure }\end{array}$ & $\begin{array}{l}\text { Auto-Flight } \\
\text { System } \\
\text { Operational } \\
\text { Error / } \\
\text { Inadequacy }\end{array}$ & & & $\begin{array}{l}\text { Flight Deck } \\
\text { Instrument } \\
\text { Inadequacy }\end{array}$ \\
\hline $\begin{array}{l}\text { The Pitot } \\
\text { probes } \\
\text { became } \\
\text { obstructed by } \\
\text { ice crystals } \\
\text { during cruise, } \\
\text { resulting in } \\
\text { the total loss } \\
\text { of airspeed } \\
\text { information } \\
\text { in the flight } \\
\text { deck. } \\
\text { At } 02: 10: 16, \\
\text { the PNF said } \\
\text { "so, we've } \\
\text { lost the } \\
\text { speeds" then } \\
\text { "alternate } \\
\text { law [...]". }\end{array}$ & $\begin{array}{l}\text { The level of } \\
\text { turbulence } \\
\text { increased } \\
\text { slightly and } \\
\text { the crew } \\
\text { decided to } \\
\text { reduce the } \\
\text { speed to } \\
\text { about Mach } \\
0.8 \text {. From } \\
02: 10: 05 \text {, the } \\
\text { autopilot } \\
\text { then auto- } \\
\text { thrust } \\
\text { disengaged, } \\
\text { and the flight } \\
\text { control mode } \\
\text { was } \\
\text { reconfigured } \\
\text { to alternate } \\
\text { law (which } \\
\text { did not } \\
\text { include alpha } \\
\text { protection). }\end{array}$ & $\begin{array}{l}\text { The airplane } \\
\text { began to roll to } \\
\text { the right and } \\
\text { the PF made a } \\
\text { left nose-up } \\
\text { input. The stall } \\
\text { warning } \\
\text { sounded twice } \\
\text { in a row.The } \\
\text { airplane's pitch } \\
\text { attitude } \\
\text { increased } \\
\text { progressively } \\
\text { beyond } 10 \\
\text { degrees and the } \\
\text { plane started to } \\
\text { climb. The PF } \\
\text { made nose- } \\
\text { down control } \\
\text { inputs and } \\
\text { alternately left } \\
\text { and right roll } \\
\text { inputs. These } \\
\text { inappropriate } \\
\text { control inputs } \\
\text { destabilized the } \\
\text { flight path. }\end{array}$ & $\begin{array}{c}\text { From } 2 \text { hours } \\
10 \text { minutes } 18 \\
\text { seconds to } 2 \\
\text { hours } 10 \\
\text { minutes } 25 \\
\text { seconds, the } \\
\text { pitch attitude } \\
\text { varied from } \\
11 \text { deg to } 13 \\
\text { deg, roll angle } \\
\text { varied } \\
\text { between } 8 \\
\text { deg right and } \\
5 \text { deg left, and } \\
\text { vertical speed } \\
\text { increased to } \\
6700 \mathrm{ft} / \mathrm{min} . \\
\text { The THS was } \\
\text { stable at } \\
\text { around }-3 \\
\text { deg. }\end{array}$ & $\begin{array}{l}\text { The vertical speed, } \\
\text { which had reached } \\
7,000 \mathrm{ft} / \mathrm{min} \text {, dropped } \\
\text { to } 700 \mathrm{ft} / \mathrm{min} \text { and the } \\
\text { roll varied between } 12 \\
\text { degrees right and } 10 \\
\text { degrees left. The } \\
\text { speed displayed on } \\
\text { the left side increased } \\
\text { sharply to } 215 \mathrm{kt} \\
\text { (Mach } 0.68 \text { ). The } \\
\text { airplane was then at } \\
\text { an altitude of about } \\
37,500 \mathrm{ft} \text { and the } \\
\text { recorded angle of } \\
\text { attack was around } 4 \\
\text { degrees. At } 02: 10: 51 \text {, } \\
\text { the stall warning was } \\
\text { triggered again. } \\
\text { Various flight deck } \\
\text { instrumentation (e.g., } \\
\text { FD1 \& FD2, ASls, and } \\
\text { stall warning) was } \\
\text { unavailable and/or } \\
\text { invalid at times and } \\
\text { continued throughout } \\
\text { the remainder of the } \\
\text { flight. }\end{array}$ \\
\hline
\end{tabular}

\begin{tabular}{|c|c|c|}
\hline $\begin{array}{l}\text { Crew Action / } \\
\text { Inaction }\end{array}$ & Vehicle Upset & $\begin{array}{l}\text { Crew Action / } \\
\text { Inaction }\end{array}$ \\
\hline $\begin{array}{c}\text { Loss of } \\
\text { Attitude } \\
\text { State } \\
\text { Awareness } \\
\text { / SD }\end{array}$ & $\begin{array}{c}\text { Stall / } \\
\text { Departure }\end{array}$ & $\begin{array}{c}\text { Improper / } \\
\text { Ineffective } \\
\text { Recovery }\end{array}$ \\
\hline $\begin{array}{l}\text { The thrust levers } \\
\text { were positioned } \\
\text { in the TO/GA } \\
\text { detent and the } \\
\text { PF maintained } \\
\text { nose-up inputs. } \\
\text { The recorded } \\
\text { angle of attack, } \\
\text { of around } 6 \\
\text { degrees at the } \\
\text { triggering of the } \\
\text { stall warning, } \\
\text { continued to } \\
\text { increase. The } \\
\text { trimmable } \\
\text { horizontal } \\
\text { stabilizer (THS) } \\
\text { passed from } 3 \text { to } \\
13 \text { degrees } \\
\text { nose-up in } \\
\text { about } 1 \text { minute } \\
\text { and remained in } \\
\text { the latter } \\
\text { position until } \\
\text { the end of the } \\
\text { flight. }\end{array}$ & $\begin{array}{l}\text { The airplane's pitch } \\
\text { attitude did not } \\
\text { exceed } 15 \text { degrees } \\
\text { and the engines' N1's } \\
\text { were close to } 100 \% \text {. } \\
\text { The airplane was } \\
\text { subject to roll } \\
\text { oscillations that } \\
\text { sometimes reached } \\
40 \text { degrees. The PF } \\
\text { made an input on the } \\
\text { sidestick to the left } \\
\text { and nose-up stops, } \\
\text { which lasted about } 30 \\
\text { seconds. } \\
\text { The aeroplane went } \\
\text { into a sustained stall, } \\
\text { signaled by the stall } \\
\text { warning and strong } \\
\text { buffet. } \\
\text { From this point } \\
\text { forward, AOA } \\
\text { remained at or above } \\
38 \text { deg. }\end{array}$ & $\begin{array}{l}\text { At 02:13:32, the PF said } \\
\text { "we're going to arrive at } \\
\text { level one hundred". } \\
\text { About fifteen seconds } \\
\text { later, simultaneous } \\
\text { inputs by both pilots on } \\
\text { the sidesticks were } \\
\text { recorded and the PF said } \\
\text { "go ahead you have the } \\
\text { controls". The angle of } \\
\text { attack, when it was valid, } \\
\text { always remained above } \\
35 \text { degrees. The } \\
\text { recordings stopped at } \\
\text { 02:14:28. The last } \\
\text { recorded values were a } \\
\text { vertical speed of -10,912 } \\
\text { tt/min, a ground speed } \\
\text { of } 107 \mathrm{kt} \text {, pitch attitude } \\
\text { of } 16.2 \text { degrees nose-up, } \\
\text { roll angle of } 5.3 \text { degrees } \\
\text { left and a magnetic } \\
\text { heading of } 270 \text { degrees. } \\
\text { The airplane struck the } \\
\text { surface of the sea. } \\
\text { Despite these persistent } \\
\text { symptoms, the crew } \\
\text { never understood that } \\
\text { they were stalling and } \\
\text { consequently never } \\
\text { applied a recovery } \\
\text { manoeuvre. }\end{array}$ \\
\hline
\end{tabular}

Figure D.5. Precursor Sequence for Accident No. 260 of Table D.1 


\begin{tabular}{|c|c|c|c|c|c|c|}
\hline \multirow{3}{*}{$\begin{array}{c}\text { Date / } \\
\text { Aircraft } \\
\text { 10/20/2002 } \\
\text { B-757 }\end{array}$} & \multirow[t]{3}{*}{ Pre-Flight } & \multirow[t]{3}{*}{ External Environment } & \multicolumn{2}{|c|}{ System Failure / Operational Error } & Crew Action / Inaction & Vehicle Upset \\
\hline & & & $\begin{array}{l}\text { Sensor / } \\
\text { Sensor } \\
\text { System } \\
\text { Failure }\end{array}$ & $\rightarrow \begin{array}{c}\text { Flight Deck } \\
\text { Instrumentation } \\
\text { Malfunction / } \\
\text { Inadequacy }\end{array}$ & $\begin{array}{l}\text { Improper / } \\
\text { Incorrect } \\
\text { Procedure }\end{array}$ & $\begin{array}{l}\text { Stall/ } \\
\text { Departure }\end{array}$ \\
\hline & & & $\begin{array}{l}\text { During the takeoff roll as } \\
\text { about to call "eighty" kno } \\
\text { called "hundred." The capt } \\
\text { standby airspeed indicato } \\
\text { first officer's and decidec } \\
\text { takeoff and address the } \\
\text { airspeed indicator a } \\
\text { Evidence from the investiga } \\
\text { anomalies of the captain's } \\
\text { were caused by a partial } \\
\text { blockage of the captain's } \\
\text { reason for the blockage wa }\end{array}$ & $\begin{array}{l}\text { During the climb the } \\
\text { captain's indicated } \\
\text { airspeed began to } \\
\text { increase, and an } \\
\text { overspeed warning } \\
\text { occurred. The first officer } \\
\text { indicated that at this time } \\
\text { his airspeed indication and } \\
\text { the standby airspeed } \\
\text { indication both decreased } \\
\text { to about } 220 \text { knots and his } \\
\text { pitch attitude felt high. }\end{array}$ & $\begin{array}{l}\text { Despite agreement } \\
\text { between the first } \\
\text { officer and standby } \\
\text { airspeed indications } \\
\text { and the pilots' belief } \\
\text { that the captain's } \\
\text { airspeed indicator } \\
\text { was inaccurate, } \\
\text { control was } \\
\text { transferred from the } \\
\text { first officer to the } \\
\text { captain. }\end{array}$ & $\begin{array}{l}\text { Pitch attitude continued to climb } \\
\text { and airspeed continued to decay } \\
\text { after the captain assumed control. } \\
\text { The airplane's pitch attitude became } \\
\text { excessively high until the airplane's } \\
\text { stick shaker activated and the } \\
\text { airplane stalled. Although stall } \\
\text { recovery was eventually effected } \\
\text { and the airplane was leveled at } \\
\text { FL300, the lack of appropriate thrust } \\
\text { and control column inputs following } \\
\text { the stall delayed the recovery. }\end{array}$ \\
\hline
\end{tabular}

Figure D.6. Precursor Sequence for Nonfatal Incident No. 142 of Table D.1

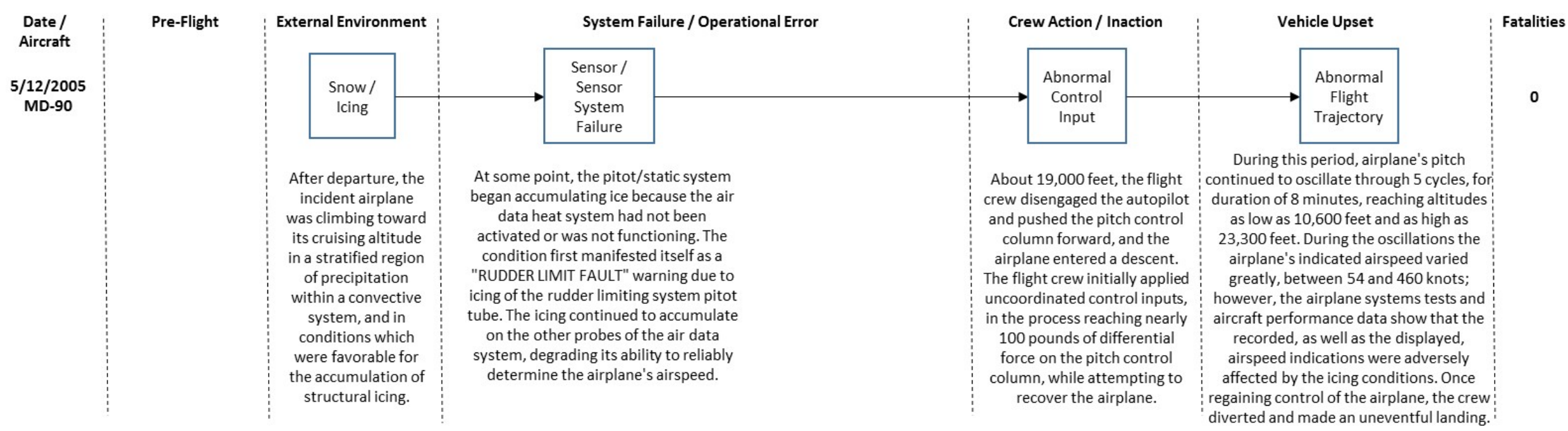

Figure D.7. Precursor Sequence for Nonfatal Incident No. 188 of Table D.1 


\begin{tabular}{|c|c|c|c|c|c|c|c|c|}
\hline Date / & Pre-Flight & External Environment & System Failure & Crew Action / Inaction & System Operational Error & Crew Action / Inaction & Vehicle Upset & Fatalities \\
\hline \multirow[t]{2}{*}{$\begin{array}{c}1 / 28 / 2005 \\
B-757\end{array}$} & $\begin{array}{l}\text { Improper } \\
\text { Maintenance } \\
\text { Action / } \\
\text { Inaction }\end{array}$ & $\begin{array}{c}\text { Poor } \\
\text { Visibility }\end{array}$ & $\begin{array}{l}\text { Sensor / } \\
\text { Sensor } \\
\text { System } \\
\text { Failure }\end{array}$ & $\begin{array}{l}\text { Improper / } \\
\text { Incorrect } \\
\text { Procedure }\end{array}$ & $\begin{array}{l}\text { Auto-Flight } \\
\text { System } \\
\text { Operational } \\
\text { Error }\end{array}$ & $\begin{array}{c}\text { Lack of Aircraft / } \\
\text { System State } \\
\text { Awareness }\end{array}$ & $\begin{array}{l}\text { Abnormal/ } \\
\text { Unusual } \\
\text { Attitude }\end{array}$ & 0 \\
\hline & $\begin{array}{l}\text { It is assumed that } \\
\text { the pitot tubes were } \\
\text { left uncovered prior } \\
\text { to flight - as } \\
\text { evidenced by the } \\
\text { discovery of the } \\
\text { remains of a } \\
\text { "beetle-like } \\
\text { creature" in the left- } \\
\text { hand pitot system } \\
\text { during the post- } \\
\text { incident engineering } \\
\text { investigation } \\
\text { conducted by the } \\
\text { operator. }\end{array}$ & $\begin{array}{l}\text { Night: } \\
\text { The flight took } \\
\text { off at } 2335 \\
\text { hours. It is } \\
\text { not clear } \\
\text { whether night } \\
\text { conditions } \\
\text { contributed to } \\
\text { the incident. }\end{array}$ & $\begin{array}{c}\text { Pilot's air speed } \\
\text { indicator (ASI) was } \\
\text { not working } \\
\text { properly and } \\
\text { resulted in a falsely } \\
\text { low ASI reading at } \\
\text { low altitude and a } \\
\text { falsely high ASI } \\
\text { reading at high } \\
\text { altitude; Co-pilot's } \\
\text { ASI seemed to be } \\
\text { working; Incorrect } \\
\text { ASI readings were } \\
\text { caused by a } \\
\text { blocked pitot tube. }\end{array}$ & $\begin{array}{l}\text { An airspeed discrepancy was } \\
\text { detected early during the takeoff } \\
\text { roll, but the commander decided to } \\
\text { continue the takeoff and deal with } \\
\text { the problem whilst airborne. } \\
\text { Note: There is no specific guidance } \\
\text { in the SOPs on what to do should } \\
\text { the ASIs disagree. However, the } \\
\text { pilot did have the authority to reject } \\
\text { the take-off below } 80 \text { kts for any } \\
\text { significant malfunction. Moreover, } \\
\text { good practice would suggest that } \\
\text { ASI malfunction would qualify for } \\
\text { rejecting the takeoff. }\end{array}$ & $\begin{array}{l}\text { After passing FL180 the crew } \\
\text { selected the left Air Data } \\
\text { switch to ALTN, believing this } \\
\text { isolated the left Air Data } \\
\text { Computer (ADC) from the } \\
\text { Autopilot \& Flight Director } \\
\text { System (AFDS). Passing FL316, } \\
\text { the VNAV mode became active } \\
\text { and the Flight Management } \\
\text { Computer's (FMCs), which use } \\
\text { the left ADC as their input of } \\
\text { aircraft speed, sensed an } \\
\text { overspeed condition and } \\
\text { provided a pitch-up command } \\
\text { to slow the aircraft. }\end{array}$ & $\begin{array}{l}\text { Despite thinking that they } \\
\text { had isolated the faulty left } \\
\text { ASI by selecting the ALTN } \\
\text { on the air data switch, the } \\
\text { automatic systems were } \\
\text { switching modes and } \\
\text { associated input sources } \\
\text { (including the use of the } \\
\text { left ASI data by the FMC). } \\
\text { This switching of modes } \\
\text { and input sources occured } \\
\text { in the background and was } \\
\text { not evident to the pilots. }\end{array}$ & $\begin{array}{l}\text { The FMCs, which used the } \\
\text { left ADC as their input of } \\
\text { aircraft speed, sensed an } \\
\text { overspeed condition and } \\
\text { provided a pitch-up } \\
\text { command to slow the } \\
\text { aircraft. This was a deviation } \\
\text { from the normal flight } \\
\text { profile. } \\
\text { The co-pilot was concerned } \\
\text { about the aircraft's } \\
\text { behaviour and, after several } \\
\text { verbal prompts to the } \\
\text { commander, pushed the } \\
\text { control column forward. }\end{array}$ & \\
\hline
\end{tabular}

Figure D.8. Precursor Sequence for Nonfatal Incident No. 254 of Table D.1 
Table D.2. Comments and Flags for Fatal Mishaps \#2, \#14, \#37, \#62, \#260

\begin{tabular}{|c|c|c|c|c|c|c|c|}
\hline $\begin{array}{c}\text { Date } \\
\text { Aircraft } \\
\text { (Fatalities) }\end{array}$ & Comments & \multicolumn{2}{|c|}{$\begin{array}{c}\text { Crew Distraction / } \\
\text { Preoccupation / Misaligned } \\
\text { Focus }\end{array}$} & \multicolumn{2}{|c|}{$\begin{array}{l}\text { Potential Human-Machine } \\
\text { Interface Issue }\end{array}$} & \multicolumn{2}{|r|}{ Potential to Mitigate through Research } \\
\hline $\begin{array}{l}\text { 2/6/1996 } \\
\text { B757 } \\
(189)\end{array}$ & & No & & Yes & $\begin{array}{l}\text { Faulty ASI to } \\
\text { Autopilot/Autothrottle } \\
\text { caused aircraft to pitch up } \\
\text { and lower airspeed, which } \\
\text { led to stall; Conflicting } \\
\text { warnings in flight deck } \\
\text { (overspeed and stick shaker) }\end{array}$ & Yes & $\begin{array}{l}\text { 1. Improved pilot training on diagnosing and } \\
\text { mitigating onboard system failures (including sensor } \\
\text { system failures and the use of alternate } \\
\text { instrumentation) } \\
\text { 2. Improved sensor failure detection and isolation } \\
\text { (FDI) systems } \\
\text { 3. Sensor Integrity Management systems } \\
\text { 4. Resilient Upset Recovery Guidance and/or } \\
\text { Automatic Recovery System } \\
\text { 5. Resilient flight control system }\end{array}$ \\
\hline $\begin{array}{c}\text { 10/2/1996 } \\
\text { B-757 } \\
(70)\end{array}$ & & Yes & $\begin{array}{l}\text { Crew was distracted by } \\
\text { erroneous sensor readings } \\
\text { and flight deck warning } \\
\text { systems }\end{array}$ & Yes & $\begin{array}{l}\text { Numerous conflicting } \\
\text { warning and alerts were } \\
\text { sounding simultaneously }\end{array}$ & Yes & $\begin{array}{l}\text { 1. Sensor integrity management system capable of } \\
\text { detecting and mitigating sensor failures (including } \\
\text { common mode failures) } \\
\text { 2. Resilient flight control system capable of ensuring } \\
\text { safety of flight under system failures } \\
\text { 3. Automatic ground collision avoidance system }\end{array}$ \\
\hline $\begin{array}{l}\text { 10/10/1997 } \\
\text { DC-9 } \\
\text { (74) }\end{array}$ & $\begin{array}{l}\text { Sequence details obtained } \\
\text { from ASN }\end{array}$ & NEI & & Yes & $\begin{array}{l}\text { Lack of situational awareness } \\
\text { or mitigation of anomalous } \\
\text { airspeed indications, which } \\
\text { led to premature extension of } \\
\text { slats }\end{array}$ & Yes & $\begin{array}{l}\text { 1. Improved crew training on diagnosing and } \\
\text { mitigating onboard system failures (including sensor } \\
\text { systems and the use of alternate instrumentation) } \\
\text { 2. Sensor integrity management system capable of } \\
\text { detecting and mitigating sensor failures (including } \\
\text { blocked pitot tubes and common mode failures) } \\
\text { 3. Resilient flight control system capable of ensuring } \\
\text { safety of flight under system failures (including sensor } \\
\text { system failures) } \\
\text { 4. Resilient upset recovery system capable of } \\
\text { providing guidance and/or automatically effecting } \\
\text { upset recovery under vehicle system failures }\end{array}$ \\
\hline $\begin{array}{l}\text { 4/7/1999 } \\
\text { B-737 } \\
\text { (6) }\end{array}$ & $\begin{array}{l}\text { Very little accident } \\
\text { information available. }\end{array}$ & Yes & $\begin{array}{l}\text { The presence of cabin crew } \\
\text { in the cockpit probably } \\
\text { distracted the attention of } \\
\text { the cockpit crew. }\end{array}$ & NEI & $\begin{array}{l}\text { Lack of reliable sensor } \\
\text { information under icing } \\
\text { conditions; lack of } \\
\text { notification of sensor system } \\
\text { problem }\end{array}$ & Yes & $\begin{array}{l}\text { 1. Improved pilot training relative to use of alternate } \\
\text { instrumentation } \\
\text { 2. Improved anti-icing methodologies } \\
\text { 3. Sensor integrity management system }\end{array}$ \\
\hline
\end{tabular}




\begin{tabular}{|c|c|c|c|c|c|c|c|}
\hline $\begin{array}{c}\text { 6/1/2009 } \\
\text { A-330 } \\
(228)\end{array}$ & $\begin{array}{l}\text { The obstruction of the Pitot } \\
\text { probes by ice crystals } \\
\text { during cruise was a } \\
\text { phenomenon that was } \\
\text { known but misunderstood } \\
\text { by the aviation community } \\
\text { at the time of the accident. } \\
\text { From an operational } \\
\text { perspective, the total loss of } \\
\text { airspeed information that } \\
\text { resulted from this was a } \\
\text { failure that was classified in } \\
\text { the safety model. After } \\
\text { initial reactions that depend } \\
\text { upon basic airmanship, it } \\
\text { was expected that it would } \\
\text { be rapidly diagnosed by } \\
\text { pilots and managed where } \\
\text { necessary by precautionary } \\
\text { measures on the pitch } \\
\text { attitude and the thrust, as } \\
\text { indicated in the associated } \\
\text { procedure. The occurrence } \\
\text { of the failure in the context } \\
\text { of flight in cruise } \\
\text { completely surprised the } \\
\text { pilots of flight AF } 447 \text {. The } \\
\text { apparent difficulties with } \\
\text { aeroplane handling at high } \\
\text { altitude in turbulence led to } \\
\text { excessive handling inputs in } \\
\text { roll and a sharp nose-up } \\
\text { input by the PF. The } \\
\text { destabilization that resulted } \\
\text { from the climbing flight } \\
\text { path and the evolution in } \\
\text { the pitch attitude and } \\
\text { vertical speed was added to } \\
\text { the erroneous airspeed } \\
\text { indications and ECAM } \\
\text { messages, which did not } \\
\text { help with the diagnosis. } \\
\text { The combination of the } \\
\text { ergonomics of the stall }\end{array}$ & Yes & $\begin{array}{l}\text { Crew was overwhelmed by } \\
\text { the multiple hazards } \\
\text { conditions involving } \\
\text { external disturbances } \\
\text { (turbulence), an onboard } \\
\text { common-mode sensor } \\
\text { system failure (blockage of } \\
\text { all pitot tubes due to ice } \\
\text { crystal formation), lack of } \\
\text { external sensory } \\
\text { information (due to night } \\
\text { low visibility conditions } \\
\text { over the ocean), and stall } \\
\text { warning system triggers at } \\
\text { high altitude during cruise }\end{array}$ & Yes & $\begin{array}{l}\text { Inability of the system to } \\
\text { detect and mitigate sensor } \\
\text { failures associated with } \\
\text { blocked pitot tubes; the } \\
\text { ergonomics of the stall } \\
\text { warning design; the lack of } \\
\text { displays providing situation } \\
\text { awareness under multiple } \\
\text { hazards and guidance for } \\
\text { upset recovery; flight } \\
\text { director indications that may } \\
\text { led the crew to believe that } \\
\text { their actions were } \\
\text { appropriate, even though } \\
\text { they were not; difficulty in } \\
\text { recognizing and } \\
\text { understanding the } \\
\text { implications of a } \\
\text { reconfiguration in alternate } \\
\text { law with no angle of attack } \\
\text { protection }\end{array}$ & Yes & $\begin{array}{l}\text { 1. Improved crew training under unexpected and } \\
\text { abnormal conditions (including multiple hazards } \\
\text { events) and in the implications of existing } \\
\text { protections associated with system operational } \\
\text { modes } \\
\text { 2. Sensor integrity management system capable of } \\
\text { detecting and mitigating sensor failures (including } \\
\text { blocked pitot tubes and common mode sensor } \\
\text { failures) } \\
\text { 3. Improved algorithms and displays that provide } \\
\text { improved situational awareness to the systems and } \\
\text { crew under multiple hazards conditions } \\
\text { 4. Resilient flight control system capable of ensuring } \\
\text { flight safety under multiple hazards (including } \\
\text { system failures, external disturbances, and } \\
\text { inappropriate control inputs by the crew and/or } \\
\text { autoflight systems) } \\
\text { 5. Resilient upset recovery system capable of } \\
\text { providing guidance for and/or automatically recovery } \\
\text { from upset conditions (including stall) under multiple } \\
\text { hazards conditions }\end{array}$ \\
\hline
\end{tabular}




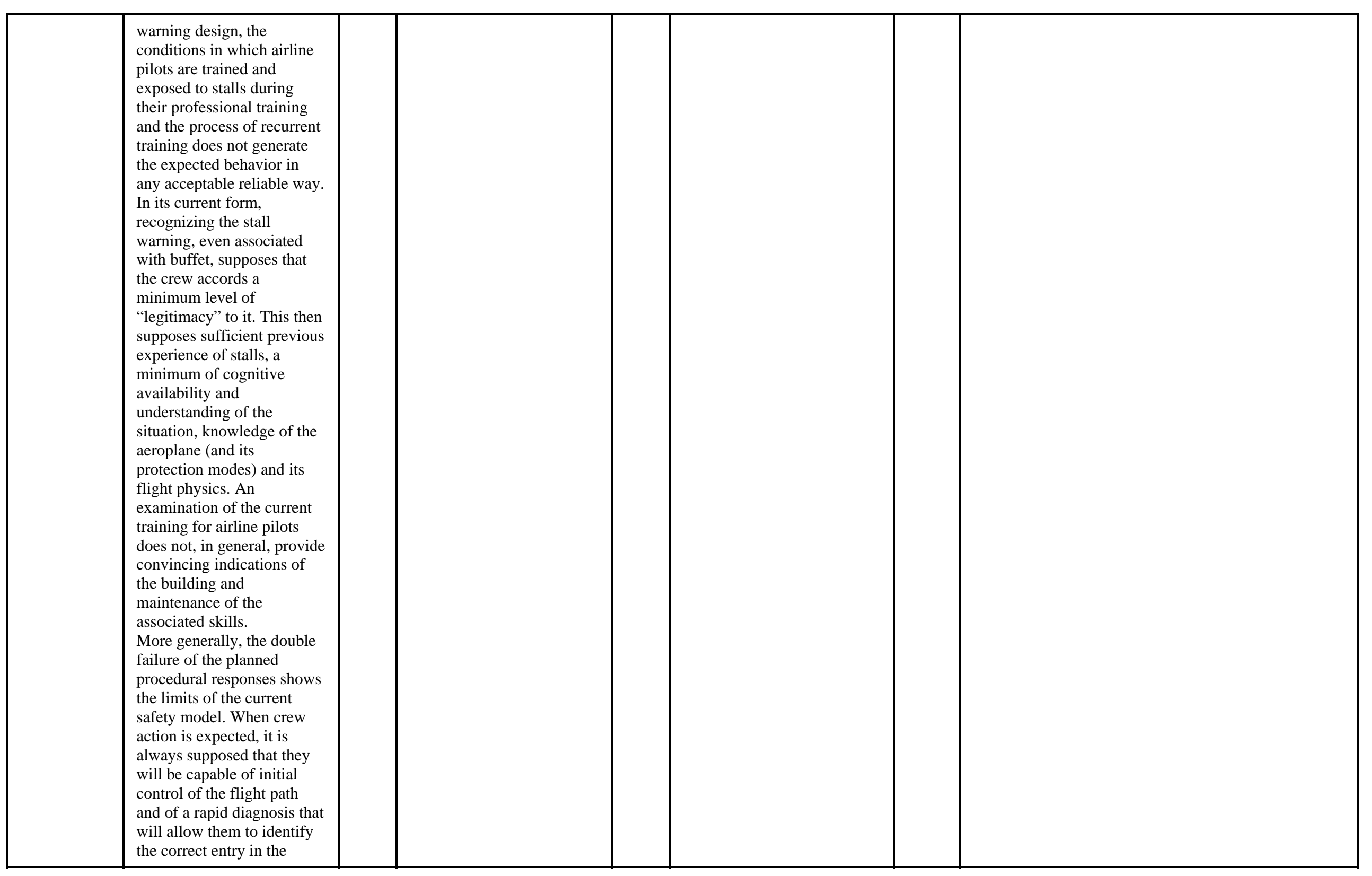




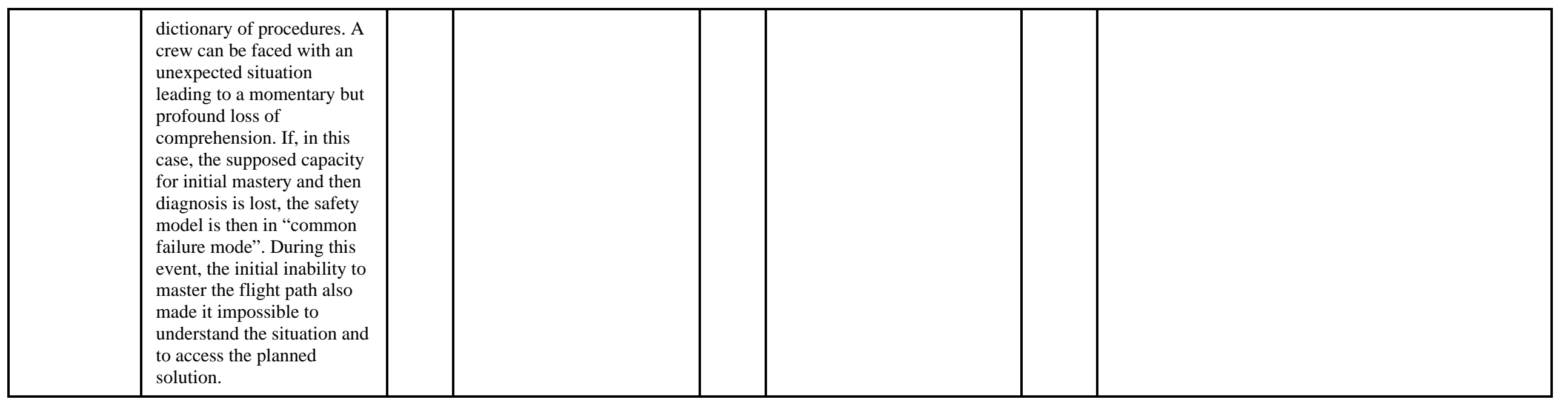


Table D.3. Comments and Flags for Nonfatal Mishaps \#142, \#188, \#254

\begin{tabular}{|c|c|c|c|c|c|c|c|}
\hline $\begin{array}{c}\text { Date } \\
\text { Aircraft } \\
\text { (Fatalities) }\end{array}$ & Comments & Preo & $\begin{array}{l}\text { Crew Distraction / } \\
\text { ccupation / Misaligned } \\
\text { Focus }\end{array}$ & \multicolumn{2}{|c|}{$\begin{array}{l}\text { Potential Human-Machine } \\
\text { Interface Issue }\end{array}$} & \multicolumn{2}{|r|}{$\begin{array}{l}\text { Potential to Mitigate through } \\
\text { Research }\end{array}$} \\
\hline $\begin{array}{c}\text { 10/20/2002 } \\
\text { B-757 } \\
\text { (0) }\end{array}$ & $\begin{array}{l}\text { The pilots indicated that EICAS messages } \\
\text { appeared and disappeared several times after } \\
\text { takeoff and during the climb, including the } \\
\text { messages MACH/SPD TRIM and RUDDER } \\
\text { RATIO. Checklists for MACH/SPD TRIM } \\
\text { and RUDDER RATIO messages did not } \\
\text { mention an unreliable airspeed as a possible } \\
\text { condition. The modifications associated with } \\
\text { Boeing Alert Service Bulletin 757-34A0222 } \\
\text { (and mandated by FAA Airworthiness } \\
\text { Directive 2004-10-15 after the incident), } \\
\text { which had not been incorporated on the } \\
\text { incident airplane, would have provided a more } \\
\text { direct indication of the airspeed anomaly. } \\
\text { According to information in the Icelandair } \\
\text { Operations Manual, these EICAS messages (in } \\
\text { conjunction with disagreements between the } \\
\text { captain and first officer airspeed indicators) } \\
\text { may indicate an unreliable airspeed. } \\
\text { Overspeed indications and simultaneous } \\
\text { overspeed and stall warnings (both of which } \\
\text { occurred during the airplane's climb from } \\
\text { FL330 to FL370) are also cited as further } \\
\text { indications of a possible unreliable airspeed. } \\
\text { The crew did take actions in an attempt to } \\
\text { isolate the anomalies (such as switching from } \\
\text { the center autopilot to the right autopilot at one } \\
\text { point during the flight). However, this did not } \\
\text { affect the flight management computer's use of } \\
\text { data from the left (captain's) air data system, } \\
\text { and the erroneous high airspeeds subsequently } \\
\text { contributed to airplane-nose-up autopilot } \\
\text { commands during and after the airplane's } \\
\text { climb to FL370. }\end{array}$ & No & & Yes & $\begin{array}{l}\text { Lack of a failure detection } \\
\text { and notification system } \\
\text { capable of detecting and } \\
\text { identifying blocked pitot } \\
\text { tubes; indistinct alerts } \\
\text { generated by the airplane's } \\
\text { crew alerting system, which } \\
\text { added to the flight crew's } \\
\text { confusion during the flight. }\end{array}$ & Yes & $\begin{array}{l}\text { 1. Improved pilot training relative to } \\
\text { diagnosing and mitigating onboard } \\
\text { system failures (including sensor } \\
\text { system failures and use of alternate } \\
\text { instrumentation) } \\
\text { 2. Sensor integrity management } \\
\text { systems capable of detecting, } \\
\text { identifying and mitigating sensor } \\
\text { system failures (including blocked } \\
\text { pitot tubes) } \\
\text { 3. Resilient flight control and } \\
\text { guidance system capable of } \\
\text { mitigating system failures and } \\
\text { providing situational awareness \& } \\
\text { guidance to the crew } \\
4 \text {. Resilient upset recovery system } \\
\text { capable of providing guidance } \\
\text { and/or automatically effecting upset } \\
\text { recovery under vehicle system } \\
\text { failures }\end{array}$ \\
\hline
\end{tabular}




\begin{tabular}{|c|c|c|c|c|c|c|}
\hline $\begin{array}{c}\text { 5/12/2005 } \\
\text { MD-90 } \\
\text { (0) }\end{array}$ & $\begin{array}{l}\text { Post-incident testing of the airplane's } \\
\text { mechanical and electronic systems revealed no } \\
\text { abnormalities that would have accounted for } \\
\text { the unreliable airspeed indications or the loss } \\
\text { of control reported by the flight crew. Post- } \\
\text { incident computer modeling also confirmed } \\
\text { that the airplane performed in a manner } \\
\text { consistent with all deviations from normal } \\
\text { flight having been initiated or exacerbated by } \\
\text { the control inputs of the flight crew. Review of } \\
\text { flight data recorder, cockpit voice recorder, } \\
\text { and flight crew interviews revealed that the } \\
\text { flight crew's actions during the event were in } \\
\text { part contradictory with operator's training and } \\
\text { operational procedures. Specifically, the crew } \\
\text { initially failed to properly identify and respond } \\
\text { to the erroneous airspeed indications that were } \\
\text { presented and failed to coordinate their } \\
\text { recovery of the airplane to controlled flight. }\end{array}$ & No & Yes & $\begin{array}{l}\text { Lack of system failure } \\
\text { detection capability for a } \\
\text { blocked pitot tube }\end{array}$ & Yes & $\begin{array}{l}\text { 1. Improved crew training on } \\
\text { diagnosing and mitigating onboard } \\
\text { system failures (including sensor } \\
\text { systems and the use of alternate } \\
\text { instrumentation) } \\
\text { 2. Sensor integrity management } \\
\text { system capable of detecting and } \\
\text { mitigating sensor failures (including } \\
\text { blocked pitot tubes and common } \\
\text { mode failures) } \\
\text { 3. Resilient flight control system } \\
\text { capable of ensuring safety of flight } \\
\text { under system failures (including } \\
\text { sensor system failures) } \\
\text { 4. Resilient upset recovery system } \\
\text { capable of providing guidance } \\
\text { and/or automatically effecting upset } \\
\text { recovery under vehicle system } \\
\text { failures }\end{array}$ \\
\hline $\begin{array}{c}\text { 1/28/2009 } \\
\text { B-757 } \\
\text { (0) }\end{array}$ & $\begin{array}{l}\text { The commander, uncertain as to what was } \\
\text { failing, believed that a stick-pusher had } \\
\text { activated*. He disengaged the automatics and } \\
\text { lowered the aircraft's nose, then handed over } \\
\text { control to the co-pilot when he became aware } \\
\text { that the co-pilot was on the controls. The FD's } \\
\text { were disengaged and the aircraft returned to } \\
\text { Accra with the co-pilot flying. } \\
\text { The company has amended their engineering } \\
\text { procedures to include the fitting of pitot covers } \\
\text { and blanks when the aircraft is on the ground } \\
\text { during long turnarounds. There were times } \\
\text { during this flight where the flight crew were } \\
\text { confused as to what was happening. In this } \\
\text { incident, the commander recognized a failure } \\
\text { of his ASI before } 80 \text { kt and the takeoff could } \\
\text { have been safely rejected. Instead, he } \\
\text { continued the takeoff using the co-pilot's and } \\
\text { standby ASIs and encountered a number of } \\
\text { related emergencies. These eventually led to } \\
\text { the declaration of a mayday and return to the } \\
\text { departure airfield. Although the commander } \\
\text { considered that conditions were suitable for } \\
\text { resolving the problem when airborne, a low }\end{array}$ & No & Yes & $\begin{array}{l}\text { Lack of system failure } \\
\text { detection capability for a } \\
\text { blocked pitot tube; } \\
\text { Numerous opportunities for } \\
\text { mode confusion in existing } \\
\text { FCS and FMS design and } \\
\text { operation as well as warning } \\
\text { and annunciations; } \\
\text { Purposeful settings by the } \\
\text { crew to isolate } \\
\text { malfunctioning equipment } \\
\text { are overridden by the } \\
\text { automatic systems without } \\
\text { notification to the crew }\end{array}$ & Yes & $\begin{array}{l}\text { 1. Improved crew training on } \\
\text { diagnosing and mitigating onboard } \\
\text { system failures (including sensor } \\
\text { systems and the use of alternate } \\
\text { instrumentation) } \\
\text { 2. Sensor integrity management } \\
\text { system capable of detecting and } \\
\text { mitigating sensor failures (including } \\
\text { blocked pitot tubes and common } \\
\text { mode failures) } \\
\text { 3. Resilient flight control system } \\
\text { capable of ensuring safety of flight } \\
\text { under system failures (including } \\
\text { sensor system failures) } \\
\text { 4. Resilient upset recovery system } \\
\text { capable of providing guidance } \\
\text { and/or automatically effecting upset } \\
\text { recovery under vehicle system } \\
\text { failures }\end{array}$ \\
\hline
\end{tabular}




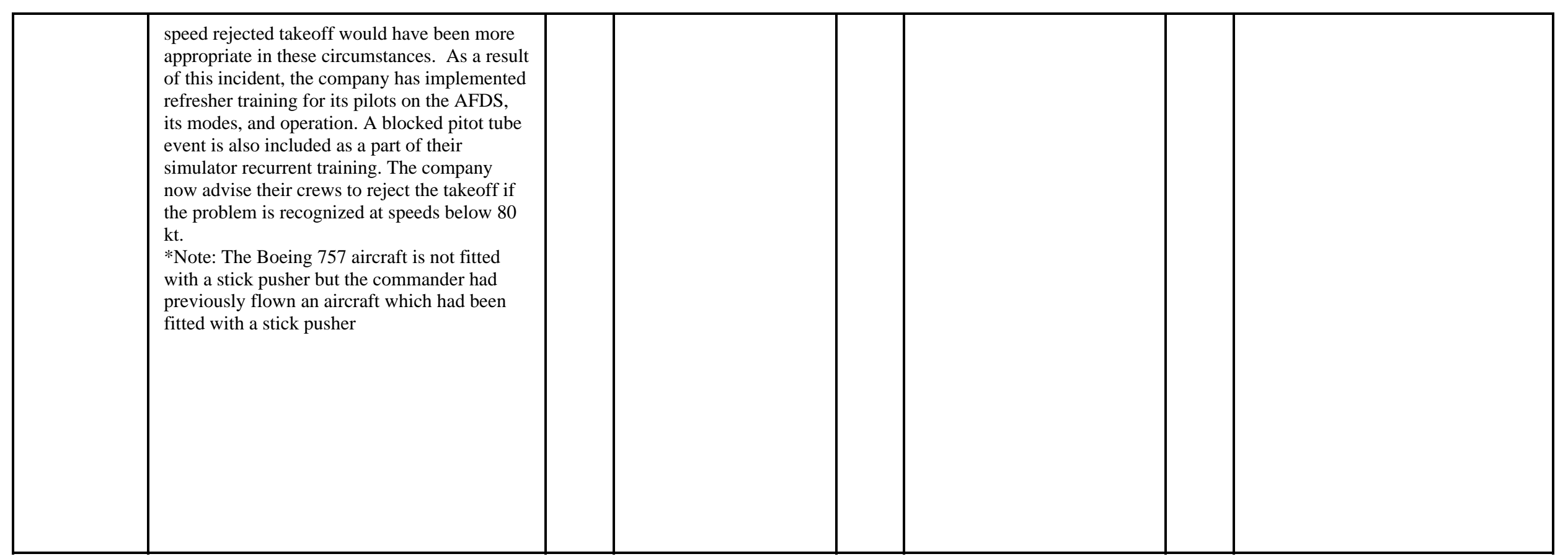




\section{Appendix E. Resilient Autonomous Systems Technology Requirements}

This Appendix will provide a preliminary roadmap for the development and validation of resilient autonomous and semi-autonomous aircraft systems, as illustrated in Figures E.1 and E.2.

\section{Technical Challenges}

Key Technology Impediment: Certification of Safety-Assured Autonomy for Reliable Operation under Uncertainties \& Hazards

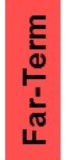

Ultra-Reliable Fully Autonomous Systems Enable Safety-Assured Operations at All NAS Levels (Vehicles, Infrastructure, and Operations)

\section{E Variable Autonomy Systems Enable Synergistic Dynamic Teaming Between Human and Intelligent Systems \\ E Resilient Systems Provide Safety Augmentation, Guidance \& Emergency Intervention to Support Baseline Systems and Human Operator}

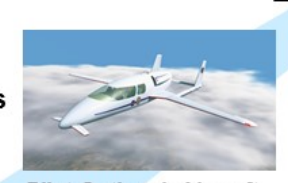

Pilot-Optional Aircraft

- Real-Time Safety Assurance

- Resilient Control \& Mission Management

- Integrated Vehicle Health Management

- Real-Time Dynamic Function Allocation \& Interfaces

- Resilient Control under LOC Hazards Sequences

- LOC Prediction, Prevention \& Recovery

- Resilient Mission Planning

- Diagnostics / Prognostics \& Decision Support

- Information Fusion \& Complex Situation Assessment / Prediction

Baseline: Technology Used to Automate Routine Operations under Nominal Conditions and Provide Information \& Alerts

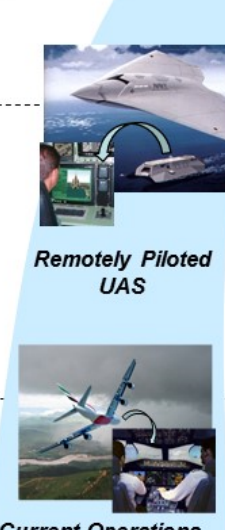

Current Operations

Figure E.1. Preliminary Technology Requirements for Resilient Autonomous Safety-Critical Systems. 


\section{Technology Impediments}

Certification of Safety-Assured Autonomy Systems for Reliable Operation under Uncertainties \& Hazards

Validation of Safety-Critical Autonomous Systems Enable the validation of complex integrated safety-assured autonomous and semi-autonomous systems with deterministic \& non-deterministic components

Validation of Integrated Resilient

E Systems

Enable validation of complex integrated systems at the functional / algorithm level (including error propagation and containment between subsystems)
Single-Pilot Operations

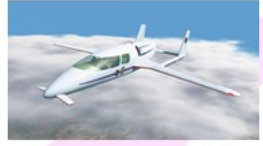

\section{Enabling Technologies / Research Needs}

Pilot-Optional
Validation Technologies for Resilient \& Autonomous Systems
- Integrated Validation Process (Analysis,
Aircraft Simulation, and Experimental Methods) for Complex Integrated Deterministic \& NonDeterministic Systems

- Level of Confidence Assessment Methods

- Analysis Methods for Non-Deterministic / Reasoning Systems

- Analysis Methods for Complex Integrated Systems

- Integrated Validation Process for Resilient Systems

- Experimental Test Methods for Integrated Multidisciplinary Systems under Uncertain / Hazardous Conditions
Validation of Resilient

른

\section{Systems}

E Develop analytical, simulation, and experimental test methods that enable validation of resilient systems technologies (including LOC hazards coverage and technology level of effectiveness and limitations

Baseline: Standard V\&V Techniques to Support Current Certification Requirements

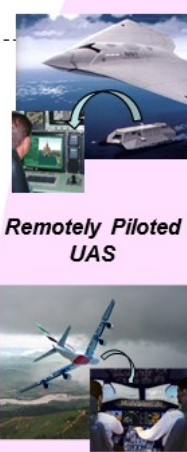

Current Operations

- Nonlinear Analysis Methods \& Tools (e.g., Bifurcation)

- Robustness Analysis Methods \& Tools for Nonlinear Systems

- Uncertainty Quantification Methods \& Tools

- Stability Analysis Methods for Stochastic Filters and Sensor Fusion Systems

- Multidisciplinary Vehicle Dynamics Simulation Modeling Methods for Characterizing Hazards Effects

- Hazards Analysis \& Test Scenarios for Resilience Testing

- Experimental Test Methods for High-Risk Operational Conditions

Baseline: Linear Analysis Methods, Gain \& Phase Margins for SISO Systems, Monte Carlo Simulations, Structured Singular Value Robustness Analysis for MIMO Linear Systems

\section{Figure E.2. Preliminary Technology Validation Requirements for Resilient Autonomous Safety-Critical Systems.}




\title{
Dedication
}

This work is dedicated to the memory and careers of the following researchers who substantially contributed to aviation safety through their tireless and dedicated research, and who were taken from the research community in the prime of their lives and careers.

\author{
Dr. Celeste M. Belcastro \\ NASA Langley Research Center \\ Dr. Gary J. Balas \\ University of Minnesota \\ Mr. David G. Ward \\ Barron Associates, Inc.
}

\section{References}

1 “Statistical Summary of Commercial Jet Airplane Accidents, Worldwide Operations, 1959-2011", Boeing Commercial Airplanes, July 2012. URL： http://www.boeing.com/news/techissues/pdf/statsum.pdf

2 Evans, Joni K., “An Examination of In Flight Loss of Control Events During 1988-2004,” Alliant Techsystems, Inc., NASA Langley Research Center, Contract No.: TEAMS:NNL07AM99T/R1C0, Task No. 5.2, 2007.

3 “Global Fatal Accident Review 1997-2006,” CAP 776, Civil Aviation Authority, July 2008.

URL: http://www.caa.co.uk/docs/33/CAP776.pdf

${ }^{4}$ Belcastro, Christine M. and Foster, John V., Aircraft Loss-of-Control Accident Analysis, AIAA Guidance, Navigation and Control Conference, Toronto, 2010.

${ }^{5}$ Belcastro, Christine M., "Loss of Control Prevention and Recovery: Onboard Guidance, Control, and Systems Technologies,” AIAA Conference on Guidance, Navigation and Control, Minneapolis, Minnesota, August 2012.

${ }^{6}$ Belcastro, Christine M. and Jacobson, Steven: Future Integrated Systems Concept for Preventing Aircraft Loss-ofControl Accidents; AIAA Guidance, Navigation and Control Conference, Toronto, August 2-5, 2010.

7 Belcastro, Christine M., Validation and Verification of Future Integrated Safety-Critical Systems Operating under Off-Nominal Conditions, AIAA Guidance, Navigation and Control Conference, Toronto, 2010.

8 Belcastro, Christine M., Validation \& Verification of Safety-Critical Systems Operating under Off-Nominal Conditions. Chapter 20 of the Book Entitled: Optimization-Based Clearance of Flight Control Laws, Springer, 2011.

${ }^{9}$ Belcastro, Christine M.: Validation of Safety-Critical Systems for Aircraft Loss-of-Control Prevention and Recovery, AIAA Guidance, Navigation and Control Conference, Minneapolis, Minnesota, 2012.

${ }^{10}$ Belcastro, Christine M., Groff, Loren, Newman, Richard L., Foster, John V., Crider, Dennis A., Klyde, David H., and Huston, A. McCall, "Preliminary Analysis of Aircraft Loss of Control Accidents: Worst Case Precursor Combinations and Temporal Sequencing”, AIAA Conference on Guidance, Navigation, and Control, SciTech Forum, National Harbor, Maryland, January 2014. 
${ }^{11}$ Wilborn, J. E. and Foster, J. V., "Defining Commercial Aircraft Loss-of-Control: a Quantitative Approach,” AIAA Atmospheric Flight mechanics Conference and Exhibit, AIAA, Providence, Rhode Island, 16-19 August 2004.

${ }^{12}$ Lambregts, A. A., Nesemeier, G., Wilborn, J. E., and Newman, R. L., “Airplane Upsets: Old Problem, New Issues,” AIAA Modeling and Simulation Technologies Conference and Exhibit, 2008, AIAA 2008-6867.

${ }^{13}$ URL: http://www.intlaviationstandards.org/

${ }^{14}$ URL: www.atsb.gov.au/

${ }^{15}$ URL: https://www.gov.uk/government/organisations/air-accidents-investigation-branch

${ }^{16}$ URL: www.tsb.gc.ca/

${ }^{17}$ URL: $\underline{\text { www.bea.aero/ }}$

${ }^{18}$ URL: www.bfu-web.de/

${ }^{19}$ URL: www.aaiu.ie/

${ }^{20}$ URL: www.ntsb.gov

${ }^{21}$ URL: www.icao.int

${ }^{22}$ URL: http://www.ascendworldwide.com/

${ }^{23}$ URL: http://aviation-safety.net/

${ }^{24}$ Dorsett, R., Aircraft Accident Reports on DVD, Flight Simulation Systems, Austin, TX, 2006.

25 Concept of Operations for the Next Generation Air Transportation System. Version 3.2, Joint Planning and Development Office, 2011. URL: http://www.dtic.mil/dtic/tr/fulltext/u2/a535795.pdf

${ }^{26}$ NextGen Implementation Plan 2015, Federal Aviation Administration, May 2015. URL: https://www.faa.gov/nextgen/media/NextGen_Implementation_Plan-2015.pdf

${ }^{27}$ Holland Michel, Arthur and Gettinger, Dan, "Drone Sightings and Near Misses," Center for the Study of the Drone, Bard College, September, 2015. URL: http://dronecenter.bard.edu/drone-sightings-and-near-misses/

${ }^{28}$ Holland Michel, Arthur and Gettinger, Dan, "Drone Sightings and Close Encounters: An Analysis," Center for the Study of the Drone, Bard College, December 2015. URL: http://dronecenter.bard.edu/drone-sightings-andclose-encounters/

${ }^{29}$ Stevenson, Beth, ERA Joins Call for More European UAV Regulations, Flight Global, London, August 10, 2015. URL: https://www.flightglobal.com/news/articles/era-joins-call-for-more-european-uav-regulation-415543/

30 “Autonomy Research for Civil Aviation: Toward a New Era of Flight,” National Research Council of the National Academies, The National Academies Press, Washington D.C., 2014.

URL: http://www.nap.edu/catalog/18815/autonomy-research-for-civil-aviation-toward-a-new-era-of-flight 